\title{
AGEs and Diabetic Complications
}

Citation for published version (APA):

Mentink, C. J. A. L. (2006). AGEs and Diabetic Complications. [Doctoral Thesis, Maastricht University]. Universitaire Pers Maastricht. https://doi.org/10.26481/dis.20060621cm

Document status and date:

Published: 01/01/2006

DOI:

$10.26481 /$ dis. $20060621 \mathrm{~cm}$

Document Version:

Publisher's PDF, also known as Version of record

\section{Please check the document version of this publication:}

- A submitted manuscript is the version of the article upon submission and before peer-review. There can be important differences between the submitted version and the official published version of record.

People interested in the research are advised to contact the author for the final version of the publication, or visit the DOI to the publisher's website.

- The final author version and the galley proof are versions of the publication after peer review.

- The final published version features the final layout of the paper including the volume, issue and page numbers.

Link to publication

\footnotetext{
General rights rights.

- You may freely distribute the URL identifying the publication in the public portal. please follow below link for the End User Agreement:

www.umlib.nl/taverne-license

Take down policy

If you believe that this document breaches copyright please contact us at:

repository@maastrichtuniversity.nl

providing details and we will investigate your claim.
}

Copyright and moral rights for the publications made accessible in the public portal are retained by the authors and/or other copyright owners and it is a condition of accessing publications that users recognise and abide by the legal requirements associated with these

- Users may download and print one copy of any publication from the public portal for the purpose of private study or research.

- You may not further distribute the material or use it for any profit-making activity or commercial gain

If the publication is distributed under the terms of Article $25 \mathrm{fa}$ of the Dutch Copyright Act, indicated by the "Taverne" license above, 
AGEs and Diabetic Complications 


\section{outrim inutinin}

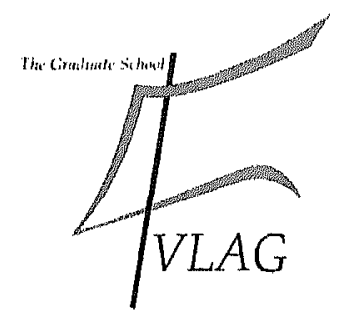

The study presented in this thesis was performed within the Nutrition and Toxicology Research Institute Maastricht (NUTRIM) which participates in the Graduate School VLAG (Food Technology, Agrobiotechnology, Nutrition and Health Sciences), accredited by the Royal Netherlands Academy of Arts and Sciences.

Cover design: Wendy Feron, Cyriel Mentink Layout: Cyriel Mentink

Printed by: Datawyse, Universitaire Pers Maastricht

(C) Cyriel Mentink, Maastricht 2006

ISBN 10: $90-5278-538-4$

ISBN 13: $978-90-5278-538-7$ 


\title{
AGEs and Diabetic Complications
}

\author{
PROEFSCHRIFT
}

ter verkrijging van de graad van doctor

aan de Universiteit Maastricht

op gezag van de Rector Magnificus,

Prof. mr. G.P.M.F. Mols

volgens het besluit van het College van Decanen,

in het openbaar te verdedigen

op woensdag 21 juni 2006 om 14:00 uur

door

Cyriel Jozef Anna Ludovicus Mentink

geboren te Elsloo op 19 september 1975

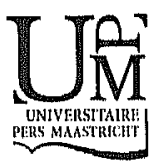




\section{Promotores}

Prof. dr. B.H.R. Wolffenbuttel (Rijksuniversiteit Groningen)

Prof. dr. ir. W.H.M. Saris

\section{Copromotores}

Dr. M.A. van Baak

Dr. ir. P.P.C.A. Menheere

\section{Beoordelingscommissie}

Prof. dr. E. Mariman (voorzitter)

Prof. dr. R.O.B. Gans (Rijksuniversiteit Groningen)

Dr. H.A. Keizer

Prof. dr. A.C. Nieuwenhuijzen Kruseman

Prof. dr. A. Scheen (Université de Liège, België)

Financial support by Novo Nordisk Pharma and GlaxoSmithKline for the publication of this thesis is gratefully acknowledged. 


\section{Contents}

Chapter 1

Introduction

Glucose mediated crosslinking of collagen in rat tendon and skin

Chapter 3

53

A liquid chromatographic method for the quantitative determination of $\mathrm{N}^{\varepsilon}$-carboxymethyllysine in human plasma proteins

\section{Chapter 4}

Time course of specific AGEs during optimized glycaemic control in type 2 diabetes

\section{Chapter 5}

AGE-induced cascade in diabetic retinopathy in patients with type 1 diabetes mellitus

\section{Chapter 6}

Endogenous and Postprandial exogenous AGE formation and accumulation in type 2 diabetic patients

\section{Chapter 7}

General Discussion

Summary

Samenvatting

Dankwoord

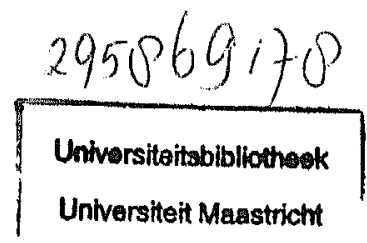

Publications 
Introduction 


\section{General aspects of diabetes mellitus}

\section{Epidemiology and etiology}

There are over 175 million people in the world ( $>3 \%$ of total world population) suffering from diabetes today and this number will be doubled in $2025^{[1 ; 2]}$. About $6 \%$ of the health budget of most European countries is spent on treatment of diabetic patients ${ }^{[3]}$. Recent data from the RIVM have established that there are 600,000 subjects with diabetes in the Netherlands, and at least 250,000 are currently undiagnosed. With changing lifestyle of modern man and an increasingly aging population diabetes mellitus is becoming one of the major health problems in the world.

Diabetes mellitus is a syndrome which is characterized by chronic hyperglycaemia and disturbances of the carbohydrate, fat and protein metabolism ${ }^{[4]}$. Blood glucose concentration is normally tightly regulated by the coordinated action of insulin and counterregulatory hormones. During fasting a balance is maintained between glucose production by the liver and glucose clearance into peripheral tissues, primarily muscles. Insulin secretion from B-cells of the pancreatic islets is constantly adjusted so that normoglycaemia is maintained. However, in patients with diabetes mellitus, the regulation of blood glucose levels is impaired and the blood glucose concentrations are elevated (hyperglycaemia). Diabetic patients are not able to maintain normal blood glucose levels due to a defect in insulin release or an ineffective utilisation of insulin: both result in hyperglycaemia.

Two types of diabetes can be identified namely type 1, or insulin dependent diabetes mellitus (IDDM) and type 2, or non-insulin dependent diabetes mellitus (NIDDM).

Type 1 diabetes is characterised by the auto-immune destruction of the insulin producing B-cells of the islets of Langerhans in the pancreas. Patients with type 1 diabetes do not produce any insulin anymore and have to be treated with insulin injections. Without this treatment patients develop severe hyperglycaemia, leading to glucosuria, dehydration and ketoacidosis, eventually leading to cerebral disturbances and coma.

Characterisation of type 2 diabetic patients is more complicated due to a complex disease process. This process starts with insulin resistance, resulting in compensatory hyperinsulinaemia by increased pancreatic insulin production in order to keep blood glucose levels within normal limits. Eventually, when the pancreas is no longer able to produce enough insulin to maintain blood 
glucose levels within the normal range, postprandial and later fasting blood glucose levels will start to increase, and patients are diagnosed as type 2 diabetics. Since most patients are obese, basic treatment consists of dietary adjustments and increased activity aiming to loose weight and -if necessary. oral medication to stimulate extra insulin secretion. Unfortunately, as diabetes is a progressive disease, many patients will eventually have to be treated with insulin.

It has been well established that hyperglycaemia leads to or accelerates the development of diabetes-related microvascular and macrovascular complications.

Although several advances have been made with respect to development of new oral agents and insulin formulations, it still is very difficult for a considerable number of patients to maintain normal glucose levels during the whole day. Due to this it is very important to increase our knowledge on the mechanisms which influence the development of these complications.

\section{Complications in humans with diabetes mellitus}

Diabetic complications can roughly be divided in two major categories, namely micro and macrovascular complications (table 1).

Table 1. Diabetic complications

\begin{tabular}{ll}
\hline microvascular & neuropathy \\
& retinopathy \\
& nephropathy \\
macrovascular & large vessel disease (stroke, \\
& myocardial infarction) \\
micro- and macrovascular & peripheral vascular disease \\
\hline
\end{tabular}


micro-vascular

Damage to the small vessels in the body leads to multiple complications gathered in the term microvascular complications. These encompasses complications of the retina, kidney and neurons.

Due to lack of consistent epidemiological studies ${ }^{[5]}$ only few comparable data are available on the impact and the frequency of diabetic peripheral neuropathy.

Neuropathy is one of the most common diabetic complications; its prevalence increases with duration and severity of hyperglycaemia as was elegantly shown in the classic studies by Pirart ${ }^{[6]}$. Diabetic neuropathy is a complex mixture of nerve diseases and can be divided roughly in two groups namely diffuse and focal neuropathy ${ }^{[7]}$. Diffuse neuropathy can be subdivided in distal symmetric sensorimotor polyneuropathy and autonomic neuropathy. Distal symmetric neuropathy is probably the most common form of neuropathy ${ }^{[5]}$ and involves sensory nerve deficits leading to complaints like loss of light touch and proprioception and diminished pain and temperature perception. Autonomic neuropathy can affect both orthosympathic and parasympathic autonomic functions like the cardiac, gastro-intestinal and genital functions ${ }^{[8]}$. Focal forms of neuropathy are less common than diffuse neuropathy and usually consist of the damage to one (mono) or multiple nerves (polyneuropathy).

Focal neuropathy usually occurs suddenly and primarily in elderly patients and has a more progressive character than diffuse neuropathy.

Diabetes may affect the eye and retinopathy is the leading cause of blindness of people 25 to 74 years of age in the US [9].

The formation of glaucoma and diabetic cataract developed by diabetic patients are the most likely complications affecting the eye lens. Next to these complications the disease can affect the retina. The first stage in retinopathy is called non-proliferative retinopathy, and is characterized by the leaking and weakening of the arteries in the retina ${ }^{[10]}$, resulting in formation of microaneurysms at the posterior end of the retina. As the process proceeds small haemorrhages will form. Most of the damage in this stage is by fluid accumulation in the macula, which is called macula oedema. The second stage of retinopathy, called preproliferative retinopathy, is marked by the forming of cotton wool spots (whitish grey spots, representing 
infarctions of the retinal tissue) and larger haemorrhages, which are associated with large areas of capillary nonperfusion. Late stage retinopathy (proliferative retinopathy) is marked by an overall vasculopathy, including retinal vascularization, glial proliferation and vitreoretinal traction. With continuing duration of the disease, massive vitreous haemorrhages and retinal detachment will occur, eventually resulting in blindness ${ }^{[11]}$.

Diabetic nephropathy (DN) is the most common cause of end-stage renal disease in the Western world, and $30-40 \%$ of patients requiring kidney transplantation are suffering form $D N{ }^{[12 ; 13]}$. The first stage of $D N$ is a supernormal GFR, called hyperfiltration ${ }^{[14 ; 15]}$. As no clinical signs are present, this stage can only be detected by the presence of microalbuminuria (increased albumin excretion rate $>30$ but $<300 \mathrm{mg} /$ day). If untreated, GFR will gradually start to decrease and macroalbuminuria will develop (excretion $>300 \mathrm{mg} /$ day) during the following years. As GFR may decrease by $10 \%$ per year, serum creatinine levels will gradually increase, and 1 to 5 years after the onset of macroalbuminuria, ESRD will develop and renal replacement therapy is necessary. For many years DN was thought to be a primarily glomerular disease ${ }^{[15]}$. Glomeruli were injured by protein denaturation by high glucose levels and the adverse effect of intraglomerular hypertension. In recent years it has been shown that in the majority of the patients early glomerular events lead to macroalbuminuria where the long-term decrease in renal function is marked by the degree of tubulointerstitial fibrosis ${ }^{[16 ; 17]}$.

macro-vascular

Macrovascular disease (MVD) is one of the most common causes of death in the western world. Prevalence of coronary artery disease (CAD), one of the outcomes of macrovascular disease) varies from $9.5-55 \%{ }^{[18-20]}$ in diabetic patients while prevalence is $1.6-4.6 \%$ in the general population ${ }^{[1 ; 22]}$. This indicates the major impact of diabetes on the overall prevalence of CAD and macrovascular disease in general.

MVD affects the larger vessels of the human body. The walls of the large vessels of the human body consist of 3 layers, the intima, media and adventitia. In the process of atherosclerosis (the primary process in macrovascular disease) the intima is the first to be affected resulting in damage of the endothelial layer. This damage causes monocytes to be attracted which move inside the arterial wall lining. These monocytes are 


\section{2 | Chapter 1}

transformed into foam cells which will eventually develop into large lipid filled plaques which will thicken the wall of the artery and bulge into the arterial lumen. This thickening causes a gradual progressive reduction of the blood flow due to narrowing of the artery. When this happens in the arteries of the coronary system, the patient may experience chest pain on exertion. Next to the narrowing of the artery, vessels affected by atherosclerosis lose their elasticity which may lead to increased blood pressure.

The danger of the lipid filled plaques is that they may rupture or show ulceration, and this can lead to the formation of a blood clot on this surface. This clot (thrombus) may in a short period of time completely obstruct the blood flow to the organ leading to tissue death and dysfunction. When this occurs in a coronary artery, a myocardial infarction is the consequence.

Peripheral vascular disease (PVD) may occur in the smaller arteries of the leg below the knee, the tibials, peroneals, their branches and arterioles ${ }^{[23]}$. PVD is especially characterised by the involvement of the arterioles. The walls of these vessels consist of the intima and the media and generally no adventitia. Arterioles modulate peripheral vascular resistance and blood flow through the capillary bed. Intimal proliferation and hyalinization of the vessel wall will eventually lead to narrowing of the vessel leading to pain during exercise, leg ischemia and in severe situations necrosis of the toes or the foot.

\section{Micro- and macrovascular}

Most non-traumatic amputations occur in diabetic patients. Amputation of one of the extremities has, next to blindness, probably the most profound effect on daily life of diabetic patients. The diabetic foot is the most common form of damage to the lower extremities and usually is caused a combination of both micro- and macrovascular processes ${ }^{[24]}$.

The process starts with a painless trauma (due to the destruction of the nerve endings of the foot) and ulceration. PVD of the lower extremities will prevent delivery of nutrients, oxygen and antibiotics to the infected area. This will prevent healing and eventually lead to severe ischemia, gangrene and amputation.

Most diabetic patient have a combination of several of the complications described in the previous paragraphs ${ }^{[25 ; 26]}$. 


\section{Molecular mechanisms underlying diabetic complications}

Several hypotheses have been postulated about the mechanisms by which hyperglycaemia leads to the development of diabetic complications ${ }^{[27 ; 28]}$. These hypotheses include increased activity of the polyol pathway, increased Protein Kinase $C$ (PKC) activation, oxidative stress and the non-enzymatic glycation of proteins (Advanced Glycation Endproducts, AGEs).

\section{The polyol pathway}

As glucose levels increase in insulin-independent tissue, glucose will react to sorbitol via the polyol pathway ${ }^{[2 ; ; 30]}$. This reaction is catalysed by aldose reductase and uses NADPH as substrate. An increase in sorbitol leads to an altered cell metabolism and it has been postulated that this increase will change osmotic pressure and will result in cellular dysfunction. Using NADPH as substrate can lead to loss of NADPH availability in other pathways. As $\mathrm{NADPH}$ is used in the recyeling of oxidized glutathione to glutathione (a powerful antioxidant), a reduction in NADPH will lead to a reduction in antioxidant capacity. NADPH is also used in the synthesis of nitrogen oxide (NO) from arginine, so a decrease in NADPH will result in a decrease in NO, which will promote vasoconstriction ${ }^{[27 ; 28]}$.

Next to this, sorbitol can react with sorbitol dehydrogenase to form fructose and NADH (figure 1). Accumulation of NADH can in some cells be sensed as hypoxia (pseudohypoxia) ${ }^{[31 ; 32]}$. As fructose reacts more easily with protein than glucose, an increase in fructose will probably lead to an increase in Advanced glycation endproduct (AGE) formation as compared to glucosemediated AGE formation.

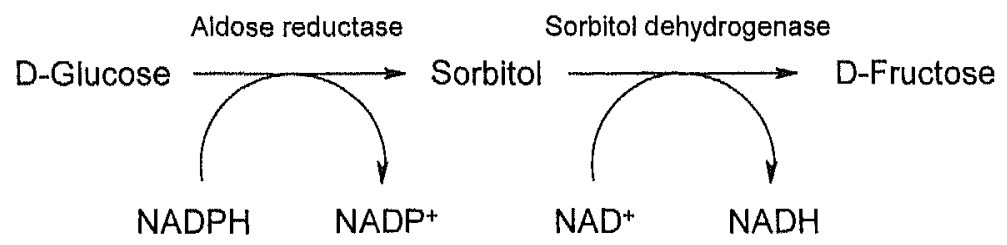

Figure 1. Reduction of D-gluose to sorbitol and the oxidation of sorbitol to D-fructose in the polyol pathway 
Oxidation of sorbitol to fructose seems to increase the $\mathrm{NADH} / \mathrm{NAD}$ ratio, giving rise to an increase in diacylglycerol (DAG) synthesis and protein kinase $C$ (PKC) activation. So inhibition of aldose reductase (and the resulting decrease in $\mathrm{NADH} / \mathrm{NAD}^{+}$ratio by normalising sorbitol levels) can hypothetically be of great use in preventing diabetic complications by inhibiting PKC activation. However as results are controversial more research has to be done to come to a more conclusive conclusion ${ }^{[3 ; ; 34]}$. Most prominent results have been observed in diabetic neuropathy, especially with the compounds which have a high nerve penetration. Aldose reductase inhibition in 'healthy' persons will probably have no negative effect on the person's well-being.

\section{Protein kinase $\mathrm{C}(\mathrm{PKC})$ activation}

Hyperglycaemia induces an increase in DAG, mainly by de novo synthesis, which will result in a change in PKC activation ${ }^{[27]}$. The opposite seems to be true in tissues with high aldose reductase levels where myoinositol is probably shifted outside the cell by a hyperglycaemia-induced increase in sorbitol. This will result in an altered phospho-inositol and DAG mechanism ${ }^{[28]}$ which in turn will affect PKC activation. PKC is a collection of serine-threonine kinases consisting of at least 12 enzymes. PKC-B is activated in the aorta and the heart of the diabetic rat. PKC $-\alpha,-\beta$ and $-\varepsilon$ are activated in the retina of the diabetic rat. PKC Activation in the glomeruli of the diabetic rat consist out of PKC $-\alpha,-\beta,-\delta,-\varepsilon$ and $-\zeta^{[35]}$.

PKC activation seems to regulate different vascular functions. As macro- and microvascular complications play an important role in diabetic disease, PKC activation will have an important role in its pathogenesis ${ }^{[35 ; 36]}$.

The fatty acid portion of DAG usually consists of arachidonate and stereate. Many other fatty acids can occupy the di-acyl portion of DAG giving rise to a broad band of DAG's making it almost impossible to prevent formation of DAG.

Due to the variety of PKC's it is almost impossible to prevent all consequences due to PKC activation. In this respect research on PKC inhibitors will focus on inhibitors for specific PKC's ${ }^{[37]}$ rather than inhibition of overall PKC activation. The role of DAG in relation to health will not be discussed in this thesis. 


\section{Increased oxidative stress}

Oxidative stress indicates an increase in oxidation adducts, the so-called reactive oxygen species (ROS) ${ }^{[38]}$. Hyperglycemia can induce oxidative stress in several ways. Mitochondrial oxidative phosphorylation generates free radicals as by-products, for example the superoxide anion ${ }^{[39]}$. Secondly, the polyol pathway has a negative effect on the anti-oxidant status of the human body ${ }^{[40 ; 41]}$. Next to this, autoxidation of glucose will generate free radicals and oxaldehydes. These oxaldhydes can react with proteins and form AGEs, which in turn can generate free radicals ${ }^{[42-44]}$.

An increase in oxidative stress will affect most of these metabolic processes in the human body which in return will result in an increase in oxidative stress resulting in a negative spiral and will have a profound effect on the general health of diabetic patients.

\section{Advanced Glycation Endproducts (AGEs)}

Reducing sugars and some carbohydrate precursors can react nonenzymatically with proteins. In this reaction, first described by Maillard in $1912^{[45]}$, the aldhyde group of the sugar reacts with the amino group of the protein. In most proteins this is the $\varepsilon$-amino group of the amino acid lysine [46]. Reducing sugars in solution exist in both open and ring (pyranose or furanose) forms where only the open form of these sugars reacts with proteins. Reactivity of the sugars in the Maillard reaction is determined by the proportion of the open form ${ }^{[47]}$. The importance of the Maillard reaction was soon recognized by food chemists as explanation for the browning of food and the reduced digestibility and nutritional value of the food. It was only in the 1970's that the importance of this reaction was acknowledged in vivo. This resulted in the discovery of $\mathrm{HbA}_{1 c}$, a minor form of haemoglobin which is glycosylated and elevated in diabetic patients, representing the mean glucose level over the preceding three to four weeks ${ }^{[48 ; 49]}$. In the next years researchers began to realize the importance of these late stage products of the Maillard reaction, the so-called Advanced Glycation Endproducts (AGEs) ${ }^{[50]}$. As time progresses, more evidence has been and will be collected indicating the important role of AGEs in diabetic complications and ageing in general. 


\section{Formation of AGEs}

The first stage in the formation of AGEs is the condensation of the aldehyde group of a sugar and the amino group of a protein resulting in the formation of an unstable $\mathrm{N}$-substituted imine called a Schiff-base type compound ${ }^{[51]}$. This Schiff-base can then undergo a spontaneous rearrangement via an enaminol precursor (Amadori rearrangement) into a more stable ketoamine (Amadori poduct) ${ }^{[52]}$ which is both time and concentration dependent (figure 2). The relatively short time required for the formation of an Amadori product allows their accumulation on both short-lived and long-lived proteins. These Amadori products can then spontaneously react further and form protein crosslinks known as advanced glycation endprodutcs.

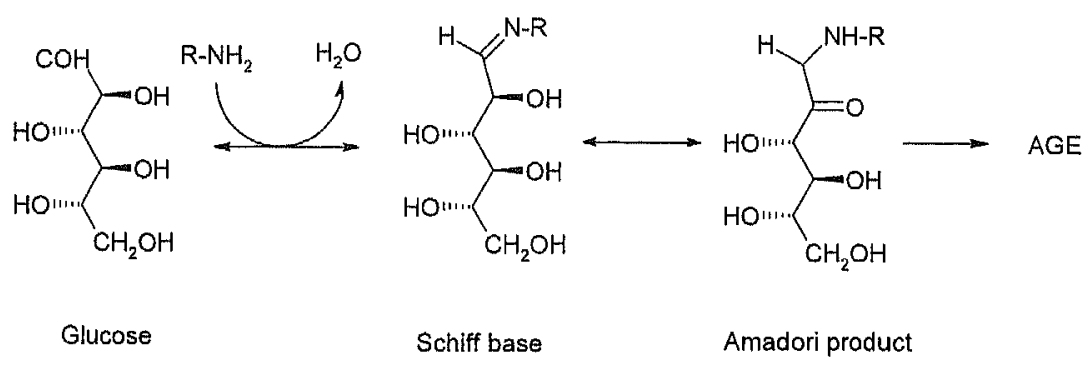

Figure 2. Mechanism of AGE formation

Some AGEs are fluorescent and the degree of fluorescence is related to the protein crosslinking. AGE accumulation on proteins in vivo is very slow, thus, proteins with a long half-life such as collagen, lens-proteins or nerve myelin are the most important targets for AGE formation ${ }^{[53-57]}$. Next to these substrates other forms of macromolecules containing a free amino group are susceptible to AGE formation, like lipids ${ }^{[58]}$ and nucleic acids ${ }^{[59 ; 60]}$.

In addition, general mechanims of AGE formation, i.e. the formation of AGEs by $\alpha$-dicarbonyls is thought to be an important player. $\alpha$-Dicarbonyls can be formed by two different pathways, namely the degradation of glucose, resulting in the formation of glyoxal, methylglyoxal and 3-deoxyglucosone ${ }^{161 .}$ ${ }^{64]}$ and the reversal of the Amadori rearrangement to its enol form resulting in several $\alpha$-oxoaldehydes.

Identification of the structure of AGEs is difficult due to both the complexity and the heterogenenity of their presumed structure. Due to this the information on the chemical structure of AGEs is still limited. Pongor et al 
were the first to propose a structure for AGEs, the fluorescent aromatic heterocyclic compound 2-(2-furoyl)-4-(5)-(2-furanyl)-1-H-imidazole (FFI) generated through a condensation of two Amadori products ${ }^{[65]}$. Later FFI appeared to be an artefact rising from the acid hydrolysis of the in vitro AGE preparations ${ }^{[66]}$. Sell and Monnier identified a fluorophore present on human dura mater collagen, which was identified as an imidazo-(4,5-b)-pyridinium ring with lysine and arginine side chains, named pentosidine ${ }^{[67]}$. Two other pyrrole-related compounds have been identified. These are 1-alkyl-2-formyl3,4-diglycosyl-pyrrole (AGFP) ${ }^{[68]}$ and pyrraline (5-hydroxymethyl-1neopentylpyrole-2-carbaldehyde) ${ }^{[69 ; 70]}$. In later years more structures and mechanisms were elucidated like, $C M L{ }^{[71 ; 72]}$ and imidazolones ${ }^{[73 ; 74]}$, which are known to be glycoxidation products and require oxidation reactions for their formation from glucose.

\section{AGE structures}

As mentioned in the last paragraph, many AGE structures have been characterised and analysed in human body fluid and tissue. The first of the AGEs isolated from in vitro preparations were fluorophores with brown pigments, the so-called classic AGEs. These were crosslinks between proteins and had fluorescent properties (figure 3).

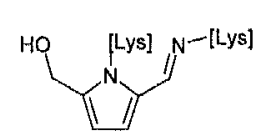

pyrraline imine

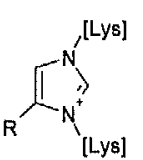

imidazolium imine

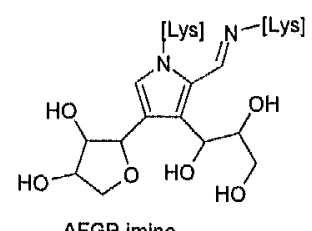

AFGP imine

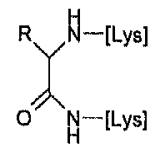

alpha-amino aclds amides

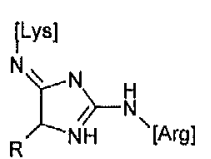

aminoimidazoline imine<smiles>CNC1NC2CC(O)NC(=O)NC2N1</smiles>

glucosepan<smiles>CNNc1n[nH]c(CCO)n1</smiles>

$A L I$

Figure 3. Fluorescent crosslinks formed under physiological conditions ${ }^{[75]}$.

Though these structures can easily be used as markers for protein glycation by their fluorescent properties, they are thought to only account for 1 percent of the total AGEs. So AGEs responsible for the major amount of protein-protein 
crosslinks have to be non-fluorescent. Although it is more difficult to characterise this group of AGEs, several structures have been elucidated (figure 4).<smiles>[AlH2]Nc1nc2c(ccc[n+]2[AlH2])[nH]1</smiles>

Pentosidine<smiles></smiles>

Vesperlysine $A, B$

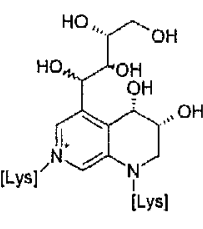

Crossine<smiles></smiles>

Vesperlysine $\mathrm{C}$

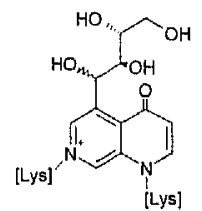

AGE-X1<smiles>OCc1cc2c(c[n+]1[AlH2])N([AlH2])C1OC(C(O)CO)CC21O</smiles>

FPPC

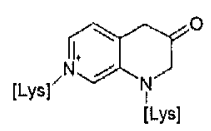

Pentodilysine

Figure 4. Non-fluorescent AGE-crosslinks of physiological relevance ${ }^{[75]}$.

Both fluorescent and non-fluorescent AGEs constitute of crosslinks formed between proteins, changing their conformation and function. Next to this, there are AGEs which are not formed as a crosslink between proteins, called non-crosslinking AGEs (figure 5). These AGEs are precursors for the development of future crosslinks or are ligands for the different receptors for AGEs. Interaction with these receptors will induce several cellular and tissue processes.

Though many structures have already been elucidated, these AGEs represent only a small percentage of the total pool of AGEs present in the human body. So using one of these AGEs as a biomarker, will not represent the total pool of AGEs, but just one of the most common AGEs in the human body. 


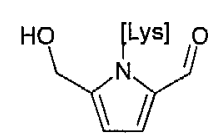

Pyrralin

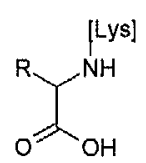

1-carboxyalkyllysine (CML,CEL)<smiles>[R]C1NC(=NN)NC1=O</smiles>

Imidazolone A<smiles>[R]C1=NC(=NN)NC1=O</smiles>

Imidazolone B

Figure 5. Non-crosslink AGEs of physiological relevance ${ }^{[75]}$.

\section{Biochemical and physiological properties of AGEs}

A lot of research has been done on the biochemical and physiological properties of AGEs, showing their important role in the occurrence of diabetic complications and ageing in general.

Table 2 gives an overview of some of the pathogenic properties of AGEs ${ }^{[76]}$. AGEs predominantly form crosslinks between long-living macro-molecules like collagen. Formation of these crosslinks will change the conformation of these proteins and their associated function. Physiological consequence of this crosslinking is thickening of the basement mebrane, glomerulosclerosis and artherosclerosis development. Atherosclerosis will also be induced by the glycation of LDL, which will be more atherogenic after glycation ${ }^{[77 ; 78]}$. Next to this crosslinking, the non-crosslinking AGEs play an important role in the development of diabetic complications.

Table 2. Various deleterious effects of AGEs in the development of complications ${ }^{[76]}$.

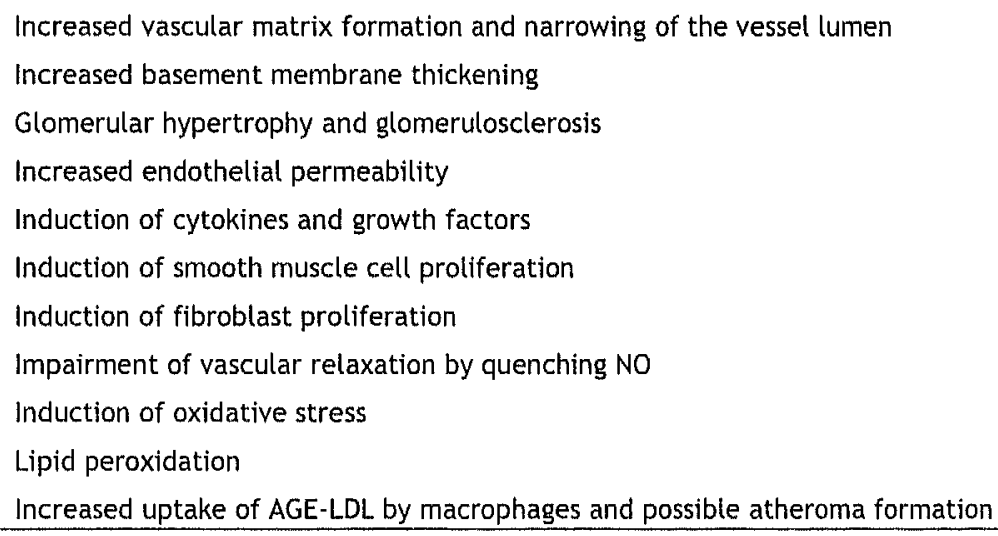




\section{AGE receptors}

Previously formation of AGEs was thought to affect proteins, explaining their physiological and structural changes, resulting in diabetic complications. But in recent years several AGE receptors have been identified like RAGE, the AGE receptor complex and an AGE macrophage scavenger, which is similar to the macrophage scavenger receptor (MSR) ${ }^{[79 ; 80]}$. These AGE receptors were first thought to be simple scavenger receptors removing AGEs from the circulation and preventing AGE-derived complications. As more research has been done it appeared that these receptors also mediate intracellular responses like endocytosis, degradation, cytokine secretion, chemotaxis and cell activation [81].

The receptor for AGEs (RAGE) is a multiligand member of the immunoglobulin superfamily of cell surface molecules. Ligands for the receptor include AGEs, members of $\$ 100 /$ calgranulin family, B-sheet familiar structures and amphoterin ${ }^{[82 ; 83]}$. Consequences of RAGE activation are broad, varying from activation of the Jak/Stat pathway to activation of $\mathrm{p}_{21}{ }^{\text {ras }}$ and the mitogen activated protein (MAP) kinase family. RAGE expression is upregulated in the presence of one of its ligands ${ }^{[84]}$.

The AGE receptor complex consists of three protein components, AGE- $R_{1},-R_{2}$ and $R_{3}$. AGE- $R_{1}$ mRNA expression is not markedly upregulated on exposure to AGE ligands indicating a more static role as an AGE docking protein. In contrast $A G E-R_{2}$ is more upregulated and is thought to play a role in receptor signalling transduction and stabilisation of the complex with AGE- $R_{3} . A G E-R_{3}$ is most liable to upregulation and will probably play a role in the assembly of the AGE receptor in the plasma membrane ${ }^{[81]}$.

AGE proteins can also be taken up by macrophages via the macrophage scavenger receptor, which behaves as a simple scavenger of AGEs.

Although much research has been done on the AGE receptors and their signalling pathways, the exact mechanism of AGE ligand binding and signalling remains unclear. 


\section{Markers of Advanced Glycation Endproducts}

As mentioned before, because of the very heterogeneous nature of AGEs it is difficult to determine total AGE content in the human body. To be able to do so, several of the more well-characterised AGEs have been used as biomarker for AGE-induced diabetic complications. However due to the variety in the methods used and the lack of a world-wide standard it is difficult to compare the results obtained in these studies.

\section{Collagen crosslinking}

The extracellular matrix protein collagen is highly prone to AGE-formation. The susceptibility of collagen to digestion by pepsin has been shown to provide an index of protein cross-linking ${ }^{[85-87]}$. In this method, often tissues are used with high amounts of collagen, like rat tail tendon, to increase specificity of the measurement. Therefore, this method only provides an indication of tissue AGE accumulation.

Using differential scanning calorimetry (DSC) ${ }^{[8 ; 89]}$, a method frequently used in polymer science, crosslinking can also be determined in tissues with less collagen. This method can provide a quantitative method for determining the crosslinking of collagen in vitro.

\section{Immunochemical methods}

From the earliest beginning of AGE research, immunochemical methods have been used in the detection of AGEs in both tissue and body fluids ${ }^{[0 ; 91]}$. The earliest antibodies were raised against an AGE mixture which resulted in a polyclonal antibody recognising several epitopes of the AGE antigen. Further evaluation of these antibodies showed that most antibodies recognised a few major epitopes such as $\mathrm{N}^{\varepsilon}$-carboxymethyllysine ${ }^{[22-94]}$. In recent years monoclonal antibodies are being developed against these major epitopes. Although these antibodies were very specific and sensitive it remained difficult to produce a reliable and reproducible assay (figure 6 ). This is mainly due to the lack of a pure and easy to produce antigen. Using antibodies in the quantitative analysis of AGEs in body fluids remains difficult, but these 
antibodies can be of great importance in qualitative histochemical analysis of AGE-affected tissue.

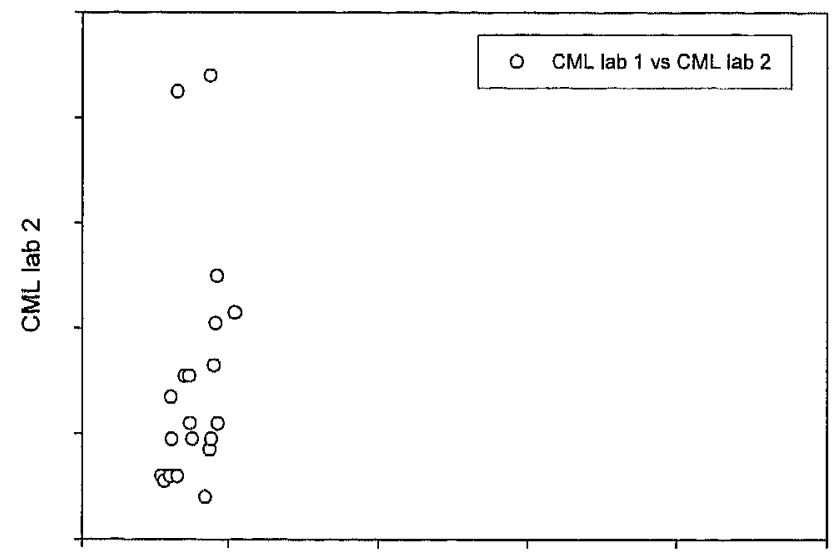

CML lab 1

Figure 6. Results of two CML assays performed in independent laboratories with two different antibodies against CML.

\section{Classical Analytical Methods}

AGEs with known structures, such as pentosidine and $\mathrm{CML}$, can be measured with a high degree of specificity using HPLC ${ }^{[72 ; 95 ; 96]}$. More sophisticated methods like GC-MS and LC-MS are now available for the determination of AGEs ${ }^{[97]}$. As these methods are quite expensive it is difficult to implement these methods in routine patient examination. AGEs with a known biochemical structure only account for a small portion of the total amount of circulating and tissue AGEs, thus making it difficult to elaborate the involvement of these AGEs in the development and exacerbation of diabetic complications. As these AGEs are frequently being used for the determination of the role of AGEs in the development of diabetic complications, it is necessary to have a well standardised analytical method which can be used as a routine diagnostic tool. 
Introduction | 23

\section{Biofluid NMR}

Using biomarkers as biological indicators of AGE-induced diabetic complications can be very useful in finding new therapies for the treatment of diabetes. However, the AGE biomarkers used at the moment probably only represent a few percent of the total AGE pool in the human body. So it is necessary to find new AGE biomarkers.

A useful tool in this can be biofluid ${ }^{1} \mathrm{H}$-NMR. NMR spectra of biofluids generate complex spectra with a large amount of data ${ }^{[98]}$. Samples can be analysed without the need of derivatisation or destruction, resulting in profiles of both endogenous and exogenous metabolites ${ }^{[99]}$. As the spectra of these biofluids are very complex, sophisticated statistical software is developed. Multivariant analysis, such as principal component analysis (PCA) ${ }^{[100]}$ can be used to recognize patterns in the NMR spectra.

As samples are not destructed, further analysis of the sample using HPLC-MS can be used for elucidating the structure of different biomarkers.

\section{Exogenous Sources of AGEs}

Next to the endogenous production of AGEs, AGE accumulation can also arise from exogenous sources like smoking and eating. It is already known that food prepared by heating undergoes a series of changes in colour, taste and nutritional value. This process is called the Maillard reaction ${ }^{[45]}$. The nutritional value of the food decreases due to the destruction of essential amino acids and becomes more difficult to digest due to the formation of crosslinks. As mentioned before the Maillard reaction is not the end stage of the glycation of proteins, but AGE formation is. So in every reaction in which the Maillard reaction occurs, AGE formation will probably take place leading to structural and nutritional changes.

Cerami showed that the curing of tobacco leads to the formation of glycation products ${ }^{[101]}$. Vlassara and co-workers [102] administered AGE-modified albumin to healthy nondiabetic rats and rabbits. After 2-4 weeks of AGEadministration, animals displayed diabetes-like vascular complications: a significant increase in vascular permeability, significant mononuclear cell migration in subendothelial and periarteriolar spaces and a defective endothelium-dependent and -independent vasodilatation. Furthermore, glomerulosclerosis and albuminuria, comparable to diabetic nephropathy were 
seen in healty rats receiving daily injection with AGEs ${ }^{[103]}$. Koschinsky et al ${ }^{[104]}$ showed that the daily influx of dietary AGEs includes glycotoxins that may constitute an added chronic risk for renal-vascular injury in DM (figure 7). It is suggested that dietary restriction of AGE food intake may greatly reduce the burden of AGEs in diabetic patients and possibly improve prognosis.

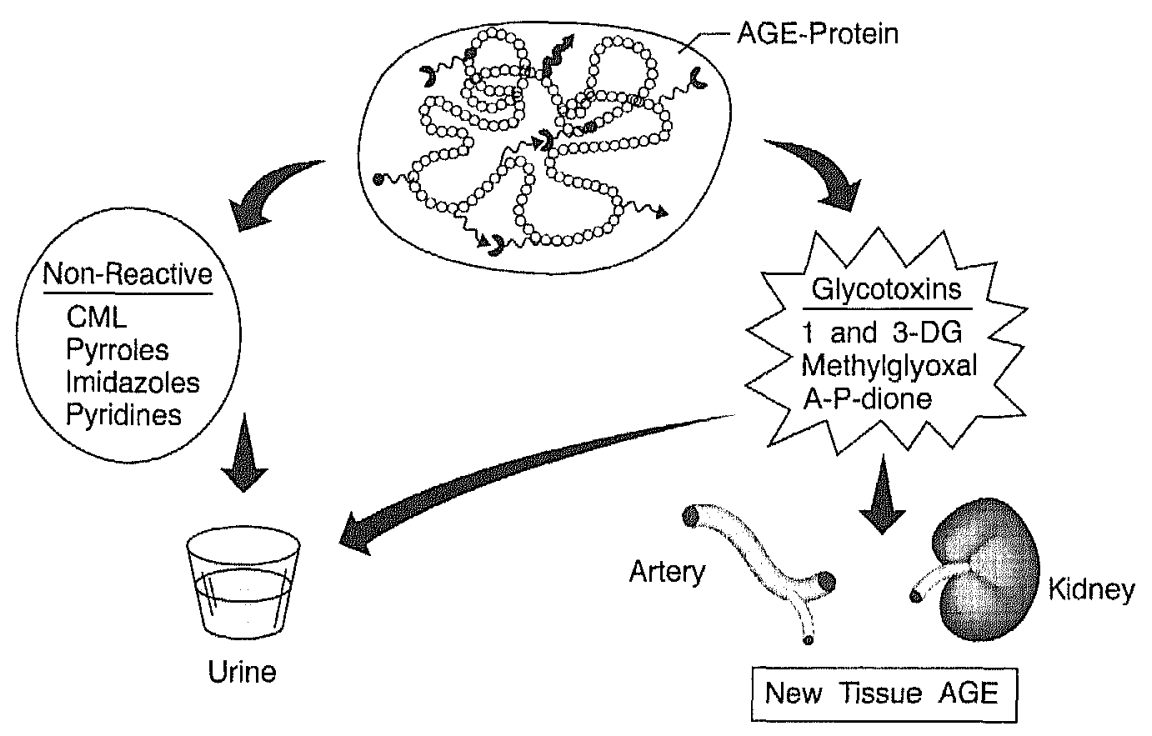

Figure 7. AGE ingestion and accumulation as hypothesised by T. Koshinsky [104]. Part of the AGEproteins ingested is non-reactive and will be excreted in urine. The remaining part are so-called glycotoxins which are reactive and can result in newly formed AGE-proteins in the body.

Next to the exogenous intake of AGEs, consumption of food can have another profound effect on AGE accumulation and production. Diabetic patients can experience fluctuations in blood glucose during the day, especially after a meal. This postprandial increase lasts approximately 2 to 3 hours. These Post Prandial Glucose Excursions (PPGE) ${ }^{[05-107]}$ may also occur in patients in whom tight blood glucose control is strived for with the use of insulin therapy. Beisswenger ${ }^{[108]}$ showed that these PPGE correlate well with serum levels of methylglyoxal and 3-deoxyglucosone, two highly reactive precursors of AGE formation. So the prevalence of PPGEs is directly related to the level of precursors for AGE formation and AGEs in general suggesting an important role 
of these PPGEs as an independent factor in the development of diabetic complications.

From the early years of research on the Maillard reaction AGE research has contributed in the understanding of the molecular mechanisms underlying the development of diabetic complications. Although much is discovered during the last years, more research is needed to fully elucidate the role of AGEs. With this it is necessary to have a reliable, reproducible and widely accepted assay to measure AGEs in order to compare worldwide data. With a better understanding of the role of AGEs new therapies can be developed to improve general health and quality of life of diabetic patients. 
26 Chapter 1

\section{Aim and outline of this thesis}

This thesis describes research on important aspects of AGE formation and the role of AGEs in the development of diabetic complications. In addition to the development of a reliable assay for specific AGE(s) we were specifically focussing on the interrelationship between overall as well as postprandial glycaemic control, AGEs, and diabetic complications like retinopathy and atherosclerosis.

Specific aims of this thesis are:

1) To develop a reliable, reproducible and easy to use analytical method to measure AGEs. For this question we have applied a technique frequently used in polymer chemistry i.e. differential scanning calorimetry to assess the consequences of hyperglycaemia in collagenous tissue obtained form diabetic rats, in order to assess overall crosslinking which could be used as marker for AGE formation. In addition, we have developed and evaluated a HPLC method for the measurement of $\mathrm{N}^{\varepsilon}$-carboxymethyllysine $(\mathrm{CML})$. This method was subsequently used as an analytical tool in the other studies.

2) To assess the significance of polymorphisms in the gene of the receptor for AGES (RAGE) and AGE formation in general and its consequences in the development of diabetic complications, especially retinopathy. The association between these polymorphisms, CML levels and messengers in the activated molecular pathways were studied.

3) To assess the changes of different AGEs during improvement of glycaemic control in subjects with type 2 diabetes. Since it is unknown whether CML levels change in parallel to glycaemic control (like $\mathrm{HbA}_{1 \mathrm{c}}$ ), patients with type 2 diabetes who switched to insulin therapy because of insufficient glycaemic control were followed prospectively.

4) To assess possible differences in AGE formation and its relation to postprandial hyperglycaemia in subjects with type 2 diabetes with and without macrovascular complications. The degree of postprandial hyperglycaemia was measured with the use of 3-day continuous blood glucose monitoring, and related to a-dicarbonyl and CML levels. It was hypothesized that patients with type 2 diabetes with macrovascular disease would have 
higher postprandial glucose excursions which results in higher a-dicarbonyl and CML levels compared to patients without macrovacular disease.

5) To assess the effect of an AGE-rich meal on serum AGE levels in subjects with type 2 diabetes and macrovascular complications and those without. Our hypothesis was that type 2 diabetics with macrovascular disease would exhibit a higher postprandial increase of AGEs in reaction to an AGE-rich test meal than patients without macrovascular disease. 


\section{References}

1. King $H$, Aubert RE, Herman WH. Global burden of diabetes, 1995-2025: prevalence, numerical estimates, and projections. Diabetes Care 1998;21:1414-31.

2. Amos AF, McCarty DJ, Zimmet P. The rising global burden of diabetes and its complications: estimates and projections to the year 2010. Diabet.Med. 1997;14 Suppl 5:51-85.

3. Passa P. Diabetes trends in Europe. Diabetes Metab Res.Rev. 2002;18 Suppl 3:53-58.

4. Bennet PH. Definition, diagnosis, and classification of diabetes mellitus and impaired glucose tolerance. In: Kahn CR, Weir GC, editors. Joslin's Diabetes Mellitus, 13 ed. Philadelphia: Lea \& Febiger, 1994:193-200.

5. Melton LJ, Dyck PJ, In: Dyck PJ, Thomas PK, Winegrad Al, Porte D, editors. Diabetic Neuropathy. Philedelphia: WB Saunders, 1987:22-37.

6. Pirart J. Why don't we teach and treat diabetic patients better? Diabetes Care 1978;1:13940.

7. Report and recommendations of the San Antonio conference on diabetic neuropathy. Consensus statement. Diabetes 1988;37:1000-4.

8. Greene DA, Pfeifer M. In: Olefsky JM, Sherwin R, editors. New Concepts in Treatment and Complications of Diabetes, Contemporary Issues in Endocrinology and Metabolism. New York: Churchill Livingstone Inc., 1985:223.

9. Vision Problems in the US. New York: National Society to Prevent Blindness, 1980.

10. Ballantyne AJ, Loewenstein A. Exudates in diabetic retinopathy. Trans.Opthalmol.Soc.Uk 1943;63:95.

11. Wise GN, Dollery CT, Henkind P, The Retinal Circulation. New York: Haper and Row, 1971.

12. Ritz E, Stefanski A. Diabetic nephropathy in type $I$ diabetes. Am.J.Kidney Dis. 1996;27:167-94.

13. Anderson S, Brenner BM. Pathogenesis of diabetic glomerulopathy: hemodynamic considerations. Diabetes Metab Rev. 1988;4:163-77.

14. Chiumello G, Beccaria L, Meschi F, Mistura L, Brambilla P, Bognetti E. Etiology, diagnosis, and prevention of renal involvement in insulin- dependent diabetes mellitus. Pediatrician. 1983;12:199-207.

15. Phillips $A O$, Steadman R. Diabetic nephropathy: the central role of renal proximal tubular cells in tubulointerstitial injury. Histol. Histopathol. 2002;17:247-52.

16. Mauer SM, Steffes MW, Ellis EN, Sutherland DE, Brown DM, Goetz FC. Structural-functional relationships in diabetic nephropathy. J.Clin. Invest 1984;74:1143-55. 
17. Bohle A, Wehrmann M, Bogenschutz $O$, Batz C, Muller CA, Muller GA. The pathogenesis of chronic renal failure in diabetic nephropathy. Investigation of 488 cases of diabetic glomerulosclerosis. Pathol.Res.Pract. 1991;187:251-9.

18. Liebow IM, Newill VA, Oseasolin R. Incidence of ischemic heart disease in a group of diabetic women. Am.J.Med.Sci. 2003;248:403-7.

19. Howard BV, Welty TK, Fabsitz RR et al. Risk factors for coronary heart disease in diabetic and nondiabetic Native Americans. The Strong Heart Study. Diabetes 1992;41 Suppl 2:411.

20. Whiteley L, Padmanabhan S, Hole D, Isles C. Should diabetes be considered a coronary heart disease risk equivalent?: results from 25 years of follow-up in the Renfrew and Paisley survey. Diabetes Care 2005;28:1588-93.

21. Bakx C, Schwarte J, van den HH, Bor H, van Weel C. First myocardial infarction in a Dutch general practice population: trends in incidence from 1975-2003. Br.J.Gen.Pract. 2005;55:860-3.

22. Kannel WB. Incidence and epidemiology of heart failure. Heart Fail.Rev. 2000;5:167-73.

23. Levin ME, Sicard GA. Peripheral Vascular Disease in the Person with Diabetes. In: Rifkin H, Porte DJr, editors. Diabetes Mellitus, 4 ed. New York: Elsevier, 1990:768-791.

24. Brand PW, Coleman WC. The Diabetic Foot. In: Rifkin H, Porte DJr, editors. Diabetes Mellitus, 4 ed. New York: Elsevier, 1990:812-823.

25. Effect of intensive diabetes management on macrovascular events and risk factors in the Diabetes Control and Complications Trial. Am.J.Cardiol. 1995;75:894-903.

26. Intensive blood-glucose control with sulphonylureas or insulin compared with conventional treatment and risk of complications in patients with type 2 diabetes (UKPDS 33). UK Prospective Diabetes Study (UKPDS) Group. Lancet 1998;352;837-53.

27. Sheetz MJ, King GL. Molecular understanding of hyperglycemia's adverse effects for diabetic complications. JAMA 2002;288:2579-88.

28. Gugliucci A. Glycation as the glucose link to diabetic complications. J.Am.Osteopath. Assoc. 2000; 100:621-34.

29. Gabbay KH. The sorbitol pathway and the complications of diabetes. N.Engl.J.Med. 1973;288:831-6.

30. Greene DA, Lattimer SA, Sima AA. Are disturbances of sorbitol, phosphoinositide, and Na+$\mathrm{K}+-A T P a s e$ regulation involved in pathogenesis of diabetic neuropathy? Diabetes 1988; 37:688-93.

31. Ziyadeh FN. Mediators of hyperglycemia and the pathogenesis of matrix accumulation in diabetic renal disease. Miner. Electrolyte Metab 1995;21:292-302.

32. Lee AY, Chung SS. Contributions of polyol pathway to oxidative stress in diabetic cataract. FASEB J. 1999;13:23-30. 
30 | Chapter 1

33. Cameron NE, Cotter MA. Contraction and relaxation of aortas from galactosaemic rats and the effects of aldose reductase inhibition. Eur.J.Pharmacol. 1993;243:47-53.

34. Frank RN. The aldose reductase controversy. Diabetes 1994;43:169-72.

35. Ishii $H$, Koya $D$, King GL. Protein kinase $C$ activation and its role in the development of vascular complications in diabetes mellitus. J.Mol.Med. 1998;76:21-31.

36. King GL, Kunisaki M, Nishio $Y$, Inoguchi $T$, Shiba T, Xia P. Biochemical and molecular mechanisms in the development of diabetic vascular complications. Diabetes 1996;45 Suppl 3:5105-5108.

37. Frank RN. Potential new medical therapies for diabetic retinopathy: protein kinase $C$ inhibitors. Am.J.Ophthalmol. 2002;133:693-8.

38. Bonnefont-Rousselot D, Bastard JP, Jaudon MC, Delattre J. Consequences of the diabetic status on the oxidant/antioxidant balance. Diabetes Metab 2000;26:163-76.

39. Nishikawa $T$, Edelstein $D, D u X L$ et al. Normalizing mitochondrial superoxide production blocks three pathways of hyperglycaemic damage. Nature 2000;404:787-90.

40. Tesfamariam B. Free radicals in diabetic endothelial cell dysfunction. Free Radic.Biol. Med. 1994;16:383-91.

41. Greene DA, Stevens MJ. The sorbitol-osmotic and sorbitol redox hypotheses. In: Le Roith D, Taylor SI, Olefsky JM, editors. Diabetes Mellitus. Philadelphia: Lipincott-Raven, 1996.

42. Hunt JV, Dean RT, Wolff SP. Hydroxyl radical production and autoxidative glycosylation. Glucose autoxidation as the cause of protein damage in the experimental glycation model of diabetes mellitus and ageing. Biochem.J. 1988;256:205-12.

43. Hunt JV, Smith CC, Wolff SP. Autoxidative glycosylation and possible involvement of peroxides and free radicals in LDL modification by glucose. Diabetes 1990;39:1420-4.

44. Giardino I, Edelstein D, Brownlee M. BCL-2 expression or antioxidants prevent hyperglycemia-induced formation of intracellular advanced glycation endproducts in bovine endothelial cells. J.Clin. Invest 1996;97:1422-8.

45. Maillard LC. Action des acides amines sur les sucres; formation des melanoidines par voie methodique. C.R.Hebd.Sceances.Acad.Sci. 1912;154:66-8.

46. Shapiro R, MCManus MJ, Zalut C, Bunn HF. Sites of nonenzymatic glycosylation of human hemoglobin A. J.Biol.Chem. 1980;255:3120-7.

47. Kohn RR, Cerami A, Monnier VM. Collagen aging in vitro by nonenzymatic glycosylation and browning. Diabetes 1984;33:57-9.

48. Koenig RJ, Peterson CM, Jones RL, Saudek C, Lehrman M, Cerami A. Correlation of glucose regulation and hemoglobin Alc in diabetes mellitus. N.Engl.J.Med. 1976;295:417-20.

49. Larsen ML, Horder M, Mogensen EF. Effect of long-term monitoring of glycosylated hemoglobin levels in insulin-dependent diabetes mellitus. N.Engl.J.Med. 1990;323:1021-5.

50. Monnier VM, Cerami A. Nonenzymatic browning in vivo: possible process for aging of long. lived proteins. Science 1981;211:491-3. 
51. Solomons TWG. Aldehydes and Ketones I. In: Organic Chemistry, 5th ed. New York: John Wiley \& Sons, Inc., 1992:704.

52. Zhang $X$, Medzihradscky KF, Cunningham J et al. Characterization of glycated hemoglobin in diabetic patients: usefulness of electrospray mass spectrometry in monitoring the extent and distribution of glycation. J.Chromatogr.B Biomed.Appl. 2001;759:1-15.

53. Brownlee $M$, Pongor S, Cerami A. Covalent attachment of soluble proteins by nonenzymatically glycosylated collagen. Role in the in situ formation of immune complexes. J.Exp.Med. 1983;158:1739-44.

54. Brownlee M, Vlassara $H$, Cerami A. Nonenzymatic glycosylation products on collagen covalently trap low- density lipoprotein. Diabetes 1985;34:938-41.

55. Brownlee $M$, Vlassara $H$, Kooney A, Ulrich P, Cerami A. Aminoguanidine prevents diabetesinduced arterial wall protein cross- linking. Science 1986;232:1629-32.

56. Eble AS, Thorpe SR, Baynes JW. Nonenzymatic glucosylation and glucose-dependent crosslinking of protein. J.Biol.Chem. 1983;258:9406-12.

57. Kent MJ, Light ND, Bailey AJ. Evidence for glucose-mediated covalent cross-linking of collagen after glycosylation in vitro. Biochem.J. 1985;225:745-52.

58. Bierhaus A, Hofmann MA, Ziegler R, Nawroth PP. AGEs and their interaction with AGEreceptors in vascular disease and diabetes mellitus. I. The AGE concept. Cardiovasc.Res. 1998;37:586-600.

59. Lee AT, Cerami A. Induction of gamma delta transposition in response to elevated glucose6-phosphate levels. Mutat, Res. 1991;249:125-33.

60. Bucala $R$, Lee AT, Rourke $L$, Cerami A. Transposition of an Alu-containing element induced by DNA-advanced glycosylation endproducts. Proc.Natl.Acad.Sci.U.S.A 1993;90:2666-70,

61. Thornalley PJ, Langborg A, Minhas HS. Formation of glyoxal, methylglyoxal and 3deoxyglucosone in the glycation of proteins by glucose. Biochem.J. 1999;344 Pt 1:109-16.

62. Wells-Knecht KJ, Zyzak DV, Litchfield JE, Thorpe SR, Baynes JW. Mechanism of Autoxidative Glycosylation; Identification of glyoxal and Arabinose as intermediates in the autoxidative modification of proteins by glucose. Biochemistry (Mosc). 1995;34:3702-9.

63. Hunt JV, Dean RT, Wolff SP. Hydroxyl radical production and autoxidative glycosylation;Glucose autoxidation as the cause of protein damage in the experimental glycation model of diabetes mellitus and ageing. Biochem.J. 1988;256:205-12.

64. Wolffenbuttel BHR, Huijberts MSP. Aminoguanidine, a potential drug for the treatment of diabetic complications. Neth.J.Med. 1993;42:205-8.

65. Pongor S, Ulrich PC, Bencsath FA, Cerami A. Aging of proteins: isolation and identification of a fluorescent chromophore from the reaction of polypeptides with glucose. Proc.Natl.Acad.Sci.U.S.A 1984;81:2684-8. 
32 | Chapter 1

66. Njoroge FG, Fernandes AA, Monnier VM. Mechanism of formation of the putative advanced glycosylation end product and protein cross-link 2-(2-furoyl)-4(5)-(2-furanyl)-1Himidazole. J.Biol.Chem. 1988;263:10646-52.

67. Degenhardt TP, Thorpe SR, Baynes JW. Chemical modification of proteins by methylglyoxal. Cell Mol.Biol. (Noisy.-le-grand) 1998;44:1139-45.

68. Farmar JG, Ulrich $P$, Cerami A. Novel pyrroles from sulfite-inhibited Maillard reactions: insight into the mechanism of inhibition. J.Org. Chem. 1988;53:2346-9.

69. Niwa T. 3-Deoxyglucosone: metabolism, analysis, biological activity, and clinical implication. J.Chromatogr.B Biomed.Sci.Appl. 1999;731:23-36.

70. Hayase F, Nagaraj RH, Miyata S, Njoroge FG, Monnier VM. Aging of proteins: immunological detection of a glucose-derived pyrrole formed during maillard reaction in vivo. J.Biol.Chem. 1989;264:3758-64.

71. Liardon R, de Weck-Gaudard D, Philippossian G, Finat PA. Identification of $N^{*}$ carboxymethyllysine: a new Maillard reaction product, in rat urine. J.Agric.Food Chem. 1987;35:427-31.

72. Ahmed $\mathrm{MU}$, Thorpe Suzanne $\mathrm{R}$, Baynes John $\mathrm{W}$. Identification of $\mathrm{N}^{\mathrm{C}}$-Carboxymethyllysine as a Degradation product of fructoselysine in glycated protein. J.Biol.Chem. 1996;261:4889-94.

73. Niwa $T$, Katsuzaki $T$, Ishizaki $Y$ et al. Imidazolone, a novel advanced glycation end product, is present at high levels in kidneys of rats with streptozotocin-induced diabetes. FEBS Lett. 1997;407:297-302.

74. Tauer A, Knerr $T$, Niwa $T$ et al. In vitro formation of N(epsilon)-(carboxymethyl)lysine and imidazolones under conditions similar to continuous ambulatory peritoneal dialysis. Biochem. Biophys. Res.Commun. 2001;280:1408-14.

75. Ulrich $P$, Cerami A. Protein glycation, diabetes, and aging. Recent Prog.Horm. Res. 2001;56:1-21.

76. Crijns, F.R.L. Functional and structural determinants of vascular dysfunction in experimental diabetes. 2000. Maastricht University.

77. Bucala R, Makita $Z$, Vega $G$ et al. Modification of low density lipoprotein by advanced glycation end products contributes to the dyslipidemia of diabetes and renal insufficiency. Proc.Natl.Acad.Sci.U.S.A 1994;91:9441-5.

78. Bucala $R$, Mitchell $R$, Arnold $K$, Innerarity $T$, Vlassara $H$, Cerami A. Identification of the major site of apolipoprotein $B$ modification by advanced glycosylation end products blocking uptake by the low density lipoprotein receptor. J.Biol.Chem. 1995;270:10828-32.

79. Stitt AW. Advanced glycation: an important pathological event in diabetic and age related ocular disease. Br.J.Ophthalmol. 2001;85:746-53.

80. Horiuchi 5 , Higashi $\mathrm{T}$, lkeda $\mathrm{K}$ et al. Advanced glycation end products and their recognition by macrophage and macrophage-derived cells. Diabetes 1996;45 Suppl 3:S73-S76. 
Introduction | 33

81. Stitt AW, He C, Vlassara H. Characterization of the advanced glycation end-product receptor complex in human vascular endathelial cells. Biochem.Biophys. Res.Commun. 1999;256:549-56.

82. Stern D, Du YS, Fang YS, Marie SA. Receptor for advanced glycation endproducts: a multiligand receptor magnifying cell stress in diverse pathologic settings. Adv.Drug Deliv. Rev. 2002;54:1615-25.

83. Stern DM, Yan SD, Yan SF, Schmidt AM. Receptor for advanced glycation endproducts (RAGE) and the complications of diabetes. Ageing Res.Rev. 2002;1:1-15.

84. Schmidt AM, Yan SD, Yan SF, Stern DM. The biology of the receptor for advanced glycation end products and its ligands. Biochim. Biophys. Acta 2000;1498:99-111.

85. Brennan $M$. Changes in solubility, non-enzymatic glycation, and fluorescence of collagen in tail tendons from diabetic rats. J.Biol.Chem. 1989;264:20947-52.

86. Kochakian M, Manjula BN, Egan JJ. Chronic dosing with aminoguanidine and novel advanced glycosylation end product-formation inhibitors ameliorates cross-linking of tail tendon collagen in STZ-induced diabetic rats. Diabetes 1996;45:1694-700.

87. Monnier VM, Kohn RR, Cerami A. Accelerated age-related browning of human collagen in diabetes mellitus. Proc.Natl.Acad.Sci.U.5.A 1984;81:583-7.

88. Zeeman R, Dijkstra PJ, van Wachem PB et al. Successive epoxy and carbodiimide crosslinking of dermal sheep collagen. Biomaterials 1999;20:921-31.

89. Melling $M$, Pfeiler $W$, Karimian-Teherani $D$ et al. Differential scanning calorimetry, biochemical, and biomechanical analysis of human skin from individuals with diabetes mellitus [In Process Citation]. Anat. Rec. 2000;259:327-33.

90. Mitsuhashi $T$, Nakayama $H$, Itoh $T$ et al. Immunochemical detection of Advanced Glycation Endproducts in Renal Cortex From STZ-induced diabetic rat. Diabetes 1993;42:826-32.

91. Makita Z, Vlassara H, Cerami A, Bucala R. Immunochemical Detection of Advanced Glycosylation Endproducts in vivo. J.Biol.Chem. 1992;267:5133-8.

92. Onorato JM, Thorpe SR, Baynes JW. Immunohistochemical and ELISA assays for biomarkers of oxidative stress in aging and disease. Ann.N.Y.Acad.Sci. 1998;854:277-90.

93. Ikeda K, Nagai $R$, Sakamoto $T$ et al. Immunochemical approaches to AGE-structures: characterization of anti- AGE antibodies. J.Immunol. Methods 1998;215:95-104.

94. Ikeda $\mathrm{K}$, Higashi $\mathrm{T}$, Sano $\mathrm{H}$ et al. $\mathrm{N}$ (epsilon)-(carboxymethyl)lysine protein adduct is a major immunological epitope in proteins modified with advanced glycation end products of the Maillard reaction. Biochemistry (Mosc). 1996;35:8075-83.

95. Takahashi $M$, Hoshino $H$, Kushida $K$, Inoue $T$. Direct measurement of crosslinks, pyridinoline, deoxypyridinoline, and pentosidine, in the hydrolysate of tissues using highperformance liquid chromatography. Anal.Biochem. 1995;232:158-62. 
34 | Chapter 1

96. Floridi A, Trizza V, Paolotti P, Lucarelli C. Analytical strategy for the assessment of the protein glycation status in uremic patients by high-performance liquid chromatography. J.Chromatogr.A 1999;846:65-71.

97. Humeny $A$, Kislinger $T$, Becker $C M$, Pischetsrieder $M$. Qualitative determination of specific protein glycation products by matrix-assisted laser desorption/ionization mass spectrometry Peptide mapping. J.Agric, Food Chem. 2002;50:2153-60.

98. Nicholson JK, Wilson ID. High resolution proton magnetic resonance spectroscopy of biological fluids. Progress in Nuclear Magnetic Resonance Spectroscopy 1989;21:449.

99. Nicholson JK, Connelly J, Lindon JC, Holmes E. Metabonomics: a platform for studying drug toxicity and gene function. Nat. Rev. Drug Discov. 2002;1:153-61.

100. Nicholson JK, Lindon JC, Holmes E. 'Metabonomics': understanding the metabolic responses of living systems to pathophysiological stimuli via multivariate statistical analysis of biological NMR spectroscopic data. Xenobiotica London 1999;29:1181.

101. Cerami $\mathrm{C}$, Founds $\mathrm{H}$, Nicholl l et al. Tobacco smoke is a source of toxic reactive glycation products. Proc.Natl.Acad.Sci.U.S.A 1997;94:13915-20.

102. Vlassara $H$, Fuh $H$, Makita $Z$, Krungkrai S, Cerami A, Bucala R. Exogenous advanced glycosylation end products induce complex vascular dysfunction in normal animals: a model for diabetic and aging complications. Proc.Natl.Acad.Sci.U.S.A 1992;89:12043-7.

103. Vlassara $H$, Striker $L J$, Teichberg $S$, Fuh $H$, Li YM, Steffes M. Advanced glycation end products induce glomerular sclerosis and albuminuria in normal rats. Proc.Natl.Acad.Sci.U.S.A 1994;91:11704-8.

104. Koschinsky $T$, He C.J, Mitsuhashi $T$ et al. Orally absorbed reactive glycation products (glycotoxins): An environmental risk factor in diabetic nephorpahty. Proc.Natl.Acad.Sci. 1997;94:6474-9.

105. Ceriello A. The emerging role of post-prandial hyperglycaemic spikes in the pathogenesis of diabetic complications. Diabet.Med. 1998;15:188-93.

106. Bonora E, Muggeo M. Postprandial blood glucose as a risk factor for cardiovascular disease in Type II diabetes: the epidemiological evidence. Diabetologia 2001;44:2107-14.

107. Salardi S, Zucchini S, Santoni R et al. The glucose area under the profiles obtained with continuous glucose monitoring system relationships with $\mathrm{HbA}(\mathrm{lc})$ in pediatric type 1 diabetic patients. Diabetes Care 2002;25:1840-4.

108. Beisswenger PJ, Howell SK, O'Dell RM, Wood ME, Touchette AD, Szwergold BS. alphaDicarbonyls increase in the postprandial period and reflect the degree of hyperglycemia. Diabetes Care 2001;24:726-32. 


\title{
Glucose mediated crosslinking of collagen in rat tendon and skin
}

\author{
C.J.A.L. Mentink, M. Hendriks, A. A.G. Levels, B.H.R. Wolffenbuttel
}

Published in: Clinica Chimica Acta, 2002, 321, 69-76 
36 1 Chapter 2

\begin{abstract}
Crosslinking of macromolecules like collagen plays an important role in the development of complications in diabetes and ageing. One of the underlying mechanisms of this crosslinking is the formation of Advanced Glycation Endproducts (AGEs). In this study we assessed the use of differential scanning calorimetry (DSC) for the determination of these crosslinks and the effects of an AGE inhibitor and breaker. Treatment with phenacylthiazoliumbromide (ALT-711) of diabetic rats with 2 months duration of diabetes normalized large artery stiffness, assessed by characteristic input impedance and systemic arterial compliance, but with the use of DSC no statistical difference in crosslinking between control and treated animals could me measured. In addition we performed in vitro incubation of collagen preparations with ribose and glucose to assess the DSC method as well as the influence of AGE breakers and inhibitors. Incubation of rat tail tendon (RTT) with $100 \mathrm{mM}$ glucose showed an increase in collagen crosslinking expressed as an increase in shrinkage temperature $\left(T_{s}\right)$. Addition of aminoguanidine, an inhibitor of AGEformation, prior to glucose incubation showed a slower increase of the amount of glucose-derived crosslinking. Replacing glucose with ribose showed a quicker increase in crosslinking and less effect on crosslinking by adding aminoguanidine, demonstrating the higher reactivity of pentoses above hexoses. Similar experiments with rat skin samples (RSS) showed that RSS (Type III collagen) are less susceptible to glucose mediated crosslinking than RTT (Type I collagen). We observed no effect of addition of ALT-711, a breaker of glucose-derived crosslinks, on the extent of collagen crosslinking in both RTT and RSS. Overall DSC is considered a useful method for assessing glucose mediated crosslinking in vitro with non-physiological glucose concentrations. The in vivo use in biological samples is limited due to the lack of sensitivity. However DSC remains a quick and well-quantitated method in comparison with other methods, like enzyme digestibility.
\end{abstract}




\section{Introduction}

Non-enzymatic glycation of proteins plays an important role in the development of complications in diabetes mellitus and ageing. In this process the carbonyl group of a sugar reacts with the amino group of a protein and forms a reversible Schiffs' base which reacts further into an Amadori product. These products of early glycation undergo further rearrangements resulting in the formation of irreversible products, the so-called Advanced Glycation Endproducts (AGEs) ${ }^{[1-3]}$. AGEs are predominantly formed on long living macromolecules and the rate of formation is accelerated under hyperglycaemic conditions. One of the main precursors in this reaction is the dicarbonyl group, a highly reactive intermediate ${ }^{[4]}$.

The crosslinking of collagen by the non-enzymatic AGE formation or the enzymatic glucose incorporation is probably one of the main mechanisms underlying the increased arterial stiffness in diabetic patients or diabetic complications in general ${ }^{[5]}$. Previously our group demonstrated an increase in large artery stiffness (measured by systemic arterial compliance, aorta input impedance and carotid artery compliance) in diabetic rats compared to healthy controls ${ }^{[6]}$. Three weeks treatment of the diabetic rats with $\mathrm{N}$ phenacylthiazolium bromide (ALT-766), a breaker of dicarbonyl-derived crosslinks ${ }^{[4]}$, nearly normalized arterial elasticity. An inhibitor of AGE formation, aminoguanidine, proved to be effective especially when given at the onset of diabetes ${ }^{[7-9]}$.

Crosslinking of collagen changes the structure and the mechanical properties of this protein ${ }^{[10 ; 11]}$. This can be measured by several methods, like differential thermal analysis ${ }^{[12 ; 13]}$ and by the enzymatic degradation of collagen ${ }^{[8]}$. Differential thermal analysis is a method widely used in polymer science to study the thermal behaviour of materials as they undergo physical and chemical changes upon heating. This method measures the heat flow necessary for heating of the sample with a constant temperature rate $\left({ }^{\circ} \mathrm{C} / \mathrm{min}\right)$. During the phase transition there is a change in the heat flow, the level of the peak heat flow and the corresponding temperature. When collagen in a hydrated state is heated, the crystalline triple helix of the collagen will be transformed in amorphous random coils resulting in shrinkage of the collagen. In figure 1 a typical DSC thermogram can be seen and a presentation of the parameters that can be derived of that. 


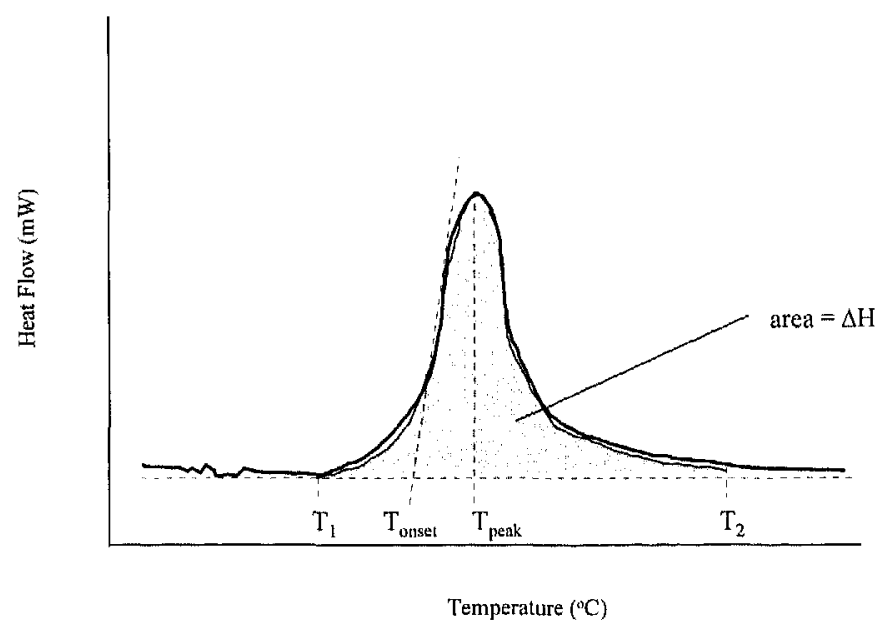

Figure 1. Typical DSC thermogram with parameters derived from that. $T_{\text {peak }}$ is the maximum temperature of denaturation. $T_{s}\left(T_{\text {onset }}\right.$ ) is the temperature at which the tangent in the inflection point crosses the baseline. It is a mathematical quantity often chosen to be representative for the denaturation or transition temperature as it is less influenced than $T_{\text {peak }}$ by changes in method parameters like scan rate. Transition Enthalpy ( $\Delta \mathrm{H}$, area under curve) provides information on the organization structure of its matrix.

$\Delta \mathrm{H}$ is expressed as $\mathrm{J} / \mathrm{mg}$ collagen, so this can only be determined when the exact mass is known. This is only the case with freeze-dried samples as all water is removed. Crosslinking of collagen will increase $T_{s}$ and $\Delta H$, with this peak width will decrease due to a better organization and stabilization of the helices ${ }^{[14]}$.

As peak width can be expressed as $T_{2}-T_{1}$, a reduction in peak width will mean a reduction in $T_{2}-T_{1}$. Due to tailing of the peak a small change in crosslinking degree will show no difference in $T_{2}-T_{1}$. Using $T_{\text {peak }}-T_{5}$ as a measure for peak width will show these small difference in crosslinking degree.

Previous studies already showed an increase in $T_{s}$ in time in rat tail tendon and rat skin ${ }^{[13 ; 15]}$ with ageing. Melling and co-workers ${ }^{[12]}$ showed an increase in $T_{s}$ in diabetic human skin compared to controls. These studies concentrated on the collagen distributed in a specified tissue namely skin and tendon. Both tissues contain collagen, tendon type I collagen and skin type I and III collagen. Although type I and type III collagen are both fibre-forming collagens there are several differences between the collagen types. Type III collagen usually co-locates with type 1 collagen and is able to form coaggregates with it. This is probably how fibre elements consisting largely of 
ype I collagen are restricted and fine tuned by addition of various amounts of ype III collagen ${ }^{[16]}$.

1 this study we studied the use of DSC measurement as a tool for glucose ediated collagen crosslinking and the effects of the inhibition of formation $r$ cleavage of these crosslinks by pharmaceutical agents. To do so we used amples obtained from a previous animal study. 
40 | Chapter 2

\title{
Material and Methods
}

\begin{abstract}
Materials
D-(+)glucose, aminoguanidine hemisulphate (AG), streptozotocin and ribose were obtained from Sigma-Aldrich Chemical $\mathrm{Co}_{\mathrm{O}}$ Zwijndrecht, The Netherlands, $\mathrm{NaCl}, \mathrm{NaH}_{2} \mathrm{PO}_{4} \cdot \mathrm{H}_{2} \mathrm{O}$ and $\mathrm{Na}_{2} \mathrm{HPO}_{4} \cdot 2 \mathrm{H}_{2} \mathrm{O}$ were obtained from Merck, Darmstadt, Germany. ALT-711 and ALT-766 were a kind gift from Alteon Inc., Ramsey, NJ, USA. Differential Scanning Calorimetry (DSC) was performed on a Perkin-Elmer Pyris-1 DSC; thermograms were evaluated using Pyris Software for Microsoft Windows. The Randox-test kit (Sanbio b.v., Uden, The Netherlands, cat. no. NX 2332) was used for Total Radical Antioxidant Potential measurements.
\end{abstract}

\section{Animal studies}

Male Wistar rats were made diabetic at the age of 9-10 weeks by i.p. injection of $70 \mathrm{mg} / \mathrm{kg}$ of streptozotocin. Animals that developed blood glucose levels of $>15 \mathrm{mmol} / \mathrm{l}$ were included in the study. After 9 weeks of diabetes the animals were divided in 5 groups. The first group received only vehicle treatment. The other groups were treated with an AGE-breaker (ALT-711 or ALT-766, $1 \mathrm{mg} / \mathrm{kg}$ daily by i.p injection) during 1 or 3 weeks ( $n=8-10$ animals in each group). Studies were performed in a fixed scheme, so all animals were equally exposed to hyperglycaemia. Diabetes duration was $64 \pm 4$ days for untreated animals and $71 \pm 2$ days and $80 \pm 4$ days for animals treated respectively for 1 or 3 weeks with the AGE breaker (ALT-711 and ALT-766). After performing the heamodynamic studies as described elsewhere ${ }^{[6]}$, tails were removed and the tail tendon was removed by gentle pulling. The tendons were cleaned of debris and fat in $0.9 \% \mathrm{NaCl}$ over ice. They were rolled in a ball, patted dry on paper towels, lyophilised, and transferred to glass containers and stored at $20^{\circ} \mathrm{C}$ for further analysis. Collagen solubility was assessed by treating tail tendon collagen with pepsin $(5.0 \mu \mathrm{g} / \mathrm{ml})$ for 45 minutes, according to previously described methods ${ }^{[8]}$. 


\section{In vitro studies}

Rat tendon was isolated from the tails of healthy male rats (Wistar, aged 3 months) and skin samples were collected from the abdominal region of healthy male rats (Wistar, aged 3 months). Tendons were cleaned free of debris and fat in ice-cold $0.9 \% \mathrm{NaCl}$. Each tendon was divided in ten equal portions and each portion immersed in incubation fluid under sterile conditions. These ten portions were incubated for 4 weeks at $37^{\circ} \mathrm{C}$ and shaken once a day. At different time intervals 2 portions of the tendon were collected and frozen at $-80^{\circ} \mathrm{C}$ for further analysis. Different tendons were incubated with either $20 \mathrm{mM}$ glucose, $100 \mathrm{mM}$ glucose or $100 \mathrm{mM}$ ribose.

Inhibition of collagen crosslinking was tested by adding aminoguanidine $(1 \mathrm{~g} / \mathrm{l})$ prior to the incubation of the tendons.

To test crosslink breaking of collagen, an AGE-breaker (ALT-711, 1 or $10 \mathrm{~g} / \mathrm{l}$ ) was added to the 43-day incubation of the tendons.

Skin samples $(5 \times 2 \mathrm{~cm})$ were put in ice-cold $0.9 \% \mathrm{NaCl}$ immediately after removal. The samples were cleaned of fat and debris by scraping and cut in 10 equal portions $(7 \times 7 \mathrm{~mm})$. To asses collagen crosslinking of these samples the same protocols as for the tendons were used.

\section{DSC measurements}

Samples for DSC were divided in two groups, freeze-dried and non freezedried samples. Freeze-dried samples $( \pm 10 \mathrm{mg})$ were put in a volatile sample pan and $20 \mu \mathrm{l} 0.1 \mathrm{M}$ phosphate buffer $(\mathrm{pH}=6.5)$ was added as a wetting agent. Non freeze-dried samples were stored in wetting buffer prior to analysis. Strains of the tendons were collected with pliers and put in a volatile sample pan. Skin samples were cut in small pieces and were put in a sample pan. All samples were measured on a Perkin Elmer Pyris-1 DSC calibrated with Indium and Gallium. As a reference an empty sample pan was used. A heating rate of $2^{\circ} \mathrm{C} / \mathrm{min}$ was used and a temperature interval from 30 to $80^{\circ} \mathrm{C}$. Peak temperature $\left(T_{\text {peak }}\right)$, shrinkage temperature $\left(T_{s}\right)$ and transition energy $(\Delta H$, in case of the freeze dried samples) were determined from the thermograms. As freeze-drying may alter the structure of the collagen it is sometimes better to use $T_{s}$ as a marker for collagen crosslinking. This is why for the in vitro incubations collagen samples were not freeze-dried. Samples of the animal study were obtained previously and already freeze-dried. To exclude the 
natural variance between animals, samples on $\mathrm{t}=0$ were used as control value. So, every incubation series consist of a tendon/skin sample from one animal and had its own control value $\left(T_{s}^{0}\right.$ or $\left.\left[T_{\text {peak }}-T_{s}\right]^{0}\right)$. Results are represented as relative values to clarify the increase or decrease due to crosslinking itself or the inhibition and breaking of these crosslinks. As for the animal studies, a comparison was made between treated and untreated animals. For this reason $T_{s}{ }^{0}$ in the animal studies is the average $T_{s}$ of the control animals.

\section{TRAP measurements}

To assess whether the anti-oxidant status of the incubation solutions was influenced by AGE formation, total radical antioxidant potential (TRAP) was measured in all incubation fluids. The method used for this analysis was the TRAP (Total Radical Antioxidant Potential) method as described in the Randox-test kit except that a $\mathrm{H}_{2} \mathrm{O}_{2}$ concentration of $745 \mu \mathrm{mol} / \mathrm{l}$ (instead of $250 \mu \mathrm{mol} / \mathrm{l})$ was used. The tendons or skin samples were removed from the incubation solutions and were put in the wetting buffer for DSC analysis. The solutions were centrifuged for 10 minutes at $3000 \mathrm{rpm}$ and TRAP was measured.

\section{Statistics}

All results were expressed as mean $\pm \mathrm{SEM}$, unless otherwise noted. Data were analysed using one-way ANOVA for repeated measurement using SPSS 8.0, SPSS Inc., Chicago,Il, USA. Differences were considered to be significantly different from baseline control by Dunnet post-hoc analysis with $P<0.05$, twotailed. 


\section{Results}

\section{DSC measurements}

In vivo

Our previous study showed an increase in collagen crosslinking in diabetic animals, resulting in a marked decrease in the susceptibility of RTT collagen to pepsin digestion [6]. Treatment of diabetic animals with ALT-711 showed the same susceptibility of RTT to pepsin digestion as observed in non-diabetic animals (figure 2).

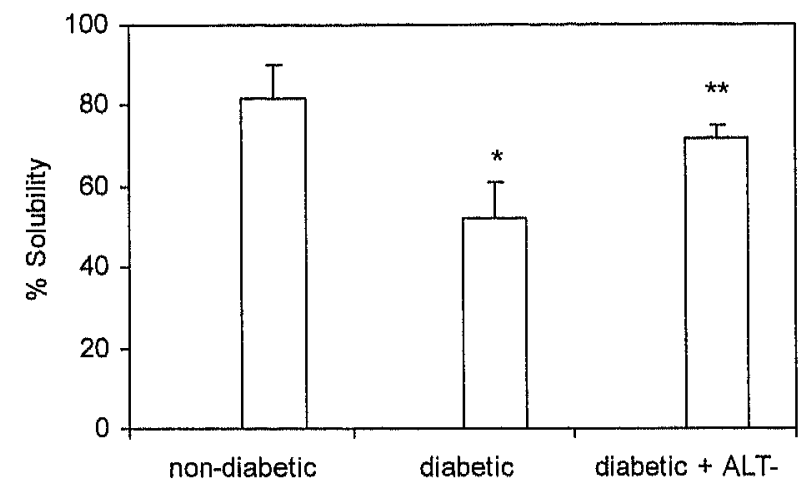

711

Figure 2. Chronic treatment with ALT-711 increase pepsin-induced tail tendon collagen solubility in diabetic rats. ${ }^{*}, P<0.05$ vs. age-matched nondiabetic control animals; ${ }^{* *}, P<0.05$ vs. diabetic animals. The ALT-711 group reflect animals that were treated for 3 weeks $(1 \mathrm{mg} / \mathrm{kg}$ daily by i.p. injection)

DSC was used to asses the effect of two AGE-breakers (ALT-711 and ALT766) on the glucose mediated crosslinking of rat tail tendon (RTT) in vivo. No significant difference in $T_{s}$ between treated and untreated animals and between the two types of AGE-breakers was observed (figure 3). 


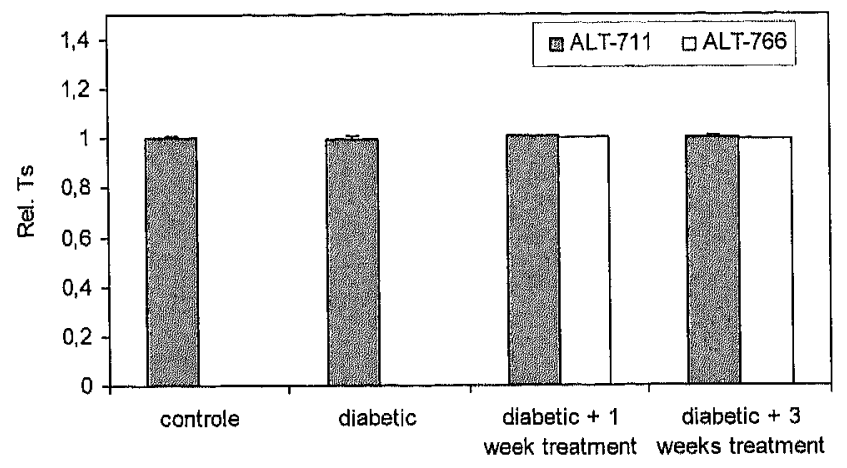

Figure 3. Relative $T_{s}\left(T_{s}{ }^{t} / T_{s}^{0}, t\right.$ in weeks) of RT as measured with DSC. $P$ values were determined with student t-test (diabetic against treated animals);

In vitro

Tendon incubation with $20 \mathrm{mM}$ glucose (in vivo hyperglycaemic value) gave no significant difference in $\mathrm{T}_{\mathrm{s}}$ or peak width compared to control tendon. Extending the incubation period to 8 weeks appeared to show a small decline in peak width. Incubating the tendons with either $100 \mathrm{mM}$ glucose or $100 \mathrm{mM}$ ribose gave an increase in $T_{s}$ (figures $4 a$ and $4 b$ ) and a decrease of peak width $\left(T_{\text {peak }}-T_{s}\right)$ after a 4 week incubation at $37^{\circ} \mathrm{C}$ with $100 \mathrm{mM}$ glucose.

Addition of aminoguanidine to the RTT incubations prevented the increase of $T_{s}$ after $100 \mathrm{mM}$ glucose incubation and slowed the increase of $T_{s}$ after 100 $\mathrm{mM}$ ribose incubation (figures $5 \mathrm{a}$ and $5 \mathrm{~b}$ ). Addition of aminoguanidine had no additional effect on the peak width.

The incubation of RTT with $100 \mathrm{mM}$ ribose gave an increase in $T_{\mathrm{s}}$ after 7 days of incubation illustrating the high reactivity of pentoses compared to hexoses. 
a)

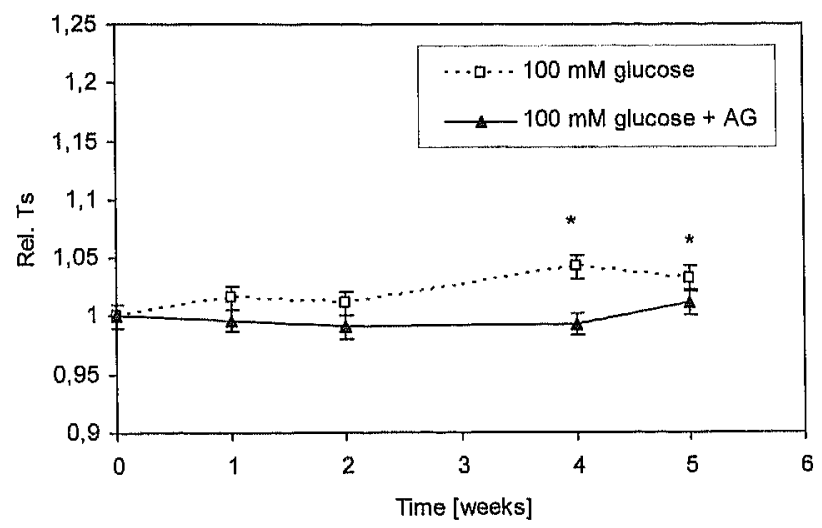

b)

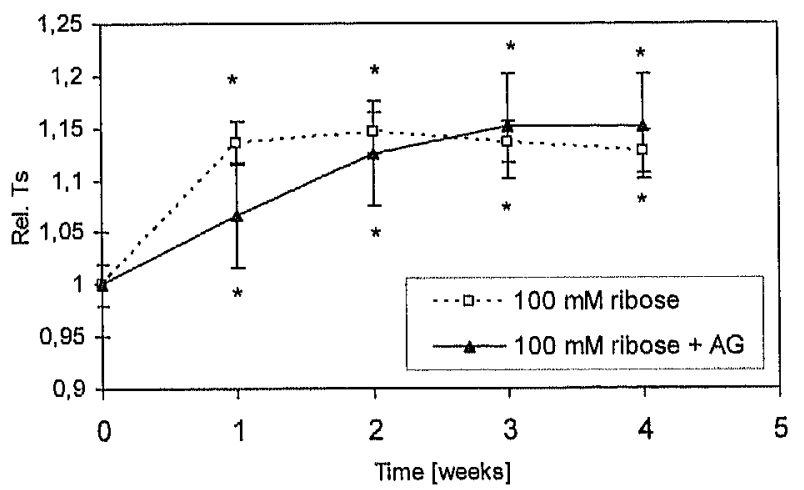

Figure 4a. Relative $T_{s}\left(T_{s}{ }^{t} / T_{s}^{0}\right.$, $t$ in weeks) of RTT incubated with either $100 \mathrm{mM}$ glucose or $100 \mathrm{mM}$ glucose $+\mathrm{ig} / \mathrm{l} \mathrm{AG}$ at $37^{\circ} \mathrm{C}$. b) Relative $T_{s}\left(T_{s}{ }^{\mathrm{t}} / T_{s}{ }^{0}, t\right.$ in weeks) of $R T T$ incubated with either $100 \mathrm{mM}$ ribose or $100 \mathrm{mM}$ ribose $+1 \mathrm{~g} / / \mathrm{AG}$ at $37^{\circ} \mathrm{C}$. * Significant difference from control $(\mathrm{t}=0)$ by Dunnet post-hoc analysis, $P<0.05$

Results obtained with skin samples were similar. Incubation of rat skin samples (RSS) gave a rise in $T_{s}$ after 7 days of incubation with $100 \mathrm{mM}$ ribose. Incubation of RSS with $20 \mathrm{mM}$ or $100 \mathrm{mM}$ glucose gave no increase in $T_{\mathrm{s}}$ but showed a convergence of the two peaks of the different types of collagen and a narrowing in peak width (decrease in $T_{\text {peak }}{ }^{-} T_{s}$ ) of the resulting peak (figures $5 a$ and $5 b)$ with time. 
No effect on $T_{s}$ was found by inhibition of glucose mediated collagen crosslinking with AG in RSS incubated with $20 \mathrm{mM}$ or $100 \mathrm{mM}$ glucose.

a)

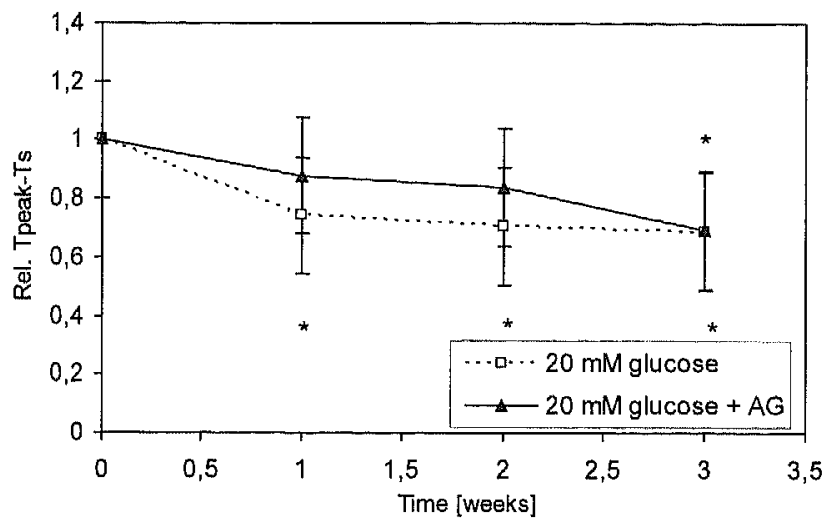

b)

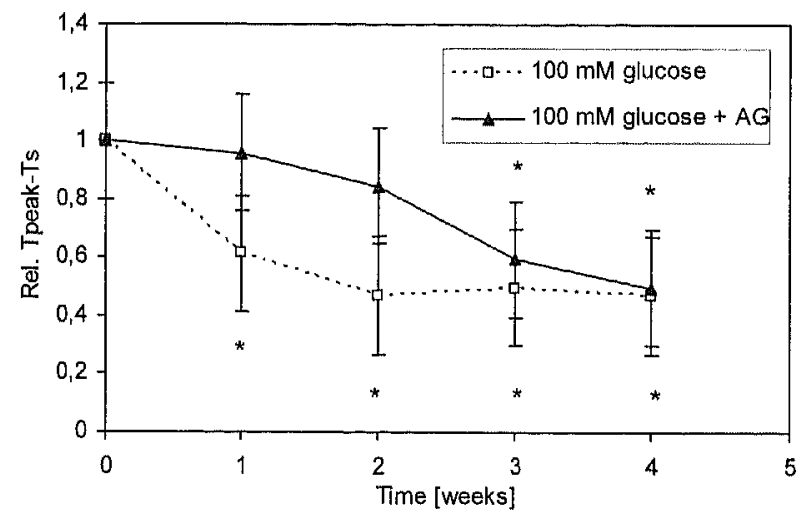

Figure 5a. Relative $T_{\text {peak }}-T_{s}\left(\left[T_{\text {peak }}-T_{s}\right]^{6} /\left[T_{\text {peak }}-T_{s}\right]^{0}\right)$ of RSS incubated with either $20 \mathrm{mM}$ glucose or 20 $\mathrm{mM}$ glucose $+1 \mathrm{~g} / \mathrm{l} \mathrm{AG}$ at $37^{\circ} \mathrm{C}$. b) Relative $T_{\text {peak }}-T_{s}\left(\left[T_{\text {peak }}-T_{s}\right]^{t} /\left[T_{\text {peak }}-T_{s}\right]^{0}\right)$ of RSS incubated with either $100 \mathrm{mM}$ glucose or $100 \mathrm{mM}$ glucose $+1 \mathrm{~g} / \mathrm{LAG}$ at $37^{\circ} \mathrm{C}$. * Significant difference from control $(\mathrm{t}=0)$ by Dunnet post-hoc analysis, $\mathrm{P}<0.05$.

There was, however, a slower decline in peak width $\left(T_{\text {peak }}-T_{s}\right.$, figures $5 a$ and 5b) than when no aminoguanidine was added. Incubation of RSS with $100 \mathrm{mM}$ 
ribose and $1 \mathrm{~g} / \mathrm{l}$ aminoguanidine showed the same effect as with the tendon incubation, a slower increase of $T_{s}$ and no additional effect on peak width.

After incubation of RTT and RSS for 43 days with $20 \mathrm{mM}, 100 \mathrm{mM}$ glucose or $100 \mathrm{mM}$ ribose, crosslinking was observed by DSC with respectively; RTT incubated with $100 \mathrm{mM}$ glucose or $100 \mathrm{mM}$ ribose and to a lesser degree in RSS with $20 \mathrm{mM}$ or $100 \mathrm{mM}$ glucose. Crosslinking of collagen was also observed with RSS incubated with $100 \mathrm{mM}$ ribose. Addition of ALT-711 (and AGE-breaker) in concentration, of 1 or $10 \mathrm{~g} / \mathrm{l}$ during 48 hours at $37^{\circ} \mathrm{C}$ caused no significant change in crosslinking degree for both RTT and RSS incubated with either glucose or ribose.

\section{TRAP measurements}

Incubation of RTT and RSS with either $100 \mathrm{mM}$ glucose or $100 \mathrm{mM}$ ribose at $37^{\circ} \mathrm{C}$ showed no rise or decrease of TRAP during a 4 week timespan. Addition of aminoguanidine or ALT-711 showed a significant rise in TRAP at the start of incubation, thus showing an increase in anti-oxidant potential.

Incubating RTT with $100 \mathrm{mM}$ ribose and $1 \mathrm{~g} / \mathrm{l}$ aminoguanidine gave a linear decrease of TRAP in time, assuming a consumption of the aminoguanidine in the incubation solutions. The same pattern was observed for RSS incubated with $20 \mathrm{mM}$ glucose and $1 \mathrm{~g} / \mathrm{l}$ aminoguanidine.

Incubating samples with ALT-711 in order to break formed crosslinks did not provide significant change in TRAP concentration with time. TRAP concentration was high at the start of incubation and stayed at this level till the end of the incubation. 


\section{Discussion}

Several studies disclose the use of DSC for assessing the crosslinking of collagen ${ }^{[12-15]}$. In our earlier studies we observed an increased resistance against acid hydrolysis of rat tail tendon obtained from diabetic animals. Our present data show that DSC measurements are not sensitive enough to discriminate between treated and untreated animals: no effect on $T_{5}$ or peak width could be found. DSC measurements yielded a considerable variety between individual animals despite comparable changes in arterial elasticity in vivo. To asses the usefulness in more detail we employed in vitro incubation of collagen tissue with glucose and ribose.

Incubation of RTT with glucose showed a dose-dependent increase in crosslinking. Ribose, -a more reactive pentose-, gave an even faster increase in crosslinking. Previous research showed evidence for a different rate of crosslinking of different types of collagen ${ }^{[13 ; 15]}$. Under similar incubation conditions it was found that RTT is more easily crosslinked than RSS. RSS consists of both type I and type III collagen, while RTT consists mostly out of type I, collagen suggesting that type I collagen is more susceptible to glucose mediated crosslinking than type III. Evidence for this difference can be found in the primary structure of collagen. Biosynthesis of collagen occurs in two steps an intracellular and an extracellular. In the intracellular step the precollagen is formed and in the extracellular step the procollagen (pro- $\alpha(1)$ for example) is excreted from the cell and transformed in collagen. These molecules rearrange into fibres and fibre bundles. Although pro- $\alpha$ collagen chains of type I, II and III collagen are almost the same, pro- $\alpha 1$ (III) is least like the pro- $\alpha 1(\mathrm{l})$ and pro- $\alpha 2$ (I) chains giving rise to the assumption that crosslinking of type III collagen is different from that of type II and I. Other differences are to be found in the molecular organisation and structure. Extracellular processing of pro- $\alpha 1(\mathrm{I})$ and pro- $\alpha 2(\mathrm{I})$ leads to the removal of both the C-terminal and $\mathrm{N}$-terminal ends of the propeptide. As for pro- $\alpha 1$ (III) a substantial part of the propeptide keeps the $\mathrm{N}$-terminal end of the propetide. Probably, this mechanism also plays an important role in the formation of extra cellular aggregate structures. This is probably accomplished by sterical hindering of the accretion of new type III molecules by the $\mathrm{N}$-terminal residue on the propeptide ${ }^{[16]}$. Due to this sterical hindering type III collagen fibers will be less accessible for glucose and the resulting crosslinking than type I fibers. 
Several studies have already shown the beneficial effect of ALT-711 on reducing collagen crosslinking ${ }^{[6]}$. With the present techniques we could not quantitate a difference in crosslinking. There was a small effect seen on $\Delta H$ in vivo with diabetic rats, however no effect could be seen after in vitro incubation of RTT and RSS. For these findings two explanations can be given. The first explanation is a rapid hydrolysis of ALT-711 as was shown for the more unstable $\mathrm{N}$-phenacylthiazolium bromide ${ }^{[17]}$ which will cause a decrease in the biological activity of the compound. This rapid hydrolysis could be much faster in vitro than in vivo, the latter being a more complex biological system with processes promoting and demoting this hydrolysis. Differently the beneficial effect in vivo may be caused by another pathway than the breaking of $\alpha$-dicarbonyl crosslinks by the AGE-breaker. Apart from being an AGE-breaker, ALT-711 is a strong antioxidant. Auto-oxidation of glucose plays a major role in AGE formation. As such ALT-711 could prevent the autooxidation of glucose and hence acting as an AGE-inhibitor rather than a AGEbreaker.

Addition of ALT-711 provokes an increase of TRAP. This high TRAP level remained throughout the whole incubation. Additional studies are needed to further explore the anti-oxidant potential of ALT-711 both in vivo as in vitro.

in general DSC is considered a useful tool in assessing glucose-mediated crosslinking in vitro with non-physiological glucose concentrations. The potential as a diagnostic tool in biological samples is small due to the relative difficulty to obtain samples and the biological variance between individual animals. Although other methods for assessing crosslinking seem to be more sensitive, DSC is a quick and well-quantitated method in comparison. 


\section{References}

1. Brownlee M, Cerami A, Vlassara $H$. Advanced glycosylation endproducts in tissue and the biochemical basis of diabetic complications. N.Engl.J.Med. 1988;318:1315-21.

2. Vlassara $H$. Recent progress on the biological and clinical significance of advanced glycosylation endproducts. J.Lab.Clin.Med. 1994;124:19-30.

3. Singh $R$, Barden A, Mori $T$, Beilin L. Advanced glycation end-products: a review. Diabetologia 2001;44:129-46.

4. Vasan $S$, Zhang $X$, Zhang $X$ et al. An agent cleaving glucose-derived protein crosslinks in vitro and in vivo. Nature 1996;382:275-8.

5. Bucala R, Cerami A. Advanced glycosylation: chemistry, biology, and implications for diabetes and aging. Adv.Pharmacol. 1992;23:1-34.

6. Wolffenbuttel $B H$, Boulanger $C M$, Crijns FR et al. Breakers of advanced glycation end products restore large artery properties in experimental diabetes. Proc.Natl.Acad.Sci. U.5.A 1998;95:4630-4.

7. Huijberts MSP, Wolffenbuttel BHR, Struijker Boudier HAJ et al. Aminoguanidine treatment increases elasticity and decreases fluid filtration of large arteries from diabetic rats. J.Clin.Invest. 1993;92:1407-11.

8. Kochakian M, Manjula BN, Egan JJ. Chronic dosing with aminoguanidine and novel advanced glycosylation end product-formation inhibitors ameliorates cross-linking of tail tendon collagen in STZ-induced diabetic rats. Diabetes 1996;45:1694-700.

9. Wolffenbuttel BHR, Huijberts MSP. Aminoguanidine, a potential drug for the treatment of diabetic complications, Neth.J.Med. 1993;42:205-8.

10. Charonis AS, Tsilbary EC. Structural and functional changes of laminin and type IV collagen after nonenzymatic glycation. Diabetes 1992;41 Suppl 2:49-51.

11. Bailey AJ, Sims TJ, Avery NC, Miles CA. Chemistry of collagen cross-links: glucosemediated covalent cross- linking of type-IV collagen in lens capsules. Biochem.J. 1993;296 (Pt 2):489-96.

12. Melling $M$, Pfeiler $W$, Karimian-Teherani $D$ et al. Differential scanning calorimetry, biochemical, and biomechanical analysis of human skin from individuals with diabetes mellitus [In Process Citation]. Anat. Rec. 2000;259:327-33.

13. Flandin F, Buffevant C, Herbage D. A differential scanning calorimetry analysis of the agerelated changes in the thermal stability of rat skin collagen. Biochim.Biophys. Acta 1984;791:205-11.

14. Zeeman R, Dijkstra PJ, van Wachem PB et al. Successive epoxy and carbodiimide cross. linking of dermal sheep collagen. Biomaterials 1999;20:921-31. 
15. Reihsner R, Pfeiler W, Menzel EJ. Comparison of normal and in vitro aging by nonenzymatic glycation as veriffed by differential scanning calorimetry. Gerontology 1998;44:85-90.

16. Miller EJ. Collagen Types: Structure, Distribution, and Functions. In: Nimni ME, editor. Collagen; Volume 1, Biochemistry. Boca Raton: CRC Press, 1988:139-156.

17. Thornalley PJ, Minhas HS. Rapid hydrolysis and slow alpha, beta-dicarbonyl cleavage of an agent proposed to cleave glucose-derived protein cross-links. Biochem.Pharmacol. 1999;57:303-7. 


\section{A liquid chromatographic method for the quantitative determination of $\mathrm{N}^{\varepsilon}$-carboxymethyllysine in human plasma proteins}

Nico C. van de Merbel, Cyriel J.A.L. Mentink, Gert Hendriks, Bruce H.R. Wolffenbuttel

Published in: Journal of Chromatography B, 2004, 808, 163-168 


\begin{abstract}
The modification of the lysine moieties of proteins to $\mathrm{N}^{\varepsilon}$-carboxymethyllysine (CML) is supposed to play a major role in the development of long-term complications in patients with diabetes mellitus. This paper presents an analytical method for the quantitative determination of CML in plasma proteins, which could be used for studying the development of diabetic complications. The method is based on isolating proteins from plasma by precipitation with trichloroacetic acid and hydrolysing these under acidic conditions $\left(6 \mathrm{M}\right.$ hydrochloric acid at $110^{\circ} \mathrm{C}$ for $\left.20 \mathrm{~h}\right)$ to the individual amino acids. After hydrolysis, CML is derivatised along with the other amino acids to 9-fluorenylmethoxycarbonyl (FMOC) derivatives, which are subsequently separated by reversed-phase column liquid chromatography using a $150 \times 4.6$ $\mathrm{mm} \mathrm{C} 8$ column and a mobile phase of $25 \mathrm{mM}$ potassium phosphate buffer $(\mathrm{pH}$ 2.0) and acetonitrile $(80: 20, \mathrm{v} / \mathrm{v})$ and detected using fluorescence detection (excitation at $260 \mathrm{~nm}$ and emission at $310 \mathrm{~nm}$ ). Quantification of the proteinbound CML content of a plasma sample is achieved using standard addition. The impact of several aspects of the sample preparation and chromatography on method performance is discussed. Method evaluation results are reported and show that this method is capable of determining CML with good accuracy and precision (below $10 \%$ ) in the relevant concentration range $(1-10 \mu \mathrm{g} / \mathrm{ml}$ ), with a limit of detection of $0.2 \mu \mathrm{g} / \mathrm{ml}$.
\end{abstract}




\section{Introduction}

Advanced glycation end-products (AGEs) are a heterogeneous group of endogenous compounds, which are associated with various long-term complications of diabetes, such as atherosclerosis and renal failure ${ }^{[1-3]}$. The first step in the formation of an AGE is the non-enzymatic reaction of a reducing carbohydrate such as glucose with an amino group (usually a lysine side chain) of a protein or other macromolecule. This is followed by cleavage and/or intra-molecular rearrangements to an irreversibly glycated compound, which can form covalent cross-links within a tissue, thus altering its functional properties ${ }^{[4 ; 5]}$. Probably the most important (yet non-cross-linking) AGE currently known is $\mathrm{N}^{\varepsilon}$-carboxymethyllysine (CML, figure 1 ).<smiles>NC(CCCCNCC(=O)O)C(=O)O</smiles>

Figure 1. Structural formula of $N^{\varepsilon}$-carboxymethyllysine (CML)

Accumulation of CML in various tissues is promoted by hyperglycaemic and oxidative conditions and has been suggested as a major cause of diabetic complications ${ }^{[3 ; 6 ; 7]}$.

For a better understanding of the underlying processes that cause tissue damage during diabetes, a reliable analytical method, capable of determining the CML content of proteins, would be of great significance. Presently, however, in the field of diabetes research it is felt that no universally applicable method is available ${ }^{[8]}$. Frequently used techniques such as fluorescence spectroscopy and immunoassays lack specificity and the different sources of anti-CML antibodies show a large variability in their affinity towards $\mathrm{CML}$, which results in inaccurate and irreproducible results and makes comparison of results between laboratories difficult, if not impossible ${ }^{[8]}$.

It has been demonstrated, that by chromatographically separating CML from other amino acids in a sample method performance can be improved. In a number of cases, CML has been determined with a classical amino acid 
analyser, which is based on ion-exchange liquid chromatography (LC) and fluorescence detection after post-column derivatisation ${ }^{[9 ; 10]}$, but the analytical performance of these methods was not evaluated. In addition, CML has been determined with good reproducibility in urine ${ }^{[11]}$ and hydrolysates of milk products ${ }^{[12]}$, both using reversed-phase LC with pre-column derivatisation and fluorescence detection. A truly quantitative method for the determination of the CML content of tissue or plasma proteins has, however, never been described. In this paper, we present such a method; it is based on pre-column derivatisation of CML and other amino acids in protein hydrolysate samples with 9-fluorenylmethoxycarbonyl (FMOC) chloride, followed by separation and detection with reversed-phase LC and fluorescence detection. Special attention is paid to the accuracy and precision of the method, which are of key importance for its universal applicability, and have been rather neglected in previously published methods. 


\section{Experimental}

\section{Chemicals}

$\mathrm{N}^{\mathrm{E}}$-carboxymethyllysine was purchased from SyMO-Chem (Eindhoven, The Netherlands). Trichloroacetic acid, amino acid solution (1 $\mathrm{mM}$ each) and FMOC were obtained from Fluka (Buch, Switzerland). Phosphoric acid, hydrochloric acid, sodium hydroxide, sodium tetraborate decahydrate, potassium dihydrogen phosphate and acetonitrile came from Merck (Darmstadt, Germany). HPLC grade water was prepared using a Milli-Q (Millipore, Bedford, MA, USA) purification system.

\section{Chromatography}

The chromatographic system consisted of a Waters (Milford, MA, USA) Separations Module Alliance 2690 for injection and pumping of the mobile phase, a Zorbax Stablebond (Agilent, Palo Alto, CA, USA) C8 column (150x4.6 $\mathrm{mm}, 3.5 \mu \mathrm{m}$ ), conditioned at $45^{\circ} \mathrm{C}$ in a Julabo (Seelbach, Germany) water bath, and a Jasco (Tokyo, Japan) FP 920 fluorescence detector, set at an excitation wavelength of $260 \mathrm{~nm}$ and an emission wavelength of $310 \mathrm{~nm}$. The mobile phase, a mixture of $25 \mathrm{mM}$ potassium phosphate buffer $(\mathrm{pH} 2.0)$ as eluent $A$ and acetonitrile as eluent $B$, was pumped at a flow-rate of 1.3 $\mathrm{ml} / \mathrm{min}$. Elution of the analyte was achieved using $80 \% \mathrm{~A}$ and $20 \% \mathrm{~B}$ for 17.5 min, after which a step gradient was applied with $15 \% A$ and $85 \% B$ until 22.5 min; finally the column was re-equilibrated at $80 \%$ A / 20\% B until 30 min.

\section{Sample preparation}

An aliquot of $200 \mu \mathrm{l}$ of human plasma was mixed with $1000 \mu \mathrm{l}$ of $10 \%$ aqueous trichloroacetic acid in a 10-ml glass hydrolysis tube (Organon Teknika, Boxtel, The Netherlands) and left to stand for $10 \mathrm{~min}$. The sample was centrifuged at $3300 \mathrm{~g}$ for 10 minutes and the supernatant was discarded. The remaining protein pellet was dissolved in $1000 \mu \mathrm{l}$ of $6 \mathrm{M}$ hydrochloric acid, thoroughly purged with nitrogen and hydrolysed at $110^{\circ} \mathrm{C}$ for $20 \mathrm{~h}$. After cooling the sample to ambient temperature, $1000 \mu \mathrm{l}$ of $5 \mathrm{M}$ sodium hydroxide was added and the mixture was centrifuged at $3300 \mathrm{~g}$ for $10 \mathrm{~min}$. A $20-\mu \mathrm{l}$ aliquot of the supernatant was added to $180 \mu \mathrm{l}$ of $0.4 \mathrm{M}$ sodium borate buffer $(\mathrm{pH} 10.4)$. 
Subsequently, $10 \mu \mathrm{l}$ of water or an aqueous $5.00-\mu \mathrm{g} / \mathrm{ml} \mathrm{CML} \mathrm{solution} \mathrm{(for}$ standard addition, see below) were added. After mixing, $20 \mu \mathrm{l}$ of this mixture were added to $180 \mu \mathrm{l}$ of $0.4 \mathrm{M}$ sodium borate buffer $(\mathrm{pH} 10.4)$ in a polypropylene injection vial and derivatisation was performed by adding $10 \mu \mathrm{l}$ of a $1-\mathrm{mg} / \mathrm{ml} \mathrm{FMOC}$ solution in acetonitrile. After vortex-mixing, the vial was transferred to the autosampler and an aliquot of $40 \mu \mathrm{l}$ was injected into the chromatographic system.

\section{Quantitation}

In order to quantitatively determine the CML concentration in a sample, the method of standard addition was applied. To this end, two aliquots of each individual protein hydrolysate were analysed, one without and one with a known amount ( $50.0 \mathrm{ng}$ ) of CML added, and the CML peak heights were determined. As the added amount of CML corresponds to a concentration of $25.0 \mu \mathrm{g} / \mathrm{ml}$ plasma, the original $\mathrm{CML}$ concentration (in $\mu \mathrm{g} / \mathrm{ml}$ ) was subsequently calculated by multiplying 25 with the ratio of the original peak height over the difference between the two peak heights.

\section{Method evaluation}

The precision of the entire procedure at a relatively low CML concentration (established as $4.13 \mu \mathrm{g} / \mathrm{ml}$ ) was assessed by the repeated analysis of a single human plasma sample. Five aliquots were separately hydrolysed, after which the resulting hydrolysates were divided into three portions and independently derivatised and analysed. The $15 \mathrm{CML}$ peak heights obtained were subjected to analysis of variance to determine the coefficients of variation originating from the hydrolysis and derivatisation steps, respectively. For the determination of the precision at a relatively high $\mathrm{CML}$ concentration, the experiment was repeated, but just before derivatisation an amount of CML corresponding to $25.0 \mu \mathrm{g} / \mathrm{ml}$ in plasma was added.

The accuracy of the method was determined by analysing calibration lines consisting of five calibrators $(0.500,1.00,2.50,10.0$ and $25.0 \mu \mathrm{g} / \mathrm{ml} \mathrm{CML})$ prepared in amino acid solution and three different lots of human plasma. The slopes of the calibration lines were compared to assess the possibility of accurately determining known amounts of CML by reference to a calibration line. 
The stability of CML during the hydrolysis procedure was determined by diluting a $1.00-\mathrm{mg} / \mathrm{ml}$ solution of $\mathrm{CML}$ in $1 \mathrm{mM}$ amino acid mixture to 5.00 $\mu \mathrm{g} / \mathrm{ml}$ with $6 \mathrm{M}$ hydrochloric acid and comparing the $\mathrm{CML}$ peak heights obtained by immediate analysis to those obtained by analysis after heating at $110^{\circ} \mathrm{C}$ for $20 \mathrm{~h}$.

The stability of the FMOC-derivatives of CML during storage in the autosampler was assessed at two concentrations. One plasma sample was hydrolysed, after which 15 aliquots of the hydrolysate were derivatised without any $\mathrm{CML}$ added and 15 after the addition of the equivalent of 25.0 $\mu \mathrm{g} / \mathrm{ml} \mathrm{CML}$. The derivatised samples were pooled per concentration, each divided over 60 injection vials and injected every $30 \mathrm{~min}$ for a period of $60 \mathrm{~h}$, during which the samples were stored in the autosampler at $10^{\circ} \mathrm{C}$. 


\section{Results and discussion}

\section{Separation and detection}

The major challenge in the determination of the CML content of proteins is the need to distinguish the analyte from a large variety of other amino acids, many of which are present in the hydrolysate at much (typically 1000-fold) higher concentrations. This implies that an efficient chromatographic separation prior to the detection of CML is essential. Two chromatographic approaches for amino acid analysis have been widely employed: (i) precolumn derivatisation to fluorescent and more hydrophobic derivatives, which are separated by reversed-phase $L C$ and (ii) separation of the native amino acids by ion-exchange LC, followed by their post-column derivatisation ${ }^{[13]}$. Both approaches have their advantages and disadvantages, but for the present application pre-column derivatisation was selected, its main benefits being technical simplicity, speed and the relative ease to manipulate the separation of the amino acids by tuning the mobile phase composition.

Pre-column derivatisation of amino acids has been achieved with a wide variety of reagents ${ }^{[13]}$. For the sake of robustness and sensitivity, FMOC chloride was employed in the present work, because this reagent forms highly fluorescent and very stable derivatives with both primary and secondary amines in a matter of seconds. It was deemed superior to the well-known and probably most frequently used o-phthalaldehyde (OPA) / 2-mercaptoethanol combination, which has the major disadvantage of forming relatively unstable derivatives.

The most efficient separation of the FMOC derivative of CML from those of the other amino acids could be obtained with an acidic mobile phase, probably because of the increased retention of the (protonated) derivatives on the octadecylsilane phase at a lower $\mathrm{pH}$. This is another reason to prefer FMOC over OPA for derivatisation, since the fluorescence intensity of OPA derivatives is greatly reduced at low $\mathrm{pH}$. Using a $15-\mathrm{cm}$ column and a mobile phase containing $20 \%$ acetonitrile, CML could be efficiently separated from other amino acids, with a retention time of about $15.5 \mathrm{~min}$. To speed up the analysis, a step gradient of $85 \%$ acetonitrile was applied between 17.5 and $22.5 \mathrm{~min}$ to simultaneously elute the more hydrophobic amino acid derivatives, which are of no importance for the present application, and the fluorescent hydrolysis products of FMOC. Altogether, the analytical run, 
including the step gradient and subsequent re-equilibration, was completed in $30 \mathrm{~min}$, which compares favourably with existing methods, especially those based on post-column derivatisation with its run times in the order of $60 \mathrm{~min}$ [9;10].

Figure 2 shows a chromatogram of $\mathrm{CML}$ in a standard amino acid solution. It illustrates that CML is well separated from the other amino acids; the major of part of which elutes together in the step gradient.

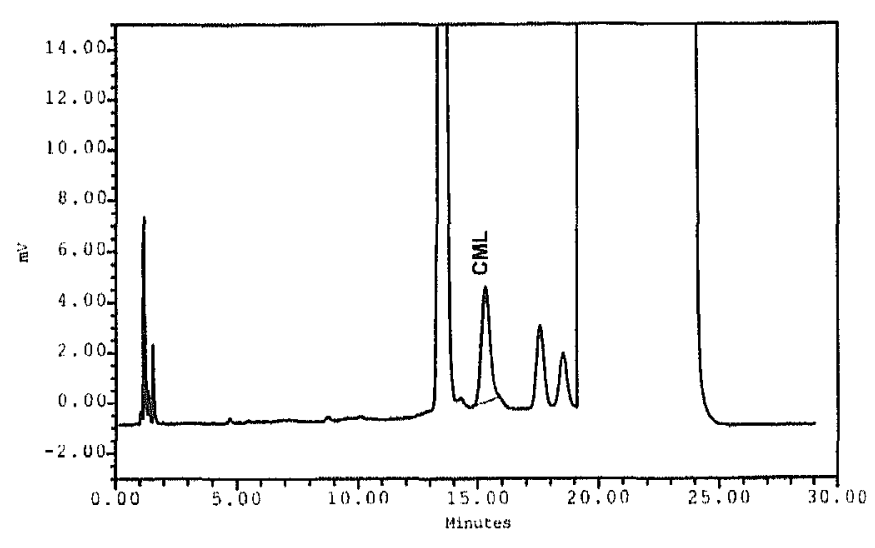

Figure 2. Chromatogram of a standard solution of $\mathrm{CML}(10.0 \mu \mathrm{g} / \mathrm{ml})$ in a $1 \mathrm{mM}$ mixture of amino acids

\section{Sample preparation}

In order to hydrolyse the plasma proteins to their individual amino acids, the common approach of acid hydrolysis in $6 \mathrm{M}$ hydrochloric acid at $110^{\circ} \mathrm{C}$ was taken. It was found that CML concentrations were significantly lower in case of hydrolysis in the absence of oxygen. Human plasma samples from a single source were hydrolysed without precautions and after thorough purging with nitrogen. The mean $(n=3)$ response found in the former case was $62 \%$ higher than in the latter case, with coefficients of variation of each set of three measurements not exceeding $11 \%$. This confirms earlier findings with milk samples that CML is formed in vitro during hydrolysis in oxidative conditions ${ }^{[12]}$. Removing oxygen prior to hydrolysis is therefore key to obtaining accurate results, as the oxidative formation of CML would otherwise lead to a substantial overestimation of the actual CML concentration. 
62 1 Chapter 3

The performance of the derivatisation also turned out to be of importance, especially for the precision of the method. It was first attempted to dilute the neutralised hydrolysate 10 -fold with borate buffer prior to the addition of the FMOC derivatisation reagent, but a very poor precision was obtained ( $\mathrm{CV}$ of $38.2 \%, n=12$ ). Apparently, the derivatisation reaction does not proceed in a controlled way under these conditions. This was suspected to be due to the high abundance of amino acids in the hydrolysate, which compete with CML for the reaction with FMOC. Higher dilution factors were tested prior to derivatisation (see figure $3 \mathrm{~A}$ ) and it was found that 100 -fold dilution resulted in a mean CML detector response that was even higher than in case of 10-fold dilution, but with a much better precision ( $C V$ of $5.5 \%, n=6$ ). Apparently, diluting out the amino acids in the sample resulted in a better proportion of FMOC to amino acids and improved reaction kinetics. Increasing the dilution factor to 200 or 400 did not further improve precision, but did lead to an approximately proportional decrease in response. It was also tried to increase the proportion of FMOC over amino acids by adding more concentrated FMOC solutions (figure $3 \mathrm{~B}$ ). Increasing the concentration 10 -fold (to $10 \mathrm{mg} / \mathrm{ml}$ ) or 20 -fold (to $20 \mathrm{mg} / \mathrm{ml}$ ) caused a 5 -fold increase in the response, but the precision remained poor: a CV of $11.5 \%$ for 10 -fold and of $26.9 \%$ for 20 -fold higher FMOC concentrations $(n=6)$. Altogether, this indicates that 100 -fold dilution prior to derivatisation with a $1-\mathrm{mg} / \mathrm{ml}$ FMOC reagent solution is optimal.

\section{Quantitation and method evaluation}

Although the analytical procedure consisted of a rather large number of steps and no internal standard was used, the precision of the method was fully satisfactory. An overall CV of only $8.9 \%(n=15)$ was found for human plasma with a physiological concentration of CML $(4.13 \mu \mathrm{g} / \mathrm{ml})$. Since the plasma was hydrolysed in five separate aliquots, which were each derivatised in triplicate, the contribution of the hydrolysis and derivatisation steps could be calculated by analysis of variance. These were $7.1 \%$ and $5.8 \%$, respectively, and indicate that hydrolysis contributes slightly more to method imprecision, although the role of the derivatisation step is not insignificant. The experiment was repeated with the same plasma sample, but before 
derivatisation an amount of CML was added to each of the 15 aliquots in order to assess the precision at a higher concentration $(29.1 \mu \mathrm{g} / \mathrm{ml})$.
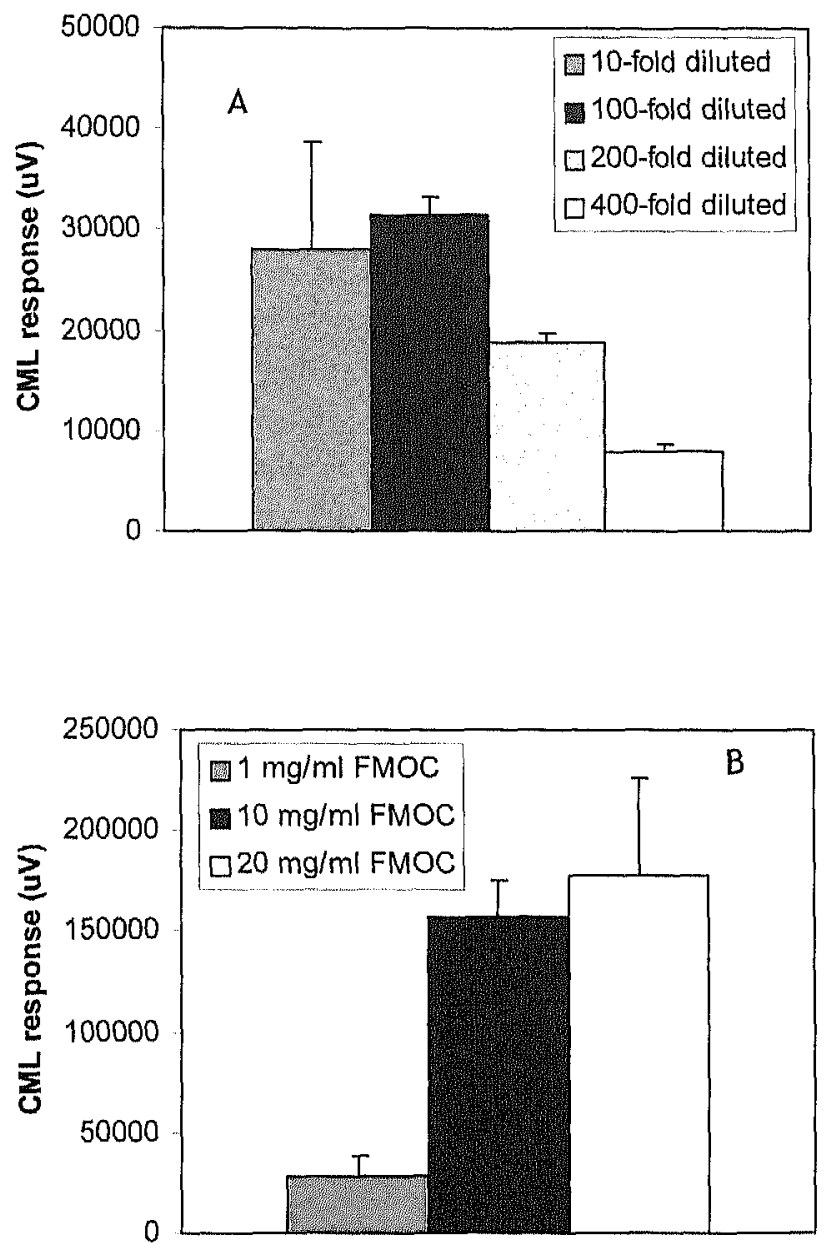

Figure 3. Influence of sample dilution (A) and FMOC concentration (B) on the response and precision of the CML determination

The overall CV was now $9.1 \%$ and the contributions of hydrolysis and derivatisation were $8.7 \%$ and $2.8 \%$, respectively. This suggests that a better precision for the derivatisation is obtained at higher CML concentrations. Altogether, method precision was found to be adequate over a relevant 
concentration range: upon application of this method it was found that the majority of the CML concentrations were around $4 \mu \mathrm{g} / \mathrm{ml}$ or above.

Ideally, it should be possible to calculate the concentration of CML in a study sample by substitution of the response found in a calibration line constructed of the responses found in calibrators of known concentration. Generally, for endogenous compounds these calibrators are standard solutions in e.g. water (external calibration), but accurate results can only be obtained in this way if the response is independent of the matrix. This was tested by analysing calibration lines of CML in a standard amino acid mixture and in three different lots of human plasma. Although the calibration lines were linear in all cases ( $r>0.99$ and back-calculated concentrations within 15\% from nominal), it was found that the slope of the calibration line in the amino acid mixture (451) was typically $30 \%$ higher than in the plasma samples $(297,279$ and 354, respectively). External calibration is, therefore, unsuitable for accurate quantification of CML. In addition, the variation between the slopes of the calibration lines in different lots of plasma (a difference of up to 20\%) was deemed too large to justify the use of calibration lines spiked in plasma. The reason behind this observation is probably related to differences in the composition of plasma from different sources, an effect which has been observed before for physiological amino acids ${ }^{[14]}$. Therefore, it was decided to calculate the concentrations by the method of standard addition, which completely rules out matrix effects. In none of the methods described so far has attention ever been paid to this phenomenon, which seems to indicate that the accuracy of the results reported using these methods is at least questionable. The limit of detection of the method, defined as the mean plus three times the standard deviation of the baseline noise $(n=6)$ and derived from $C M L$ in an amino acid mixture, was $0.2 \mu \mathrm{g} / \mathrm{ml}$. The practical limit of quantitation was set at the lowest $\mathrm{CML}$ calibration standard that was investigated and showed accuracy and precision below $20 \%: 0.5 \mu \mathrm{g} / \mathrm{ml}$.

The stability of CML itself during hydrolysis was investigated and found to be satisfactory. The mean response $(n=9)$ obtained for $C M L$ after heating at $110^{\circ} \mathrm{C}$ for $20 \mathrm{~h}$ in $6 \mathrm{M}$ hydrochloric acid in the presence of a standard mixture of amino acids was not statistically different from that of the same sample that had not been heated (difference of $4 \%$ ).

The stability of the FMOC derivatives of CML in the autosampler was investigated over a period of $60 \mathrm{~h}$, by injecting pretreated samples every hour. Regression analysis of the responses over time showed an increase of $4.1 \%$ for CML at the low level $(5.27 \mu \mathrm{g} / \mathrm{ml})$ and a decrease of $5.2 \%$ at the high 
level $(30.3 \mu \mathrm{g} / \mathrm{ml})$ over the first $15 \mathrm{~h}$. Over $30 \mathrm{~h}$, these results were a decrease of $1.2 \%$ and a decrease of $7.9 \%$, respectively; over the total of $60 \mathrm{~h}$, a decrease of $8.0 \%$ and a decrease of $14.6 \%$ were found, respectively. Thus, the responses were typically found to decrease over time, which was most pronounced at the highest concentration. Still, if a deviation of no more than $10 \%$ is considered acceptable, samples can be stored in the autosampler at $10^{\circ} \mathrm{C}$ for up to $30 \mathrm{~h}$ without problems.

\section{Application}

The described method has been applied to several hundreds of human plasma samples originating from a variety of clinical trials. CML concentrations found in plasma typically ranged from 1 to $4 \mu \mathrm{g} / \mathrm{ml}$ in healthy subjects and from 2$10 \mu \mathrm{g} / \mathrm{ml}$ in diabetic patients. When related to the amount of plasma protein, a significant difference can be seen between the two populations: in type 1 diabetics, the CML concentrations ( $95 \%$ confidence interval) range from 56 to $73 \mathrm{ng} / \mathrm{mg}$ protein, while in (age-matched) healthy subjects, they range between 15 and $42 \mathrm{ng} / \mathrm{mg}$ protein. This shows that $\mathrm{CML}$ accumulates in plasma proteins during diabetes and that the determination of the CML concentration in plasma proteins is potentially useful to investigate the progress of the disease and the development of diabetic complications.

As an illustration, figure 4 shows chromatograms of a plasma sample of a diabetic patient without (figure 4A) and with (figure 4B) standard addition. Comparison of these chromatograms with the one in Fig. 2 clearly illustrates that separation of CML from the standard amino acids alone is not sufficient: upon hydrolysis of plasma proteins, a variety of less abundant amino acids is set free and separation from these is also crucial for a proper quantitation of CML. As is shown in figure 4, the separation efficiency as obtained in the present method is sufficient to achieve this. 


\section{Conclusion}

A reliable $L C$ method has been developed and evaluated for the determination of the protein-bound CML concentration in human plasma. It allows the accurate quantitation of CML in the physiological range (typically $1-10 \mu \mathrm{g} / \mathrm{ml}$ ), which is adequate for the use as a marker for diabetic complications. In comparison with other methods, it is equally sensitive, shows a favourable run time (30 min) and, especially compared to ELISA methods, a much better accuracy and precision. So far, the method has only been applied to plasma proteins; more research is underway to investigate the suitability of the method for proteins from other tissues.

\section{Acknowledgement}

The authors want to thank Ms. Bettine Haandrikman for skilful technical assistance during the evaluation of this method. 
Liquid chromatography method for CML determination | 67
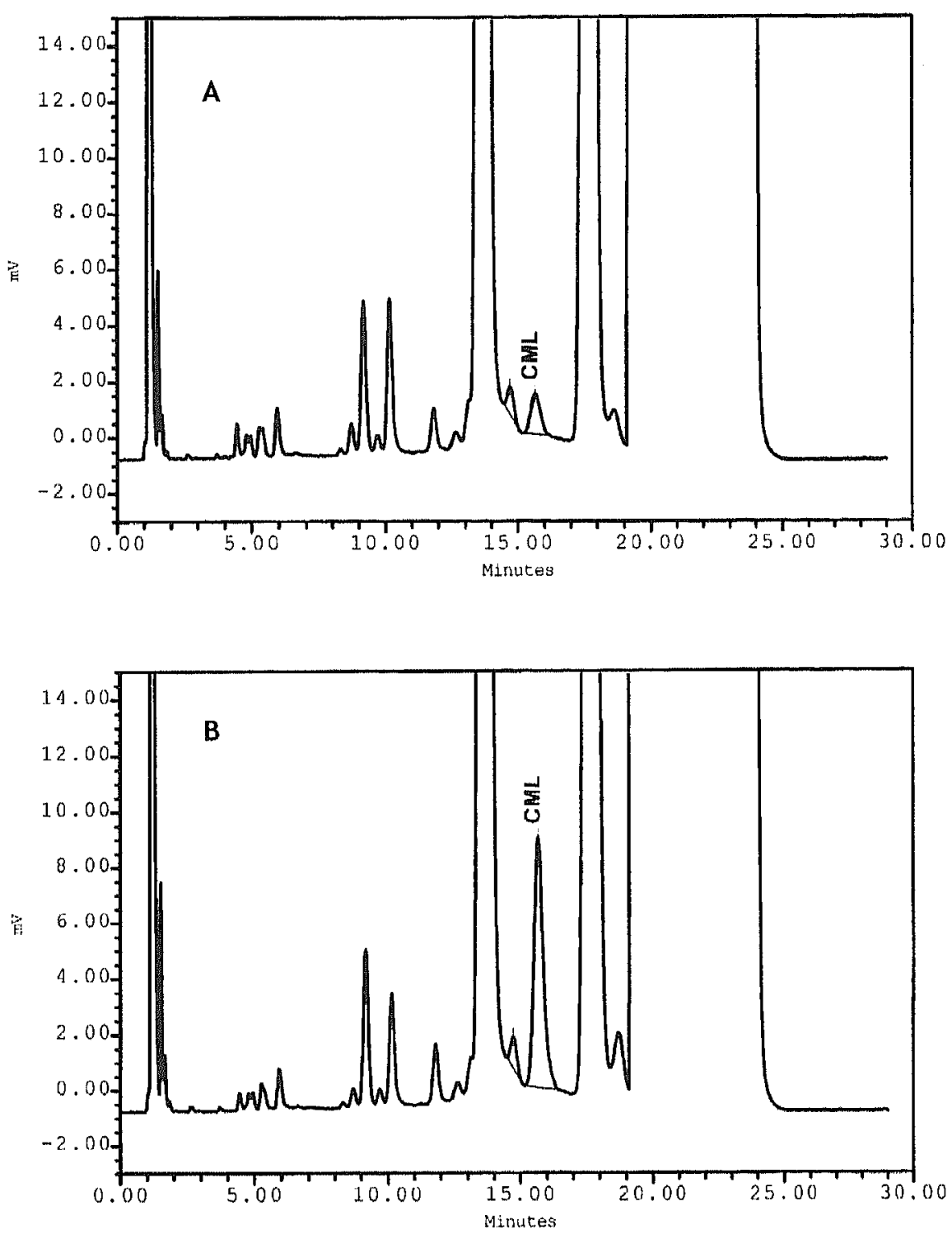

Figure 4. Chromatograms of a plasma sample taken from a diabetic patient; A: without standard addition (CML concentration $4.82 \mu \mathrm{g} / \mathrm{ml}$ ); $B$ : with standard addition (CML concentration 29.8 $\mu \mathrm{g} / \mathrm{ml})$ 


\section{References}

1. Bucala $R$, Makita $Z$, Vega $G$ et al. Modification of low density lipoprotein by advanced glycation end products contributes to the dyslipidemia of diabetes and renal insufficiency. Proc.Natl.Acad.Sci.U.S.A 1994;91:9441-5.

2. Bucala $R$, Mitchell $R$, Arnold $K$, Innerarity $T$, Vlassara $H$, Cerami A. Identification of the major site of apolipoprotein $B$ modification by advanced glycosylation end products blocking uptake by the low density lipoprotein receptor. J.Biol.Chem. 1995;270:10828-32.

3. Kilhovd BK, Berg TJ, Birkeland Kl, Thorsby P, Hanssen KF. Serum levels of advanced glycation end products are increased in patients with type 2 diabetes and coronary heart disease. Diabetes Care 1999;22:1543-8.

4. Mentink CJ, Hendriks M, Levels AA, Wolffenbuttel BH. Glucose-mediated cross-linking of collagen in rat tendon and skin. Clin.Chim.Acta 2002;321:69-76.

5. Wolffenbuttel BH, Giordano D, Founds HW, Bucala R. Long-term assessment of glucose control by haemoglobin-AGE measurement [see comments]. Lancet 1996;347:513-5.

6. Dominguez JH, Tang $\mathrm{N}, \mathrm{X} \cup \mathrm{W}$ et al. Studies of renal injury III: Lipid-induced nephropathy in type II diabetes. Kidney Int. 2000;57:92-104.

7. Hammes HP, Alt A, Niwa $T$ et al. Differential accumulation of advanced glycation end products in the course of diabetic retinopathy. Diabetologia 1999;42:728-36.

8. Ikeda $K$, Nagai $R$, Sakamoto $T$ et al. Immunochemical approaches to AGE-structures: characterization of anti- AGE antibodies. J.Immunol.Methods 1998;215:95-104.

9. Miki HC, Nagai R, Miyazaki $K$ et al. Conversion of Amadori products of the Maillard reaction to $\mathrm{N}$ (epsilon)- (carboxymethyl)lysine by short-term heating: possible detection of artifacts by immunohistochemistry. Lab Invest 2002;82:795-808.

10. Nagai R, Unno $Y$, Hayashi MC et al. Peroxynitrite induces formation of $N$ (epsilon ). (carboxymethyl) lysine by the cleavage of Amadori product and generation of glucosone and glyoxal from glucose: novel pathways for protein modification by peroxynitrite. Diabetes 2002;51:2833-9.

11. Friess $\mathrm{U}$, Waldner $\mathrm{M}$, Waht $\mathrm{HG}$ et al. Liquid chromatography-based determination of urinary free and total N(epsilon)-(carboxymethyl)lysine excretion in normal and diabetic subjects. J.Chromatogr.B Analyt.Technol.Biomed.Life Sci. 2003;794:273-80.

12. Drusch S, Faist V, Erbersdobler HF. Determination of Ne-carboxymethyllysine in milk products by a modified reversed phase HPLC method. Food Chemistry 1999;65:547.53.

13. Mant CT, Zhou NE, Hodges RS, J. Chromatogr. Library. Amsterdam: Elsevier, 1992.

14. Fernandez-Figares I, Rodriguez LC, Gonzalez-Casado A. Effect of different matrices on physiological amino acids analysis by liquid chromatography: evaluation and correction of the matrix effect. J.Chromatogr. B Analyt.Technol.Biomed.Life Sci. 2004;799:73-9. 


\section{Time course of specific AGEs during optimized glycaemic control in type 2 diabetes}

C.J.A.L. Mentink, B.K. Kilhovd, G.J.W.M. Rondas-Colbers, P.A. Torjesen, B.H.R. Wolffenbuttel

Published in: The Netherlands Journal of Medicine, 2006, 64 (1), 12-18 
70 | Chapter 4

\begin{abstract}
Several Advanced Glycation Endproducts (AGEs) are formed in the hyperglycaemic state. Although serum AGEs correlate with average glycaemic control in patients with type 2 diabetes and predict the development of complications, it is not known how serum AGEs change during optimization of diabetes therapy.

We evaluated the change in serum levels of total AGE and the AGEs

CML ( $N^{\varepsilon}$-carboxymethyllysine) and MGHI (methylglyoxal-derived hydroimidazolone), as well as markers of endothelial function in 28 subjects with type 2 diabetes, who were poorly controlled on oral agents, before and after the institution of insulin therapy.

Mean subject age $( \pm S E M)$ was $58 \pm 2$ years, body mass index $27.7 \pm 0.8 \mathrm{~kg} / \mathrm{m}^{2}$, and known duration of diabetes was $8.1 \pm 0.9$ years. With insulin treatment fasting blood glucose levels dropped from $12.1 \pm 0.9 \mathrm{mmol} / /$ to $6.9 \pm 0.3$ and $8.1 \pm 0.4 \mathrm{mmol} / \mathrm{l}$ after 3 and 6 months, respectively (both $p<0.001$ ), while $\mathrm{HbA}_{1 \mathrm{c}}$ decreased from $10.0 \pm 0.3$ to $7.8 \pm 0.2 \%(p<0.001)$. Endothelial function improved as indicated by a small but significant decrease of soluble intercellular adhesion molecule (slCAM-1; $152 \pm 10$ to $143 \pm 8 \mathrm{ng} / \mathrm{ml}, \mathrm{p}<0.02$ ) and sE-selectin ( $111 \pm 16$ to $102 \pm 12 \mathrm{ng} / \mathrm{ml}, \mathrm{p}<0.02)$ levels. In contrast, we observed only a tendency towards a decrease in CML levels $(110 \pm 22$ to $86 \pm$ $13 \mu \mathrm{g} / \mathrm{mg}$ protein, $\mathrm{p}=\mathrm{ns}$ ), but a small increase of $\mathrm{MGHI}$ (from $0.23 \pm 0.02$ to $0.29 \pm 0.04 \mathrm{U} / \mathrm{mg}$ protein, $\mathrm{p}<0.02$ ). At baseline, 16 patients used metformin, which is known to reduce methylglyoxal levels and reduce generation of reactive oxygen species. They had similar levels of $C M L$ and $M G H I$ to the 12 non-metformin users, although their $\mathrm{HbA}_{1 \mathrm{c}}$ was lower $(9.4 \pm 0.3$ vs $10.7 \pm 0.6$ $\%)$. During insulin, patients receiving concomitant metformin therapy showed a similar course of $\mathrm{CML}$ and $\mathrm{MGHI}$ to those not using metformin.

Although insulin therapy improved $\mathrm{HbA}_{1 \mathrm{c}}$ and markers of endothelial function, the levels of serum AGEs did not follow the same time course. This suggests that these specific AGEs are influenced by other factors in addition to overall glycaemia, like oxidative stress.
\end{abstract}


Time course of specific AGEs | 71

\section{Introduction}

Hyperglycaemia is a major factor responsible for the development of diabetic complications. In recent years, several studies reported on the effects of intensive glucose-lowering therapy in preventing both micro- and macrovascular complications. Two of these major trials were the United Kingdom Prospective Study (UKPDS) and the Diabetes Control and Complications Trial (DCCT) ${ }^{[1-3]}$. It was clearly shown that optimized diabetes treatment resulted in a reduction in the development and progression of microvascular complications in both type 2 and type 1 diabetic patients, and to a lesser extent- of macrovascular disease.

The biochemical changes induced by hyperglycaemia are complex and several mechanisms are involved ${ }^{[4]}$, including the polyol pathway, activation of protein kinase $C$, increased oxidative stress and the formation of advanced glycation endproducts (AGEs).

AGE formation results from the reaction of a carbonyl group of a reducing sugar with the free amino groups of a protein. This so-called Schiff's base will react further to an Amadori product which rearranges to the AGEs ${ }^{[5 ; 6]}$. This glycation process leads to the formation of a group of heterogeneous components which are associated with several pathological processes in patients with diabetes ${ }^{[7]}$. Next to this glycation process lipid peroxidation or oxidative stress in general can lead to the formation of reactive carbonyl compounds (methylglyoxal, glyoxal or 3-deoxyglucosone) which can react with proteins thus forming respectively so-called Advanced lipid peroxidation endproducts or ALEs ${ }^{[8]}$. Circulating AGEs can react with their receptors and induce several cellular responses in the vessel wall such as formation and activation of cytokines and increased expression of adhesion molecules tike ESelectin, intercellular adhesion molecule-1 (ICAM-1) and vascular cell adhesion molecule-1 (VCAM-1) by the endothelium [9-11]. Endothelial dysfunction plays an important role in the development of long-term diabetic complications ${ }^{[12]}$, and it has been shown in vivo as well as in vitro that these adhesion molecules correlate well with endothelial dysfunction ${ }^{[13-18]}$.

It is expected that intensive glucose-lowering therapy will lead to a gradual reduction in the formation of AGEs, as was shown for haemoglobin-AGE several years ago ${ }^{[19]}$. Although serum AGEs correlate with average glycaemic control and predict the development of complications, it is not known how other specific serum AGEs change during optimization of diabetes therapy ${ }^{[20]}$. 
72. Chapter 4

In this study we assessed the metabolic effects of improved glucose control by institution of insulin therapy in subjects with type 2 diabetes, who failed on blood glucose-lowering therapy. We followed the changes of specific AGEs over time, their interaction and studied whether improvement in glycaemic control resulted in an improved endothelial function indicated by the levels of circulating adhesion molecules. 


\section{Methods and Materials}

\section{Subjects and study design}

Twenty-eight subjects (14 males, 14 females) with type 2 diabetes, who were insufficiently controlled on oral glucose-lowering medication (sulphonylurea with or without metformin) and therefore started insulin therapy, participated in this study. Their mean age $( \pm$ S.E.M) was $58 \pm 2$ years, body mass index $27.7 \pm 0.8 \mathrm{~kg} / \mathrm{m}^{2}$, and known duration of diabetes was $8.1 \pm 0.9$ years. Subjects were attending the outpatient departments of four Dutch hospitals, the Maastricht University Hospital, University Medical Centre St Radboud and the hospitals of Boxmeer and Leidschendam. They were all participating in a larger international study assessing the effects of therapy with a new recombinant human insulin preparation (Sanofi-Aventis). Men and women between the age of 30 and 80 years were included in this study, if they had documented type 2 diabetes, had normal kidney function, and failed to achieve adequate glycaemic control on oral bloodglucose lowering agents. Written informed consent was obtained from all participants.

At the start of the study subjects were screened and demographic data as well as fasting blood samples were taken. Data on concomitant medication were obtained throughout the study. Nine patients were taking an ACEinhibitor, 6 patients an B-blocker, while 8 patients were treated with a statin and 2 patients used acetylsalicylic acid. These treatments were not altered during the study.

The choice for a specific insulin regimen was made by the treating physician for the individual patient, and based on the results of home blood glucose monitoring. Patients were seen at regular intervals in the outpatient clinic to monitor insulin therapy, and insulin dose was adjusted by the treating physician on the basis of home blood glucose monitoring. For the purpose of the study, fasting blood samples were taken at baseline, i.e. before insulin therapy, and 3 and 6 months after initiation of insulin therapy. On these occasions, blood samples were directly centrifuged and serum was stored in small aliquots at $-80^{\circ} \mathrm{C}$ until further analysis. 
74 | Chapter 4

\section{Methods}

$\mathrm{HbA}_{1 \mathrm{c}}$ levels were measured with HPLC (Bio-Rad Variant II, Hercules CA). The non-diabetic reference range was 4.2 to $6.5 \%$, and the assay was linear up to $17.9 \%$. Fasting blood glucose was measured by a hexokinase method (Olympus, Southall, UK).

Measurements of the adhesion molecules (SE-selectin and sICAM-1) were performed with an ELISA ${ }^{[21]}$. sICAM-1 standard was obtained from Bender MedSystems (Vienna, Austria), sE-selectin standard was prepared as described elsewhere ${ }^{[21]}$.

Serum total AGE levels were determined with a polyclonal antibody raised against AGE-RNAse by the DELFIA method ${ }^{[22]}$. One AGE unit was defined according to Makita et al as the competitive activity of $1 \mu \mathrm{g}$ AGE-BSA standard ${ }^{[23]}$. The final serum concentration of AGEs was corrected for total protein concentration in each serum sample in the following equation [AGE, $\mathrm{U} / \mathrm{ml}$ ] $\mathrm{x}$ [sample protein/mean protein concentration of all sera measured]. All analyses were performed in the same run. Methylglyoxal-derived hydroimidazolone (MGHI) levels were determined using a method similar to the total AGE measurement ${ }^{[24]}$. One hydroimidazolone unit was defined as the competitive activity of $1 \mu \mathrm{g}$ of MG-modified BSA standard. The serum concentration of hydroimidazolone was adjusted for the total protein concentration in each sample, and is expressed as $U / \mathrm{mg}$ protein. In this way, possible systematic errors due to the differences in protein content between groups were avoided.

$\mathrm{N}^{\mathrm{E}}$-carboxymethyllysine (CML) was measured using a newly developed HPLC method ${ }^{[25]}$. CML data were then normalised against plasma protein concentration resulting in the final concentration of $\mathrm{ng} \mathrm{CML} / \mathrm{mg}$ plasma protein.

\section{Statistics}

At baseline several patients were on metformin. Since this was an open study, some subjects continued this medication concomitantly with their insulin treatment, while others stopped all oral agents and switched to insulin alone. As it is known that metformin may scavenge intermediate glycation products such as methylglyoxal ${ }^{[26]}$ the results of insulin therapy were analyzed in the whole group, and post-hoc for metformin users and non-users separately. Also 
the observed changes were compared between patients who showed a good improvement of metabolic control (decrease in $\mathrm{HbA}_{1 \mathrm{c}}$ of more than 1.5\%: good responders), and those with only moderate changes $(1.5 \%$ or less decrease of $\mathrm{HbA}_{1 \mathrm{c}}$; poor-responders).

All results were expressed as means \pm S.E.M. Data were analysed using oneway ANOVA, paired t-tests and Pearson correlations. Statistical analysis was performed using SPSS 10.0, SPSS, Chicago, II., USA. P-values $<0.05$ were considered to indicate statistical significance. 


\section{Results}

At baseline metabolic control was insufficient, indicated by mean $\mathrm{HbA}_{1 \mathrm{c}}$ levels of $10.0 \pm 0.3 \%$ and fasting blood glucose (FBG) levels of $12.1 \pm 0.9 \mathrm{mmol} / \mathrm{l}$. Insulin therapy resulted in a significant improvement in glycaemic control: $\mathrm{HbA}_{1 c}$ in the total group decreased to $7.8 \pm 0.2 \%$ at 3 months with no additional change after 6 months (table 1). Mean daily insulin dose was $39 \pm 5$ $U$ at 6 months, and at that time 4 subjects were using one daily insulin injection, 16 used a mixture of fast-acting and neutral protamine Hagedorn (NPH) insulin twice daily, and 8 were on a 4-injection regimen comprising fast-acting insulin before meals and $\mathrm{NPH}$-insulin at bedtime. The serum levels of the adhesion molecules E-selectin and ICAM-1 also decreased significantly, indicating an improvement in endothelial function. It appeared that total AGE serum levels did not change significantly after 6 months.

Table 1. Changes of the main variables during the course of the study, after initiation of insulin therapy at baseline

\begin{tabular}{llll}
\hline & Baseline & 3 months & 6 months \\
\hline FBG [mmol/l] & $12.1 \pm 0.9$ & $6.9 \pm 0.3 \#$ & $8.1 \pm 0.4 \#$ \\
$\mathrm{HbA}_{1 \mathrm{c}}[\%]$ & $10.0 \pm 0.3$ & $7.8 \pm 0.2 \#$ & $7.8 \pm 0.2 \#$ \\
Insulin dose [U/day] & - & $38 \pm 4$ & $39 \pm 5$ \\
slCAM-1 [ng/ml] & $152 \pm 10$ & $143 \pm 8 \dagger$ & $147 \pm 8 \dagger$ \\
sE-selectin [ng/ml] & $111 \pm 16$ & $96 \pm 12 \dagger$ & $102 \pm 14 \dagger$ \\
Total AGE [U/ml] & $6.7 \pm 0.7$ & $6.7 \pm 0.5$ & $7.4 \pm 1.0$ \\
MGHI [U/mg protein] & $0.23 \pm 0.03$ & $0.23 \pm 0.02$ & $0.29 \pm 0.04 \dagger$ \\
CML [ng/mg protein & $114 \pm 23$ & $126 \pm 18$ & $86 \pm 13 \$$ \\
\hline
\end{tabular}

\# $p<0.001$ vs. baseline; $\uparrow p<0.02$ vs baseline; $\$ p=0.086$.

Abbreviations: $\mathrm{FBG}=$ fasting blood glucose; $\mathrm{MGHI}=$ Methylglyoxal-modified hydroimidazolone; $\mathrm{CML}=\mathrm{N} \varepsilon$-carboxymethyllysine

We observed a small decrease in CML levels, which was not statistically significant, while levels of MGHI increased significantly (table 1). The course of $\mathrm{HbA}_{1 \mathrm{c}}$ and $\mathrm{CML}$ in the individual patients is depicted in figure 1. 
Overall, $\mathrm{HbA}_{1 c}$ levels were not correlated with serum AGE levels (Total AGE, CML and MGHI) nor with serum adhesion molecule levels (E-selectin and ICAM1). Total $A G E$ and $C M L$ did correlate with $S E$-selectin (respectively $R_{\text {Pearson }}=0.36, p=0.013$ and $R_{\text {Pearson }}=0.29$, respectively, $p=0.004$ ), but not with SICAM-1.
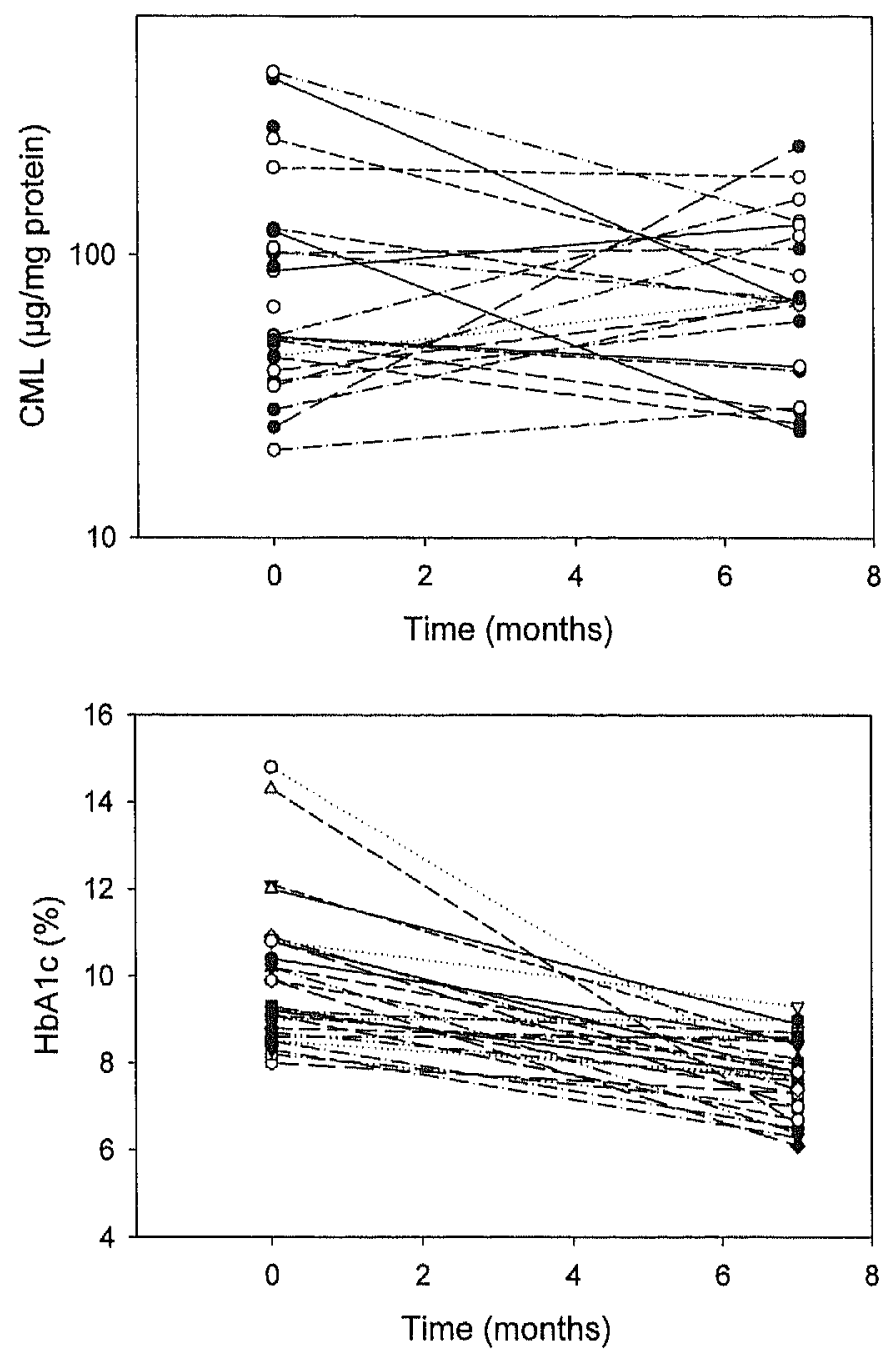

Figure 1. Course of $\mathrm{HbA}_{1 \mathrm{c}}$ and $\mathrm{CML}$ in the individual patients during the study period. Different symbols depict different patients 


\section{Influence of metformin use}

The relevant laboratory parameters at baseline were compared between subjects who were on sulphonylurea (SU) and those taking SU with metformin. As shown in table 2, FBG and $\mathrm{HbA}_{1 \mathrm{c}}$ were significantly lower in metformin users, although their diabetes duration was longer.

Table 2. Relevant laboratory parameters at baseline according to use of metformin

\begin{tabular}{lll} 
& Metformin + SU & SU only \\
\hline Gender [male/female] & $7 / 9$ & $7 / 5$ \\
Age [yrs] & $60 \pm 2$ & $55 \pm 3$ \\
BMI [kg/mZ] & $27.0 \pm 0.8$ & $29.0 \pm 1.5$ \\
Known diabetes duration [yrs] & $10.1 \pm 1.1$ & $5.3 \pm 1.0 \#$ \\
Fasting blood glucose [mmol/l] & $10.5 \pm 0.7$ & $14.2 \pm 1.6 \#$ \\
HbA1c [\%] & $9.4 \pm 0.3$ & $10.7 \pm 0.6 \#$ \\
sICAM-1 [ng/ml] & $153 \pm 14$ & $150 \pm 15$ \\
sE-selectin [ng/ml] & $98 \pm 19$ & $127 \pm 29$ \\
Total AGE [U/ml] & $6.2 \pm 0.9$ & $7.3 \pm 0.9$ \\
MGHI [U/mg protein] & $0.25 \pm 0.05$ & $0.21 \pm 0.03$ \\
CML [ng/mg protein] & $109 \pm 31$ & $112 \pm 32$ \\
\hline
\end{tabular}

$\# \mathrm{p}<0.05$ vs metformin $+\mathrm{SU}$ group

Abbreviations: see also table 1 ; $S U=$ Sulphonylurea, $B M I=$ Body Mass Index

No differences were observed in the levels of adhesion molecules or the different AGE measurements. Of the 16 metformin users, 6 continued this drug during insulin therapy, and 10 switched to therapy with insulin alone. The decrease in $\mathrm{HbA}_{1 \mathrm{c}}$ in subjects who continued metformin in addition to insulin treatment was $1.7 \%$ (from $9.3 \pm 0.4$ to $7.6 \pm 0.4 \%$ ), which was comparable to subjects who switched to insulin alone $1.3 \%$ (from $9.4 \pm 0.4$ to $8.1 \pm 0.4 \%$ ). There were, however, considerable differences in insulin dose: the metformin users injected $18 \pm 3 \mathrm{U}$ of insulin per day at 6 months, while subjects on insulin alone used $45 \pm 5 U$ daily $(p=0.009)$. We were unable to demonstrate significant differences in the changes of the various AGE-levels between metformin users and non-users, but the group sizes may be too small. 


\section{Influence of insulin efficiency}

As insulin therapy has a variable effect on glycaemic control in patients, we assessed whether the observed changes were related to the efficiency of insulin therapy. Poor-responders were at better metabolic control at baseline $\left(\mathrm{HbA}_{1 \mathrm{c}} 8.9 \pm 0.2\right.$ vs. $\left.10.7 \pm 0.5 \%\right)$, but had longer duration of diabetes (table 3). Baseline levels of total AGE, MGHI and CML were not different between the groups. At 6 months no significant difference could be seen between the two groups, their insulin dose was identical, and the change of total AGE, MGHI, CML and adhesion molecule levels over time was not significantly different between the two groups.

Table 3. Characteristics of subjects responding or not responding to insulin therapy

\begin{tabular}{lllll}
\hline & \multicolumn{2}{l}{ poor-responders $(\mathrm{n}=12)$} & \multicolumn{2}{l}{ good-responders $(\mathrm{n}=16)$} \\
& baseline & 6 months & baseline & 6 months \\
\hline Gender [male/female] & $5 / 7$ & - & $9 / 7$ & - \\
Diabetes duration & $11.1 \pm 1.2$ & - & $5.8 \pm 0.9 \#$ & - \\
[yrs] & & & & \\
FBG [mmol/l] & $9.5 \pm 0.7$ & $8.1 \pm 0.7$ & $14.3 \pm 1.2 \#$ & $8.1 \pm 0.5$ \\
HbA $_{1 \mathrm{c}}[\%]$ & $8.9 \pm 0.2$ & $8.3 \pm 0.3$ & $10.7 \pm 0.5 \#$ & $7.3 \pm 0.2 \#$ \\
Insulin dose [U/day] & - & $40 \pm 7$ & - & $39 \pm 6$ \\
s/CAM-1 [ng/ml] & $146 \pm 18$ & $158 \pm 16$ & $155 \pm 12$ & $142 \pm 10 \dagger$ \\
sE-selectin [ng/ml] & $98 \pm 23$ & $109 \pm 29$ & $120 \pm 23$ & $99 \pm 16 \dagger$ \\
CML [ng/mg protein] & $90 \pm 21$ & $73 \pm 22$ & $124 \pm 34$ & $92 \pm 16$ \\
MGHI [U/mg protein] & $0.26 \pm 0.05$ & $0.33 \pm 0.08$ & $0.20 \pm 0.03$ & $0.26 \pm 0.04$ \\
Total AGE [U/ml] & $6.1 \pm 0.9$ & $9.5 \pm 1.8$ & $7.2 \pm 0.9$ & $6.5 \pm 0.6$ \\
\hline
\end{tabular}

\# $p<0.05$ vs poor-responders; $\uparrow p<0.05$ vs baseline; Abbreviations: see table 1 .

Poor responders were considered those subjects in whom $\mathrm{HbA}_{1 \mathrm{c}}$ decreased by $1.5 \%$ or less (at 6 months compared with start of the study) and good responders were those individuals in whom a decrease in $\mathrm{HbA}_{1 c}$ of more than $1.5 \%$ was observed. 


\section{Discussion}

It has been suggested that the formation of AGEs plays an important role in the development of micro- and macrovascular complications in patients with diabetes mellitus, and the level of glycated haemoglobin $\left(\mathrm{HbA}_{1 c}\right)$ is a major predictor. However it is not known how serum AGEs change during optimisation of diabetes therapy. In the present study we observed that insulin therapy improved glycaemic control after 3 and 6 months as indicated by a considerable decrease of both FBG and $\mathrm{HbA}_{1 \mathrm{c}}{ }^{[3]}$. However, this improvement of glycaemic control did not result in a significant decrease in total AGE levels. A slight, but not significant decrease in CML levels was observed, while $M G H I$ even increased significantly.

In addition to the insulin therapy, several patients received concomitant medication such as metformin. The UKPDS has shown that metformin treatment in obese type 2 diabetic patients reduced cardiovascular complications to a greater extent than could be expected from its glucose lowering potential ${ }^{[27 ; 28]}$ This resulted in the hypothesis that metformin also interacts with another molecular mechanism resulting from hyperglycaemia. Several studies ${ }^{[2629]}$ have shown that metformin plays an important role in inhibiting dicarbonyl-mediated AGE formation and accumulation, which should be reflected in decreased $M G H{ }^{[24]}$ and $C M L$ levels. At baseline, metformin users had lower $\mathrm{HbA}_{1 \mathrm{c}}$ and fasting blood glucose levels than non-users. However, in this small group of patients we observed no differences in total AGE, MGHI or CML levels. Of the 16 metformin users, 6 subjects continued this medication in addition to insulin. No different changes in the levels of $\mathrm{HbA}_{1 c}$, fasting blood glucose or the various AGE measurements were seen.

Thus it is apparent that $\mathrm{HbA}_{1 \mathrm{c}}$ and the levels of AGEs did not follow the same time course. This suggests that these specific AGEs such as CML and MGHI are influenced by other factors in addition to overall glycaemia, and that these factors are of greater importance in determining AGE levels. It has been suggested that CML and MGHI in serum may also be derived from lipid peroxidation ${ }^{[8]}$ or be formed as a consequence of the generation of reactive oxygen species ${ }^{[9]}$. Again this may relate to changes in metformin treatment. It has been shown that metformin may also decrease production of reactive oxygen species ${ }^{[30 ; 31]}$. In addition, elevated methylglyoxal levels, increasing after withdrawal of metformin, may directly increase oxidative stress, as was demonstrated in vitro in vascular smooth muscle cells ${ }^{[32]}$. 
Furthermore, increased oxidative stress can be generated by postprandial blood glucose excursions, occurring in diabetic patients even when on good metabolic control ${ }^{[33]}$.

Several studies have shown the potential use of AGEs as marker for the progression and severity of diabetic complication independent from markers for hyperglycaemia such as $\mathrm{HbA}_{1 \mathrm{c}}$. The discrepancy in the changes of $\mathrm{HbA}_{1 \mathrm{c}}$ and AGEs after insulin treatment supports the notion that they are independent determinants of prognosis ${ }^{[34 ; 35]}$.

In addition to the time course of AGEs we measured serum levels of ICAM-1 and E-selectin as an estimate of endothelial function ${ }^{[36]}$. Insulin therapy resulted in a slight, but consistent and statistically significant decrease of both adhesion molecules, which indicates an improvement in endothelial function. Baseline levels of total AGEs correlated with E-selectin, but not with ICAM-1 levels. It has previously been suggested that AGES induces the upregulation of adhesion molecules ${ }^{[13 ; 15]}$. Since we observed that the decrease of adhesion molecules was not paralleled by a decrease in AGE levels, this suggests that other (glycaemic or non-glycaemic) factors add to the effect of AGEs in upregulation of adhesion molecule expression. As receptor for AGE (RAGE) is a multiligand member of the immunoglobulin superfamily of cell surface molecules, other ligands can interact with RAGE resulting in the same effect as activation of intracellular signalling pathways such as MAP-kinases and NF-KB and the resulting upregulation of adhesion molecules.

To assess the efficiency of insulin therapy on both endothelial function and AGE levels, patients were divided in two groups. Poor responders were considered those subjects in whom $\mathrm{HbA}_{1 \mathrm{c}}$ decreased by $1.5 \%$ or less (at 7 months compared with start of the study) and good responders were those individuals in whom a decrease in $\mathrm{HbA}_{1 c}$ of more than $1.5 \%$ was found. Good responders did achieve an average $\mathrm{HbA}_{1 \mathrm{c}}$ of $7.3 \%$, whereas in poor responders $\mathrm{HbA}_{1 \mathrm{C}}$ after 6 months was 8.3\%. Endothelial function, total AGE, CML and MGderived hydroimidazolone showed no significant difference at the different time intervals, nor a significant different increase or decrease over time. Insulin therapy has a varying efficiency in different patients resulting in different levels of glycaemic control. However, this variance in glycaemic control did not result in a difference in the underlying molecular mechanisms as AGE production and accumulation and the resulting change in adhesion molecule levels. 
We conclude that improvement of glycaemic control by glucose lowering therapy ameliorates endothelial function as assessed by SICAM-1 and SEselectin levels. Although insulin therapy improved $\mathrm{HbA}_{1 \mathrm{c}}$, the levels of serum AGEs, CML and MGHI did not follow the same time course. This indicates that these AGEs are formed in different pathways and improving glycaemic control in diabetic subjects will not automatically lead to a reduction in AGE levels. This suggests that their presence in serum is influenced by other factors in addition to overall glycaemia, such as lipid peroxidation or -in generaloxidative stress. The influence of specific treatment, like metformin, may be of significance as well, since this drug can scavenge methylglyoxal and reduce generation of reactive oxygen species.

\section{Acknowledgement:}

We thank prof. dr. J. Lutterman (University Medical Centre St Radboud), dr. A.J. van Bork (Maasziekenhuis Boxmeer) and dr. J. van Hoogenhuijze (Hospital Antoniushove Leidschendam) for their participation. 


\section{References}

1. The effect of intensive treatment of diabetes on the development and progression of longterm complications in insulin-dependent diabetes mellitus. The Diabetes Control and Complications Trial Research Group. N.Engl.J.Med. 1993;329:977-86.

2. Effect of intensive diabetes management on macrovascular events and risk factors in the Diabetes Control and Complications Trial. Am.J.Cardiol. 1995;75:894-903.

3. Bucala R, Cerami A. Advanced glycosylation: chemistry, biology, and implications for diabetes and aging. Adv.Pharmacol. 1992;23:1-34.

4. Singh R, Barden A, Mori T, Beilin L. Advanced glycation end-products: a review. Diabetologia 2001;44:129-46.

5. Gugliucci A. Glycation as the glucose link to diabetic complications. J.Am.Osteopath. Assoc. 2000;100:621-34.

6. Ceriello A, Falleti E, Motz E et al. Hyperglycemia-induced circulating ICAM-1 increase in diabetes mellitus: the possible role of oxidative stress. Horm.Metab Res. 1998;30:146-9.

7. Kunt $T$, Forst $T$, Harzer $O$ et al. The influence of advanced glycation endproducts (AGE) on the expression of human endothelial adhesion molecules. Exp.Clin.Endocrinol.Diabetes 1998;106:183-8.

8. Sengoelge $G$, Fodinger $M$, Skoupy $S$ et al. Endothelial cell adhesion molecule and PMNL response to inflammatory stimuli and AGE-modified fibronectin. Kidney Int. 1998;54:163751.

9. Smulders RA, Stehouwer CD, Schalkwijk CG, Donker AJ, van Hinsbergh VW, TeKoppele JM. Distinct associations of HbA1C and the urinary excretion of pentosidine, an advanced glycosylation end-product, with markers of endathelial function in insulin-dependent diabetes mellitus. Thromb. Haemost. 1998;80:52-7.

10. Vlassara $H$, Fuh $H$, Donnelly $T$, Cybulsky $M$. Advanced glycation endproducts promote adhesion molecule (VCAM-1, ICAM- 1) expression and atheroma formation in normal rabbits. Mol.Med. 1995;1:447-56.

11. Boulanger E, Wautier MP, Wautier $J L$ et al. AGEs bind to mesothelial cells via RAGE and stimulate VCAM-1 expression. Kidney Int. 2002;61:148-56.

12. Wolffenbuttel BH, Heine R.J. [Glycemic regulation and management of essential hypertension in diabetics with type 2 diabetes mellitus; the 'United Kingdom prospective diabetes study' of diabetic complications (see comments)]. Ned.Tijdschr.Geneeskd. 1999;143:1197-201.

13. Beisswenger PJ, Ruggiero-Lopez D, Howell S, Szwergold BS, Wiernsperger $n$, metformin reduces methylglyoxal levels by formation of a stable condensation product (Triazepinone). ADA congress $20002000 ; \mathrm{P}-502$. 


\section{4 | Chapter 4}

14. Meerwaldt $R$, Graaff $R$, Oomen $P H$ et al. Simple non-invasive assessment of advanced glycation endproduct accumulation. Diabetologia 2004;47:1324-30. 


\section{AGE-induced cascade in diabetic retinopathy in patients with type 1 diabetes mellitus}

C.J.A.L. Mentink, G.N.M. Swennen, W.J.R.R. Venekamp, B.J. Looij,

F. Hendrikse, B.H.R. Wolffenbuttel

Submitted for publication 


\begin{abstract}
To asses the role of advanced glycation end products (AGEs) in the development of diabetic retinopathy and to clarify the differences in progression of diabetic retinopathy by polymorphisms in the RAGE (Receptor for AGEs) gene, 85 type 1 diabetic patients were studied. Patients were eligible to participate in the study when they had type 1 diabetes for over 20 years without significant retinopathy (group A, 5 microaneurysms or fewer) or when they had developed proliferative retinopathy (level 60 or more according to the ETDRS modification of the Airlie House classification) and needed laser photocoagulation within 15 years of the diagnosis of diabetes (group B). No significant differences were found between patients in CML and adhesion molecule levels, but patients with proliferative diabetic retinopathy (PDR) tended to have higher VEGF levels (341 vs. $235[\mathrm{pg} / \mathrm{ml}, \mathrm{P}=0.086$ ) than patients with minimal or non-proliferative diabetic retinopathy (NoDR).

Allele distribution of three polymorphisms in the RAGE gene, Gly82Ser, T/A or $T /$ del in the promoter region $374 \mathrm{bp}$ upstream of the start codon and $T / C$ or $\mathrm{T} / \mathrm{del}$ in the promoter region $429 \mathrm{bp}$ upstream of the start codon polymorphisms of the RAGE genotype were not different between patients. However the deletions in the promoter region $388 \mathrm{bp}$ and 452 bp upstream of the start codon only occurred in patients with NoDR and coincided with markedly lower sICAM-1, sE-selectin and aberrant CML levels. No statistical analysis could be done as these deletions occurred in only 3 patients. Studying these deletions in larger scale evaluations could give additional information on the role of RAGE in the development and progression of diabetic retinopathy.
\end{abstract}




\section{Introduction}

The development of visual abnormalities as a consequence of diabetic retinopathy has a profound effect on the daily life of an individual with diabetes. Diabetic retinopathy progresses through distinct and rather welldefined stages ${ }^{[1]}$ from background/non-proliferative or exsudative diabetic retinopathy (NoDR) to proliferative diabetic retinopathy (PDR). Progression of the disease is not uniform in individual patients. The major risk factors for the development of diabetic retinopathy are hyperglycaemia ${ }^{[2 ; 3]}$, age ${ }^{[4 ; 5]}$, hypertension ${ }^{[3 ; 4 ; 6-8]}$ and abdominal obesity ${ }^{[9]}$.

It is believed that hyperglycaemia induces changes in the retinal vasculature through different pathways ${ }^{[10]}$, including ${ }^{[11]}$ increased flux through the polyol pathway, activation of protein kinase $C$, increased oxidative stress and the formation of advanced glycation endproducts (AGEs).

Non-enzymatic glycation of proteins plays an important role in the development of diabetic complications and ageing in general. The carbonyl group of a reducing sugar reacts with the free amino group of amino acids in proteins and forms a Schiff's base which reacts further into an Amadori product. These early products of glycation will undergo further rearrangements resulting in the formation of AGEs ${ }^{[12 ; 13]}$. AGE-formation affects predominantly long-living macromolecules, is irreversible and increases with increasing blood and tissue glucose concentration [14]. Circulating AGEs can react with specific receptors which are located on various cell types, like vascular endothelium and smooth muscle cells, mononuclear phagocytes, pericytes, neurons, cardiac myocytes, and Muller and bipolar ganglion cells of the retina ${ }^{[15-18]}$. Receptor-mediated AGE-uptake induces several cellular responses like upregulation of several cytokines and increased expression of adhesion molecules like ICAM-1 (intercellular adhesion molecule-1), VCAM-1 (vascular cell adhesion molecule-1) and E-Selectin ${ }^{[19]}$. Upregulation of these adhesion molecules will result in the adhesion of leucocytes on the endothelial cells of the retinal capillaries which coincides with endothelial cell death and the formation of acellular capillaries. In addition, AGEs are deposited on tissue proteins, and have been shown to induce thickening of the basement membranes resulting in decreased blood flow in the affected capillaries and increased vascular permeability. All these processes will lead to retinal ischaemia and the subsequent upregulation of VEGF (vascular endhothelial growth factor). VEGF has been shown to induce the formation of new vessels in both the retina and the vitreous body. These 
fragile vessels will tear easily causing bleeding in the eye which leads to vision loss and eventually blindness ${ }^{[20]}$.

The present study aims to address two questions: 1. do AGEs play a role in the cascade responsible for the development of retinopathy in type 1 diabetes, and 2. can differences in the progression of diabetic retinopathy be explained by polymorphisms in the RAGE (Receptor for AGEs) gene? Genetic polymorphisms in the RAGE gene ${ }^{[21 ; 22]}$ could influence the binding of AGEs to the receptor and accelerate the development and severity of hyperglycemiainduced complications. In this respect the Gly82Ser, T/A or T/del in the promoter region $374 \mathrm{bp}$ upstream of the start codon and $\mathrm{T} / \mathrm{C}$ or $\mathrm{T} / \mathrm{del}$ in the promoter region 429 bp upstream of the start codon polymorphisms were examined by restriction analysis. 


\section{Subjects and Methods}

\section{Subjects}

We studied 85 patients with type 1 diabetes mellitus attending the outpatient clinics of the Maastricht University Hospital and the neighbouring general hospitals of Sittard and Brunssum. Patients were eligible to participate in the study when they had type 1 diabetes for over 20 years duration without significant retinopathy (NoDR, group A, 5 microaneurysms or fewer) or when they had developed proliferative retinopathy (level 60 or more according to the ETDRS modification of the Airlie House classification ${ }^{[23]}$ ) and needed laser photocoagulation within 15 years of the diagnosis of diabetes (group B). Patients with intermediate grades of retinopathy (levels 20-60) were excluded to enhance separation between the two groups.

All patients were had type 1 diabetes for over 20 years and written informed consent was obtained. The study was approved by the Medical Ethics Committee of the Maastricht University Hospital and of the participating centers. Data from age- -matched control subjects (group C) were obtained from previous studies by our group. Controls had no diabetes, inflammation, hypertension or any other pathological symptoms. As controls were obtained from an existing pool at our department, no further demographic data were available.

Data regarding history were obtained directly from the patients and from their hospital charts. Complete ophthalmologic evaluation was available from all patients, and these investigations were done within the previous 6 months. They included results of retinal examination by indirect fundoscopy by a certified ophthalmologist, and assessment of visual acuity, which was assessed using a Snellen visual acuity chart.

To asses long-term metabolic control the mean of the HbA1c values $(n=6-10$ per patient) of the previous 3 years was derived from their charts and hospital laboratory records. Venous blood was drawn by venapuncture and centrifuged The buffy coat and plasma were separated. Both samples were stored at $80^{\circ} \mathrm{C}$ until further analysis. 


\section{Methods}

$\mathrm{HbA}_{1 \mathrm{c}}$ levels were measured with HPLC (Bio-Rad Variant II, Hercules CA), with a non-diabetic reference range of $4.2-6.5 \%$; the assay was linear up to $17.9 \%$.

\section{Adhesion molecules (SE-selectin and sICAM-1)}

Both measurements were performed with an ELISA (24). sICAM-1 standard was obtained from Bender MedSystems (Vienna, Austria), sE-selectin standard was prepared as described elsewhere ${ }^{[24]}$. Briefly, 96-well plates were coated overnight with $\pm 3 \mu \mathrm{g} / \mathrm{ml} \mathrm{HM} M_{1}\left(1^{\text {st }}\right.$ antibody $(a b)$ against sICAM-1) and ENA $A_{1}\left(1^{\text {st }}\right.$ $a b$ against $S E$-selectin). Plates were washed 5 times after every step with phosphate-buffered saline (PBS). Non-specific binding was blocked by incubating the plates with $1 \%$ bovine serum albumin (BSA, Sigma) in PBS. Then $100 \mu$ of serum samples $(1: 20)$ and the calibration curve were added and incubated for 1 hour at RT. $H M_{2}\left(2^{\text {nd }}\right.$ ab against sICAM-1) and $\operatorname{ENA}_{2}\left(2^{\text {nd }}\right.$ ab against $\mathrm{SE}$-selectin) were added and incubated for 1 hour. Peroxidase conjugate was added $(1: 5000)$ and incubated for 1 hour. Colour reaction was started by the addition of TMB substrate and incubation for 10-15 minutes. Reaction was stopped by addition of $100 \mu \mathrm{l} 1 \mathrm{M} \mathrm{H}_{2} \mathrm{SO}_{4}$ and absorbance was measured at $450 \mathrm{~nm}$ against blank with reference $\lambda$ set at $570 \mathrm{~nm}$ to correct for plate opacity. Samples were measured in duplo and concentrations of sESelectin and SICAM-1 were determined using an external calibration curve.

sVEGF

VEGF ELISA was purchased from R\&D systems (DVE00, ITK diagnostics, The Netherlands) and performed according to the kit's instructions. Briefly, $100 \mu \mathrm{l}$ serum sample, standard or control was added to a well of the 96-well plate which already contained $100 \mu \mathrm{l}$ sample diluent and was incubated for 2 hours at RT. Plates were aspired and washed 3 times with washing buffer. $200 \mu \mathrm{l}$ conjugate (polyclonal ab against VEGF conjugated with horseradish peroxidase) was added to each well and incubated for 2 hours at RT. After aspiration and washing $200 \mu \mathrm{lTMB}$ substrate was added and incubated for \pm 25 minutes. Reaction was stopped by adding $50 \mu \mathrm{l}$ of stop solution and absorbance was measured at $450 \mathrm{~nm}$ against blank with reference $\lambda$ set at 570 
$\mathrm{nm}$ to correct for plate opacity. Samples were measured in duplo and concentration VEGF was determined by an external calibration curve.

\section{CML analysis}

CML was measured using a newly developed method ${ }^{[25]}$. Briefly, a $200 \mu \mathrm{l}$ aliquot of plasma was mixed with $1000 \mu \mathrm{l}$ of $10 \%$ aqueous trichloroacetic acid in a $10 \mathrm{ml}$ glass hydrolysis tube (Organon Teknika, Boxtel, The Netherlands) and left to stand for 10 minutes. The sample was centrifuged at $3300 \mathrm{~g}$ for 10 minutes and the supernatant was discarded. The remaining protein pellet was dissolved in $1000 \mu \mathrm{l}$ of $6 \mathrm{M}$ hydrochloric acid, thoroughly purged with nitrogen and hydrolysed at $110^{\circ} \mathrm{C}$ for 20 hours. After cooling the sample to ambient temperature, $1000 \mu \mathrm{l}$ of $5 \mathrm{M}$ sodium hydroxide was added and the mixture was centrifuged at $3300 \mathrm{~g}$ for 10 minutes. A $20-\mu \mathrm{l}$ aliquot of the supernatant was added to $180 \mu \mathrm{l}$ of $0.4 \mathrm{M}$ sodium borate buffer $(\mathrm{pH} 10.4)$. Subsequently, $10 \mu \mathrm{l}$ of water or an aqueous $5.00 \mu \mathrm{g} / \mathrm{ml} \mathrm{CML}$ solution (for standard addition, see below) were added. After mixing, $20 \mu \mathrm{l}$ of this mixture were added to $180 \mu \mathrm{l}$ of $0.4 \mathrm{M}$ sodium borate buffer $(\mathrm{pH} 10.4)$ in a polypropylene injection vial and derivatisation was performed by adding $10 \mu \mathrm{l}$ of a $1 \mathrm{mg} / \mathrm{ml}$ FMOC solution in acetonitrile. After vortex-mixing, the vial was transferred to the autosampler and an aliquot of $40 \mu \mathrm{l}$ was injected into the chromatographic system. The chromatographic system consisted of a Waters (Milford, MA, USA) Separations Module Alliance 2690 for injection and pumping of the mobile phase, a Zorbax Stablebond (Agilent, Palo Alto, CA, USA) C8 column (150x4.6 mm, $3.5 \mu \mathrm{m})$, conditioned at $45^{\circ} \mathrm{C}$ in a Julabo (Seelbach, Germany) water bath, and a Jasco (Tokyo, Japan) FP 920 fluorescence detector, set at an excitation wavelength of $260 \mathrm{~nm}$ and an emission wavelength of $310 \mathrm{~nm}$. The mobile phase, a mixture of $25 \mathrm{mM}$ potassium phosphate buffer $(\mathrm{pH} \mathrm{2.0)}$ as eluent $\mathrm{A}$ and acetonitrile as eluent $B$, was pumped at a flow-rate of $1.3 \mathrm{ml} / \mathrm{min}$. Elution of the analyte was achieved using $80 \% \mathrm{~A}$ and $20 \% \mathrm{~B}$ for $17.5 \mathrm{~min}$, after which a step gradient was applied with $15 \% \mathrm{~A}$ and $85 \% \mathrm{~B}$ until $22.5 \mathrm{~min}$; finally the column was re-equilibrated at $80 \%$ A / $20 \%$ B until $30 \mathrm{~min}$. In order to quantitatively determine the CML concentration in a sample, the method of standard addition was applied. To this end, two aliquots of each individual protein hydrolysate were analysed, one without and one with a known amount (50.0 ng) of CML added, and the CML peak heights were determined. As the added amount of CML corresponds to a concentration of $25.0 \mu \mathrm{g} / \mathrm{ml}$ plasma, the original $\mathrm{CML}$ concentration (in $\mu \mathrm{g} / \mathrm{ml}$ ) was subsequently calculated by 
92 | Chapter 5

multiplying 25 with the ratio of the original peak height over the difference between the two peak heights. CML data were then normalised against plasma protein concentration resulting in the final concentration of $\mathrm{ng} C M L / m g$ plasma protein.

\section{SNP analysis}

Buffy coats were incubated for 10 minutes at room temperature with $300 \mu \mathrm{l}$ of red cell lysis buffer ( $155 \mathrm{mM} \mathrm{NH}_{4} \mathrm{Cl}, 10 \mathrm{mM} \mathrm{KHCO}{ }_{3} 0.1 \mathrm{mM}$ EDTA). The mixture was centrifuged for 8 minutes and the supernatant was discarded. For extraction of DNA from the nuclei, the Promega Wizard Genomic DNA purification kit (\#TM050, Promega Benelux b.v., Leiden, The Netherlands) was used. DNA concentration was determined and samples were stored at $4^{\circ} \mathrm{C}$ until further analysis. Several polymorphisms of the RAGE were determined by amplifying DNA fragments by PCR using forward and reverse primers (table 1).

Table 1. Primer sequences, annealing temperatures $\left(T_{a}\right)$, restriction enzymes, restriction enzyme digestion temperature $\left(T_{r}\right)$ and time of enzyme digestion of the SNP analysis performed

\begin{tabular}{|c|c|c|c|c|}
\hline RAGE polymorphism & primer sequence & $\begin{array}{l}\mathrm{Ta} / \mathrm{Tr} \\
{\left[{ }^{\circ} \mathrm{C}\right]}\end{array}$ & RE & $\begin{array}{l}\text { Time } \\
\text { [hrs] }\end{array}$ \\
\hline Gly82Ser & $\begin{array}{l}\text { for. 5' GTAAGCGGGGCTCCTGTTGCA 3' } \\
\text { rev. 5' GGCCAAGGCTGGGGTTGAAGG 3' }\end{array}$ & $63 / 37$ & Alul & 2 \\
\hline $\begin{array}{l}\text { promoter } \\
\text { region } 388 \text { bp } \\
\text { upstream } \\
\end{array}$ & $\begin{array}{l}\text { for. 5' CCCTGGGTTIAGTTGAGAATTTTT 3' } \\
\text { rev. 5' CAGAGCCCCCGATCCTATITA 3' }\end{array}$ & $61 / 65$ & Tsp509l & 2 \\
\hline $\begin{array}{l}\text { promoter } \\
\text { region } 452 \text { bp } \\
\text { upstream }\end{array}$ & $\begin{array}{l}\text { for. 5' AAATATGGGTTGGGGTGCTT 3' } \\
\text { rev. 5' CTGCATCATGAAGGCAAGG 3' }\end{array}$ & $61 / 37$ & Alul & 1 \\
\hline
\end{tabular}

RE: Restriction Enzyme

After initial denaturation at $95{ }^{\circ} \mathrm{C}$ for 10 minutes, DNA was amplified by 30 cycles, each cycle consisting of $95^{\circ} \mathrm{C}$ for 30 seconds, primer annealing for 30 seconds, primer extension for $1 \mathrm{~min}$ at $75^{\circ} \mathrm{C}$ followed by a final extension for 10 minutes at $75^{\circ} \mathrm{C}$. Restriction analysis was performed using different restriction enzymes (table 1). Digestion products were identified by electrophoresis on agarose gel with ethyliumbromide as a colouring reagent. 
AGE induced cascade in diabetic retinopathy | 93

\section{Statistics}

All results were expressed as mean \pm S.E.M., unless otherwise noted. Data were analysed using one-way ANOVA with post-hoc Dunnet analysis and using SPSS 10.0 (SPSS, Chicago, IL, USA). Differences in allelic distribution between cases and controls were determined by $\chi^{2}$-test. Correlation was tested using the Pearson correlation coefficient. P-values $<0.05$ were considered statistically significant. 
94 | Chapter 5

\section{Results}

Table 2 depicts the demographics of the participating subjects. There was an equal distribution of male and female subjects. Group B subjects had shorter duration of diabetes and were younger. Glycaemic control was similar, and despite the fact that they had received laser coagulation earlier in their disease, visual acuity (VODS) was not different from group A. The levels of CML were significantly higher in the diabetic subjects than in the control population ( $P=0.005)$. No significant differences were observed in sICAM-1, $E$ selectin and VEGF levels between the groups of diabetic subjects.

Table 2. Subject characteristics and sICAM-1, E-Selectin and VEGF concentrations.

\begin{tabular}{llll}
\hline & $\begin{array}{l}\text { group A } \\
\text { (NoDR) }\end{array}$ & $\begin{array}{l}\text { group B } \\
\text { (PDR) }\end{array}$ & $\begin{array}{l}\text { group C } \\
\text { (control) }\end{array}$ \\
\hline Gender [M/F] & $26 / 25$ & $15 / 19$ & na \\
Age [yrs] & $49 \pm 2$ & $40 \pm 2 \# \#$ & $51 \pm 2$ \\
HbA 1 [\%] $_{\text {VODS }}$ & $8.3 \pm 0.1$ & $8.4 \pm 0.2$ & na \\
Diabetes duration [yrs] & $29 \pm 1$ & $20 \pm 1 \#$ & na \\
slCAM-1 [ng/ml] & $118 \pm 5$ & $122 \pm 6$ & $149 \pm 14$ \\
sE-selectin [ng/ml] & $58 \pm 4$ & $65 \pm 5$ & $61 \pm 9$ \\
VEGF [pg/ml] & $235 \pm 37$ & $341 \pm 53$ & $304 \pm 33$ \\
CML [ng/mg protein] & $70 \pm 6$ & $57 \pm 6$ & $29 \pm 6 *$ \\
\hline
\end{tabular}

Data are expressed as mean \pm S.E.M.

\#P<0.000 vs. group $A ; \#$; $<0.002$ vs group $A ;{ }^{*} p<0.005$ vs group $A$ and $B ;$ na $=$ not applicable

No correlation was found between the levels of $\mathrm{HbA}_{\mathrm{ic}}$ as a measure of longterm glycaemic control, and levels of sICAM-1, sE-selectin, VEGF and CML. CML did not correlate with the levels of adhesion molecules and VEGF. When all data were pooled a weak correlation was found between sICAM-1 and VEGF $\left(R_{\text {eearson }}=0.234, P=0.048\right)$.

Allele frequencies of the Gly82Ser, T/A or T/del in the promoter region 374 bp upstream of the start codon and $T / C$ or $T / d e l$ in the promoter region 429 bp upstream of the start codon were only determined in the diabetic individuals (Table 3 ). No significant differences in the distribution of the alleles could be found between the two groups. 
Table 3. Allele frequencies of the RAGE polymorphisms Gly82Ser, T/A in the promoter region 388 bp upstream of the start codon and $T / C$ in the promoter region 452 bp upstream of the start codon.

\begin{tabular}{lllll}
\hline & N & Variant & group A (NoDR) & group B (PDR) \\
\hline Gly82Ser & 72 & GG & 91.1 & 85.2 \\
& & AG & 9.9 & 14.8 \\
T/C 452 & 70 & CC & 9.1 & 15.4 \\
& & CT & 31.8 & 23.1 \\
& & TT & 52.3 & 61.5 \\
T/A 388 & \multirow{5}{*}{85} & T/del & 6.8 & 0 \\
& & TT & 49.0 & 53.0 \\
& & AT & 35.3 & 47.0 \\
& & AA & 9.8 & 0 \\
\hline
\end{tabular}

Three patients with background retinopathy showed a deletion in two of the alleles of the promoter region which was associated with considerable lower sICAM-1 and E-selectin levels (table 4) and aberrant CML levels in two of these subjects (not enough material was available to asses these parameters in the third subject). Due to the low frequency of this deletion no statistical analysis could be done.

Table 4. sICAM-1, sE-Selectin and CML levels for Gly28Ser, T/C 452 and T/A 388 RAGE polymorphisms.

\begin{tabular}{lllll}
\hline & Variant & s/CAM-1 [ng/ml] & sE-selectin [ng/ml] & CML [ng/mg protein] \\
\hline Gly82Ser & GG & $118 \pm 4$ & $62 \pm 4$ & $67 \pm 5$ \\
& AG & $100 \pm 9$ & $50 \pm 5$ & $60 \pm 13$ \\
T/C 452 & CC & $110 \pm 10$ & $65 \pm 6$ & $76 \pm 17$ \\
& CT & $111 \pm 7$ & $49 \pm 6$ & $64 \pm 9$ \\
& TT & $123 \pm 6$ & $66 \pm 5$ & $61 \pm 5$ \\
& T/A 388 & $75 ; 51$ & $39 ; 29$ & $26 ; 161$ \\
& TT & $118 \pm 6$ & $58 \pm 4$ & $64 \pm 6$ \\
& AT & $122 \pm 5$ & $64 \pm 5$ & $64 \pm 6$ \\
& AA & $139 \pm 11$ & $78 \pm 16$ & $57 \pm 16$ \\
& T/del* & $75 ; 51$ & $39 ; 29$ & $26 ; 161$ \\
\hline
\end{tabular}

* Data from two subjects with deletion in two of the alleles of the promoter region Data expressed as mean \pm S.E.M. 


\section{Discussion}

Several risk factors for the development of diabetic retinopathy have been identified, such as hyperglycaemia, blood pressure levels and age. Analysis of a cohort of the Diabetes Control and Complication Trial (DCCT) showed evidence for possible genetic factors that influence the severity of diabetic retinopathy ${ }^{[26]}$. Because of the involvement of AGEs in the development of retinopathy, we studied the possible influence of three polymorphisms in the Receptor for AGEs (RAGE) on the development of early retinopathy in type 1 diabetes. To enhance separation between the group subjects with early diabetic retinopathy who needed laser coagulation and subjects with long duration of diabetes but without significant retinopathy were recruited. Following this approach, we were not able to find a difference in the distribution of the polymorphisms of the RAGE between the two groups.

In an earlier study with 966 type 1 diabetic patients, Petterson et al [27] reported an association between the RAGE - 374 T/A homozygous AA genotype and cardiovascular disease as well as albumin excretion in those patients with poor metabolic control, which suggest a gene-environment interaction. The frequency of the AA genotype was $13 \%$ in their patients, which was lower in our study $(6 \%)$. Due to the relatively small sample and the low prevalence of the $A A$ genotype we were not able to find such an association. It proved difficult to identify in our outpatient clinic enough subjects who underwent laser coagulation early in the course of their disease.

The plasma levels of CML were increased in our diabetic patients as compared to controls which is consistent with previous studies ${ }^{[28]}$. No difference in $C M L$ could be seen between patients with and without retinopathy, and no differences in the levels of adhesion molecules were found. Several studies ${ }^{[29 ; 30]}$ showed a difference in CML plasma levels in patients with different stages of retinopathy. However these studies used an ELISA assay based on an antibody recognising mainly CML antigen but also some other AGE epitopes. This could in part explain the difference in CML levels as compared to our own study.

It must be stressed that all patients were assessed after their retinopathy had become quiet after earlier laser coagulation. Following interaction with their receptor (RAGE), AGEs may increase the expression of adhesion molecules ${ }^{[31]}$. Although CML levels did not differ between the two groups of diabetics, we did, however, notice that a specific deletion in the promoter region of the 
RAGE was accompanied by markedly lower levels of adhesion molecules and aberrant CML levels as compared to subjects without these deletions. This preliminary finding was only done in patients without proliferative retinopathy, and may suggest a different or reduced signal transduction pathway, less expression of adhesion molecules, and slower progression of diabetic retinopathy. Due to the relatively low frequency of this deletion no statistical analysis was possible. As Rudofsky et al ${ }^{[32]}$ showed that the $63 \mathrm{bp}$ deletion (from $-407 \mathrm{bp}$ to $-345 \mathrm{bp}$ ) in the promoter region seemed to protect from diabetic nephropathy, our study seems to confirm the importance of this deletion. Larger scale evaluations should give additional information on the protective effects of this polymorphism, since its prevalence appears to be low.

Patients with previous laser coagulation had slightly higher serum levels of VEGF, although this difference was of borderline significance. Earlier studies have indicated that in patients with proliferative retinopathy undergoing laser photocoagulation therapy, VEGF levels are gradually falling towards normal values as seen in controls or in patients without retinopathy ${ }^{[33]}$. Also in our patients, laser photocoagulation therapy succeeded to retain normal vision on the long term, and in the same group we have demonstrated that healthrelated quality of life was not impaired ${ }^{[34]}$.

Although our study did not find any changes in allele frequencies of the different polymorphisms we did find an interesting relation between a specific deletion in the promoter region and adhesion molecule levels. Further studies are needed to evaluate the consequences of these specific polymorphisms in the promoter region of the RAGE gene on the development and progression of retinopathy. 


\section{References}

1. Stitt AW. The role of advanced glycation in the pathogenesis of diabetic retinopathy. Exp.Mol.Pathol. 2003;75:95-108.

2. Progression of retinopathy with intensive versus conventional treatment in the Diabetes Control and Complications Trial. Diabetes Control and Complications Trial Research Group. Ophthalmology 1995;102:647-61.

3. Marshall G, Garg SK, Jackson WE, Holmes DL, Chase HP. Factors influencing the onset and progression of diabetic retinopathy in subjects with insulin-dependent diabetes mellitus. Ophthalmology 1993;100:1133-9.

4. Klein R, Klein BE, Moss SE, Cruickshanks KJ. The Wisconsin Epidemiologic Study of Diabetic Retinopathy: XVII. The 14-year incidence and progression of diabetic retinopathy and associated risk factors in type 1 diabetes. Ophthalmology 1998;105:1801-15.

5. Davis MD, Fisher MR, Gangnon RE et al. Risk factors for high»risk proliferative diabetic retinopathy and severe visual loss: Early Treatment Diabetic Retinopathy Study Report \#18. Invest Ophthalmol.Vis.Sci. 1998;39:233-52.

6. Sparrow JM, MCLeod BK, Smith TD, Birch MK, Rosenthal AR. The prevalence of diabetic retinopathy and maculopathy and their risk factors in the non-insulin-treated diabetic patients of an English town. Eye 1993;7:158-63.

7. Moss SE, Klein R, Klein BE. Ten-year incidence of visual loss in a diabetic population. Ophthalmology 1994;101:1061-70.

8. Cohen 0 , Norymberg K, Neumann E, Dekel H. Complication-free duration and the risk of development of retinopathy in elderly diabetic patients. Arch. Intern. Med. 1998;158:641-4.

9. van Leiden HA, Dekker JM, Moll AC et al. Risk factors for incident retinopathy in a diabetic and nondiabetic population: the Hoorn study. Arch.Ophthalmol. 2003;121:245-51.

10. Sheetz MJ, King GL. Molecular understanding of hyperglycemia's adverse effects for diabetic complications. JAMA 2002;288:2579-88.

11. Gugliucci A. Glycation as the glucose link to diabetic complications, J.Am.Osteopath. Assoc. 2000;100:621-34.

12. Bucala R, Vlassara $H$, Cerami A. Advanced Glycosylation Endproducts: Role in Diabetic and Non-diabetic vascular disease. Drug Development Research 1994;32:77-89.

13. Bucala R, Cerami A. Advanced glycosylation: chemistry, biology, and implications for diabetes and aging. Adv. Pharmacol. 1992;23:1-34.

14. Brownlee $M$, Cerami A, Vlassara $H$. Advanced glycosylation endproducts in tissue and the biochemical basis of diabetic complications. N.Engl.J.Med. 1988;318:1315-21. 
15. Kislinger T, Fu C, Huber B et al. N(epsilon)-(carboxymethyl)lysine adducts of proteins are ligands for receptor for advanced glycation end products that activate cell signaling pathways and modulate gene expression. J.Biol.Chem. 1999;274:31740-9.

16. Schmidt AM, Stern DM. RAGE: a new target for the prevention and treatment of the vascular and inflammatory complications of diabetes. Trends Endocrinol.Metab 2000;11:368-75.

17. Schmidt AM, Yan SD, Yan SF, Stern DM. The biology of the receptor for advanced glycation end products and its ligands. Biochim.Biophys.Acta 2000;1498:99-111.

18. Stern DM, Yan SD, Yan SF, Schmidt AM. Receptor for advanced glycation endproducts (RAGE) and the complications of diabetes. Ageing Res.Rev. 2002;1:1-15.

19. Boulanger $E$, Wautier MP, Wautier JL et al. AGEs bind to mesothelial cells via RAGE and stimulate VCAM-1 expression. Kidney int. 2002;61:148-56.

20. Cai J, Boulton $M$. The pathogenesis of diabetic retinopathy: old concepts and new questions. Eye 2002;16:242-60.

21. Kumaramanickavel G, Ramprasad VL, Sripriya S, Upadyay NK, Paul PG, Sharma T. Association of Gly82Ser polymorphism in the RAGE gene with diabetic retinopathy in type II diabetic Asian Indian patients. J.Diabetes Complications 2002;16:391-4.

22. Kankova K, Zahejsky J, Marova 1 et al. Polymorphisms in the RAGE gene influence susceptibility to diabetes- associated microvascular dermatoses in NIDDM. J.Diabetes Complications 2001;15:185-92.

23. Diabetic retinopathy study. Report Number 6. Design, methods, and baseline results, Report Number 7. A modification of the Airlie House classification of diabetic retinopathy. Prepared by the Diabetic Retinopathy. Invest Ophthalmol.Vis. Sci. 1981;21:1-226.

24. Leeuwenberg JF, Smeets EF, Neefjes JJ et al. E-selectin and intercellular achesion molecule-1 are released by activated human endothelial cells in vitro. Immunology 1992;77:543-9.

25. Merbel, N., Mentink, C., Hendriks, G., Wolffenbuttel, B. Liquid chromatographic method for the quantitative determination of $\mathrm{N}^{\mathrm{E}}$-carboxymethyllysine in human plasma proteins. Journal of Chromatography B: Biomedical Applications 2004;808, 163-168.

26. Clustering of long-term complications in families with diabetes in the diabetes control and complications trial. The Diabetes Control and Complications Trial Research Group. Diabetes 1997;46:1829-39.

27. Pettersson-Fernholm K, Forsblom C, Hudson BI, Perola M, Grant PJ, Groop PH. The functional -374 T/A RAGE gene polymorphism is associated with proteinuria and cardiovascular disease in type 1 diabetic patients. Diabetes 2003;52:891-4.

28. Kilhovd BK, Berg TJ, Birkeland KI, Thorsby P, Hanssen KF. Serum levels of advanced glycation end products are increased in patients with type 2 diabetes and coronary heart disease. Diabetes Care 1999;22:1543-8. 
$100 \mid$ Chapter 5

29. Boehm BO, Schilling S, Rosinger $S$ et al. Elevated serum levels of N(epsilon)carboxymethyl-lysine, an advanced glycation end product, are associated with proliferative diabetic retinopathy and macular oedema. Diabetologia 2004;47:1376-9.

30. Hirata K, Kubo K. Relationship between blood levels of $\mathrm{N}$-carboxymethyl-lysine and pentosidine and the severity of microangiopathy in type 2 diabetes. Endocr.J. 2004;51:537 44 .

31. Boulanger E, Wautier MP, Wautier JL et al. AGEs bind to mesothelial cells via RAGE and stimulate VCAM-1 expression. Kidney Int. 2002;61:148-56.

32. Rudofsky G, Jr., Isermann B, Schilling $T$ et al. A 63bp deletion in the promoter of rage correlates with a decreased risk for nephropathy in patients with type 2 diabetes. Exp.Clin. Endocrinol.Diabetes 2004;112:135-41.

33. Lip PL, Belgore F, Blann AD, Hope-Ross MW, Gibson JM, Lip GY. Plasma VEGF and soluble VEGF receptor FLT-1 in proliferative retinopathy: relationship to endothelial dysfunction and laser treatment. Invest Ophthalmol.Vis.Sci. 2000;41:2115-9.

34. Wolffenbuttel, B. H. R., Swennen, G. N., Buijsen, J., Venekamp, W. J. R., and Looy, B. J. Impact of retinopathy on quality of tife in Type 1 diabets. Diabetologia 45(Suppl 1), A319. $1 \cdot 1-2002$. 


\section{Endogenous and Postprandial exogenous AGE formation and accumulation in type 2 diabetic patients}

C.J.A.L. Mentink, B.H.R. Wolffenbuttel, M. van Baak, C.G. Schalkwijk, G.J. Hageman, A. Bast, P.P.C.A. Menheere, W. H.M.Saris ${ }^{1}$

In preparation 


\begin{abstract}
Advanced glycation endproducts (AGEs) are formed by the non-enzymatic glycation of proteins with glucose or a-dicarbonyls. Postprandial hyperglycaemia plays an important role in the development of macrovascular complications in diabetes patients and accumulation of postprandial levels of a-dicarbonyls and AGEs could be one of the underlying metabolic processes.

In the present study we evaluated the role of postprandial glucose excursions (PPGE) on the accumulation of a-dicarbonyls and the major AGE (CML) in diabetic patients with $(n=9)$ or without $(n=9)$ macrovascular comorbidity as well as in healthy matched controls $(n=5)$.

Fasting blood glucose (FBG) levels and PPGE were significantly higher in diabetic patients than in healthy controls with no significantly difference between the two diabetic groups.

PPGE expressed as total area under curve ( $\left.T A \cup C_{\text {glucose }}\right)$ correlated with the TAUC of glyoxal and 3-deoxyglucsone $(r=0.54, P=0.009$ and $r=0.68, P<0.001$, respectively) thus suggesting an important relation between post-prandial hyperglycaemia and formation of a-dicarbonyls.

Fasting blood levels of 3-deoxyglucosone (3-DG) and $T_{A U C}$ 3-DG were significantly higher in diabetic subjects with macrovasular disease as in those without and in healthy age-matched controls. However, no correlation was found between post-prandial excursions of a-dicarbonyls and CML levels while CML levels correlated with NF-KB in all subjects.

In summary this study showed that PPGE were correlated with postprandial levels of a-dicarbonyls. However, these a-dicarbonyl levels did not correlate with CML plasma levels, a potential marker for overall AGE formation and linked to the molecular mechanisms underlying the development of diabetic complications.
\end{abstract}


Exogenous and endogenous AGEs | 103

\section{Introduction}

Hyperglycaemia is one of the major risk factors for the development of diabetic complications. In recent years it has been shown that non-enzymatic glycation of proteins plays an important role in the development of both microvascular and macrovascular diabetic complications ${ }^{[1 ; 2]}$. The process of non-enzymatic glycation involves the reaction of a carbonyl group of a reducing sugar and a free amino group of a protein resulting in the formation of a Schiff's base which reacts further to a more stable ketoamine, called an Amadori product. These Amadori products can undergo different rearrangements which result in the formation of so-called advanced glycation endproducts (AGEs). This reaction is known as the Maillard reaction and occurs also in food products prepared by heating ${ }^{[3]}$.

Next to this more classical pathway, AGEs can also be formed by the reaction of $\alpha$-dicarbonyl compounds such as methylglyoxal, glyoxal and 3deoxyglucosone with amino acids. These reactive intermediates are formed during glucose oxidation, lipid peroxidation and by oxidative stress in general and are formed readily in subjects suffering from diabetes mellitus ${ }^{[4]}$.

Several AGEs have been chemically characterized, like pentosidine, several hydroimidazolones and $\mathrm{N}^{\varepsilon}$-carboxymethyllysine $(\mathrm{CML})$, which are frequently used as markers for overall AGE accumulation.

Modification of proteins by AGEs alters their structure and function. In addition, the reaction of AGEs with their receptors results in the degradation of these AGEs or up-regulation of several intracellular processes (like activation of the Jak/Stat pathway, activation of p21ras and the mitogenactivated protein (MAP) kinase family) and cell activation (e.g. oxidative stress mediated activation of $\mathrm{NF}-\mathrm{KB}$ ). Activation of intracellular processes is thought to play a pivotal role in the development of diabetic complications and ageing in general.

Treatment of patients with diabetes mellitus aims to maintain blood glucose levels during the day close to normal. However, after a meal patients can experience hyperglycaemic excursions even when using pharmacological agents or insulin as an adjunct to diet. Several studies have suggested that an exaggerated postprandial increase of blood glucose may contribute to the development of cardiovascular complications ${ }^{[5]}$, although this is still a matter of intense debate ${ }^{[6-8]}$. Beisswenger et al ${ }^{[9]}$ showed that these so-called 
104 | Chapter 6

postprandial glucose excursions (PPGE) correlated well with serum levels of $\alpha$ dicarbonyls.

Based on the concept that PPGE, may be a major determinant in the development of cardiovascular disease by formation of AGEs, we hypothesized that in diabetic subjects with macrovascular disease higher levels of $\alpha$ dicarbonyls can be found in the fasting condition and after a meal than in subjects free of cardiovascular disease. These high a-dicarbonyl levels could increase AGE burden resulting in activation of NF-KB by induction of oxidative stress which could in part explain some of the variety in diabetic complications.

Therefore we assessed the relationship of PPGE with plasma levels of dicarbonyl compounds and a major AGE i.e. $\mathrm{N}^{E}$-carboyxymethyllysine (CML) in type 2 diabetic patients with and without severe macrovascular complications as well as in healthy matched controls. This was done both under normal daily living with the use of continuous blood glucose monitoring and after ingestion of a test meal. 


\section{Subjects and Methods}

\section{Subjects}

A total of 26 subjects participated in the study; 21 with type 2 diabetes and 5 non-diabetic healthy age-matched controls. Three type 2 diabetics did not complete the study for various reasons and were excluded from analysis. All type 2 diabetic patients previously had been diagnosed according to the 1997 WHO criteria and diagnosed 10 years or longer. All patients were on insulin therapy in order to control blood glucose levels. Nine of the patients were known to have macrovascular disease $(\mathrm{DM}+)$, and the other 9 had no clinically significant macrovascular disease (DM-). Macrovascular disease was defined as stable angina pectoris, previous myocardial infarction, previous transient ischemic attack or complaints of peripheral vascular disease. No patient had active or recently worsened complications or had undergone any surgery during the year before the study. All diabetic subjects were recruited from an existing pool of our department while the 5 age-matched controls (C) were recruited in the region. Written informed consent was obtained from all subjects. The study protocol was approved by the Medical Ethics Committee of Maastricht University.

\section{Methods}

\section{CGMS}

On day 1 , subjects were equipped with a MiniMed CGMS monitor (MMT7102, Minimed, Northridge, CA, USA). A glucose sensor (MMT7002, MiniMed, Northridge, CA, USA) was inserted subcutaneously in the abdomen and connected to the monitor ${ }^{[10]}$. The sensor was equilibrated for one hour and calibrated manually by introducing blood glucose values (at least 4 times a day), measured with a Euroflash blood glucose monitor (Lifescan, Milpitas, CA, USA). The CGMS unit registered glucose values every 5 minutes during the test period. Subjects carried the CGMS unit for 3 days and at day 4 they returned to the research centre where the sensor was removed and the data were downloaded into a personal computer. All participants were instructed to lead their normal daily life with respect to diet and physical activity, and to keep a food and activity diary during the time they carried the CGMS. Energy intake 
for every meal during the monitoring period was calculated from using the Dutch Food table. The daily activity level was divided in three levels, respectively normal, medium, high (normal $=$ comparable to a 15-30 minutes walk/cycling, medium = comparable to a 30-60 minutes walk/cycling and high = comparable to a more than 60 minutes walk/cycling).

PPGE was calculated as the incremental area under curve (IAUC) during 3 hours after each meal and the highest incremental value (IV) obtained during this 3-hour period. Total glucose burden during this 3-hour period was expressed as total area under curve (TAUC).

Breakfast with an AGE-rich meal

A meal test was performed on a separate day, at least one week after the CGMS study. After overnight fasting, subjects came to the research centre where baseline blood and urine was collected $(\mathrm{t}=0)$. Participants subsequently received a test meal (table 1), and blood samples were collected every hour for 8 hours. From this standard meal the nutritional profile was calculated (Dutch Food table 2002, The Netherlands Nutrition Centre Foundation, The Hague, The Netherlands) and CML levels of the test meal were analysed.

Table 1. Contents of test meal

\begin{tabular}{lllllll}
\hline Product & $\begin{array}{l}\text { Amount } \\
{[\mathrm{gram}]}\end{array}$ & $\begin{array}{l}\text { Energy } \\
{[\mathrm{KJ}]}\end{array}$ & $\begin{array}{l}\text { Fat } \\
\text { [gram] }\end{array}$ & $\begin{array}{l}\text { Carbohydrate } \\
\text { [gram] }\end{array}$ & $\begin{array}{l}\text { Protein } \\
{[\mathrm{gram}]}\end{array}$ & $\begin{array}{l}\text { CML } \\
{[\mathrm{mg}]}\end{array}$ \\
\hline Milk & 512 & 1046.5 & 8 & 25 & 18 & 1.93 \\
Rice crispies & 22 & 355.8 & 0 & 19 & 1 & 0.04 \\
Grilled cheese & 45 & 568.0 & 11 & 0 & 11 & 0.07 \\
Hot cocoa mix, & 22 & 355.8 & 0 & 19 & 1 & 0.04 \\
prepared with & & & & & & \\
water & & & & & 5 & 0.45 \\
Grilled sandwich & 56 & 627.9 & 1 & 29 & 7 & 0.10 \\
egg (fried) & 50 & 460.5 & 9 & 0 & 43 & 2.63 \\
\hline Total & & 3432.5 & 29 & 92 & &
\end{tabular}

Diabetic patients were instructed to take their usual insulin dose, and no adjustment in insulin intake was made for the difference between the patients' normal diet and the test meal. The participants received no further food until 8 hours after the test meal. During this period participants received 
$200 \mathrm{ml}$ of apple juice after every two hour to prevent any episodes of hypoglycaemia. Water was freely available.

Blood was collected every hour in heparin and EDTA tubes, centrifuged and stored at $-20^{\circ} \mathrm{C}$ until further analysis. For the measurement of 1,2 -dicarbonyls $0.5 \mathrm{ml}$ blood was mixed with $0.5 \mathrm{ml} 1.2 \mathrm{M}$ perchloric acid on ice, mixed well and stored at $-80^{\circ} \mathrm{C}$ until analysis.

\section{Plasma Analysis}

Standard laboratory analysis (glucose, cholesterol, triglyceride and total protein) was performed on a COBAS MIRA Plus analyser (Roche Diagnostics, Almere, The Netherlands). Tests were performed as described in the kit's instructions. Glucose (glucose HK $125 \mathrm{kit}, \mathrm{ABX}$, Montpellier, France) and total protein (total protein $250 \mathrm{kit}, \mathrm{ABX}$, Montpellier, France) were measured in duplicate. $\mathrm{HbA}_{1 \mathrm{c}}$ was measured with the use of HPLC (Bio-Rad Variant II, Hercules (A, USA). This method has a non-diabetic reference range of 4.2$6.5 \%$, and the assay is linear up to $17.9 \%$.

\section{a-dicarbonyls}

Methylglyoxal (MGO) and 3-deoxyglucosone (3-DG) were prepared freshly as described ${ }^{[11]}$. Glyoxal (GO) was obtained from Sigma Chemical Co. Gradient grade ethanol (LiChrosolv) was purchased from Merck (Darmstadt, Germany) and HPLC grade acetonitrile (Hipersolv) from BDH (Poole, UK). 1,2-Diamino4,5-dimethoxybenzene (DDB) was obtained from Molecular Probes (Eugene, OR, USA).

3-DG, GO and MGO were determined by reversed-phase HPLC after derivatization to their dimethoxyquinoxaline adducts.

The acidified samples were centrifuged $(10 \mathrm{~min}, 3000 \mathrm{xg})$ and an aliquot of supernatant was adjusted to $\mathrm{pH} 7.0$ by adding 0.5 volumes of $\mathrm{K}_{3} \mathrm{PO}_{4}(1.2 \mathrm{M})$. After centrifugation ( $10 \mathrm{~min}, 3000 \mathrm{xg}$ ), $50 \mu \mathrm{l}$ of the samples were mixed with an equal amount of potassium phosphate buffer $(0.2 \mathrm{M}, \mathrm{pH} 7.0), 75 \mu$ lethanol and $20 \mu \mathrm{l}$ of freshly prepared derivatization reagent ( $20 \mathrm{mM}$ 1,2-diamino-4,5dimethoxybenzene dissolved in $10 \mathrm{mM} \mathrm{HCl}$ ). The mixtures were incubated at ambient temperature for at least 4 hours, followed by HPLC analysis. The HPLC equipment consisted of an Alliance model 2690 Separations Module and a model 474 fluorescence detector from Waters (Milford, MA, USA). Millennium 3.05 software was used for data acquisition and processing. 3-DG 
was analysed on two Waters Symmetry columns $(5 \mu \mathrm{m}, 3.9 \times 150 \mathrm{~mm})$ protected by a guard column containing the same stationary phase with gradient elution. Mobile phase A was a mixture of $10 \mathrm{mM}$ potassium phosphate buffer $(\mathrm{pH} 3.5)$ and acetonitrile $(90 / 10, \mathrm{v} / \mathrm{v})$ and mobile phase $\mathrm{B}$ consisted of a mixture of acetonitrile and water $(50 / 50, v / v)$. Samples $(10 \mu \mathrm{l})$ were injected and separation was performed with a linear gradient from $0-15 \%$ mobile phase B over 25 min and after a wash step for 5 minutes with $100 \% \mathrm{~B}$, the gradient was returned to initial conditions and the column was equilibrated for $5 \mathrm{~min}$ before injection of the next sample. The flow rate was $0.9 \mathrm{ml} / \mathrm{min}$ and fluorescence detection was performed with excitation and emission wavelengths of 352 and $385 \mathrm{~nm}$, respectively. GO and MGO were analysed using an isocratic elution with $20 \%$ mobile phase $B$ on a single Waters Symmetry column $(5 \mu \mathrm{m}, 3.9 \times 150 \mathrm{~mm})$. Quantitation was based on peak area measurement using external standardization. Calibration curves of peak area versus concentration were linear up to $10 \mu \mathrm{mol} / \mathrm{L}$ (correlation coefficients $>0.9999$ ) for all components. The lower limit of determination at a signal/noise ratio of 10 was approximately $0.05 \mu \mathrm{mol} / \mathrm{l}$. For all components, the within-day precision and between-day precision expressed as coefficient of variation were better than $4 \%$ and $9 \%$, respectively,

\section{$C M L$}

CML was measured using a newly developed method ${ }^{[12]}$. A $200 \mu \mathrm{l}$ aliquot of plasma was mixed with $1000 \mu \mathrm{l}$ of $10 \%$ aqueous trichloroacetic acid in a $10 \mathrm{ml}$ glass hydrolysis tube (Organon Teknika, Boxtel, The Netherlands) and left to stand for 10 minutes. The sample was centrifuged at $3300 \times$ for 10 minutes and the supernatant was discarded. The remaining protein pellet was dissolved in $1000 \mu$ of $6 \mathrm{M}$ hydrochloric acid, thoroughly purged with nitrogen and hydrolysed at $110^{\circ} \mathrm{C}$ for 20 hours. After cooling the sample to ambient temperature, $1000 \mu \mathrm{l}$ of $5 \mathrm{M}$ sodium hydroxide was added and the mixture was centrifuged at $3300 \times$ for 10 minutes. A $20-\mu l$ aliquot of the supernatant was added to $180 \mu \mathrm{l}$ of $0.4 \mathrm{M}$ sodium borate buffer ( $\mathrm{pH} 10.4$ ). Subsequently, $10 \mu \mathrm{l}$ of water or an aqueous $5.00 \mu \mathrm{g} / \mathrm{ml} \mathrm{CML}$ solution (for standard addition, see below) were added. After mixing, $20 \mu \mathrm{l}$ of this mixture was added to $180 \mu \mathrm{l}$ of $0.4 \mathrm{M}$ sodium borate buffer $(\mathrm{pH} 10.4)$ in a polypropylene injection vial and derivatization was performed by adding $10 \mu \mathrm{l}$ of a $1 \mathrm{mg} / \mathrm{ml} 9$. fluorenylmethoxycarbonyl (FMOC) solution in acetonitrile. After vortexmixing, the vial was transferred to the autosampler and an aliquot of $40 \mu \mathrm{l}$ 
was injected into the chromatographic system. The chromatographic system consisted of a Waters (Milford, MA, USA) Separations Module Alliance 2690 for injection and pumping of the mobile phase, a Zorbax Stablebond (Agilent, Palo Alto, CA, USA) C8 column $(150 \times 4.6 \mathrm{~mm}, 3.5 \mu \mathrm{m})$, conditioned at $45^{\circ} \mathrm{C}$ in a Julabo (Seelbach, Germany) water bath, and a Jasco (Tokyo, Japan) FP 920 fluorescence detector, set at an excitation wavelength of $260 \mathrm{~nm}$ and an emission wavelength of $310 \mathrm{~nm}$. The mobile phase, a mixture of $25 \mathrm{mM}$ potassium phosphate buffer ( $\mathrm{pH} \mathrm{2.0)}$ as eluent $A$ and acetonitrile as eluent $B$, was pumped at a flow-rate of $1.3 \mathrm{ml} / \mathrm{min}$. Elution of the analyte was achieved using $80 \% A$ and $20 \% B$ for $17.5 \mathrm{~min}$, after which a step gradient was applied with $15 \% A$ and $85 \% \mathrm{~B}$ until $22.5 \mathrm{~min}$; finally the column was re-equilibrated at $80 \%$ A / 20\% B until 30 min.

In order to quantitatively determine the $\mathrm{CML}$ concentration in a sample, the method of standard addition was applied. To this end, two aliquots of each individual protein hydrolysate were analysed, one without and one with a known amount $(50.0 \mathrm{ng})$ of $\mathrm{CML}$ added, and the CML peak heights were determined. As the added amount of CML corresponds to a concentration of $25.0 \mu \mathrm{g} / \mathrm{ml}$ plasma, the original $\mathrm{CML}$ concentration (in $\mu \mathrm{g} / \mathrm{ml}$ ) was subsequently calculated by multiplying 25 with the ratio of the original peak height over the difference between the two peak heights.

This method is capable of determining CML with good accuracy and precision (below 10\%) with a limit of detection of $0.2 \mu \mathrm{g} / \mathrm{ml}$.

CML data were then normalised against plasma protein concentration, resulting in the final concentration of $\mathrm{ng} \mathrm{CML} / \mathrm{mg}$ plasma protein.

CML levels in fluid food products were assessed in a similar fashion. For solid food, $200 \mathrm{mg}$ of food product was dissolved in $1 \mathrm{~mL}$ of $6 \mathrm{M}$ hydrochloric acid and processed similar to plasma proteins. CML levels were expressed as $\mathrm{mg}$ $\mathrm{CML} / \mathrm{mg}$ of food product.

\section{Markers of oxidative stress}

To determine oxidative stress and anti-oxidant status in patients, malondialdehyde, total equivalent antioxidant capacity (TEAC) and uric acid (endproduct of ATP degradation by xanthine oxidase) were determined in plasma. $150 \mu \mathrm{l}$ of plasma was deproteinized with $10 \%$ trichloric acid, centrifuged and stored at $-70^{\circ} \mathrm{C}$ until analysis for the TEAC assay, as described elsewhere ${ }^{[13]}$. Remaining plasma was centrifuged for 10 minutes at $10000 \mathrm{rpm}$ in an Eppendorf centrifuge (Eppendorf AG, Hamburg, Germany) and the 
supernatant was stored at $-70^{\circ} \mathrm{C}$ until analysis of uric acid, which was enzymatically analyzed using a colorimetric assay (Sigma Chemical Co., St. Louis, MO, USA). Rest plasma was stored at $-20^{\circ} \mathrm{C}$ until further analysis.

The determination of malondialdehyde (MDA) is based on the formation of a colored adduct of MDA with 2-thiobarbituric acid (TBA) ${ }^{[14]}$. Briefly, $100 \mu \mathrm{l}$ sample was added to $1 \mathrm{ml}$ of reagent (containing $0.12 \mathrm{~mol} / \mathrm{l}$ TBA, $0.32 \mathrm{~mol} / \mathrm{l}$ o-phoshoric acid, $0.68 \mathrm{mmol} / \mathrm{/}$ butylated hyrdoxytoluene (BHT) and $0.01 \%$ $(\mathrm{m} / \mathrm{v})$ EDTA). The mixture was incubated for 1 hour at $100^{\circ} \mathrm{C}$ in a water bath. MDA-products were extracted after cooling with $500 \mu \mathrm{l}$ butanol and $30 \mu \mathrm{l}$ of the butanol layer was injected on a HPLC system (Agilent, Palo Alto, CA, USA) equipped with a fluorescence detector $\left(\lambda_{\mathrm{ex}}=532 \mathrm{~nm}, \lambda_{\mathrm{em}}=553 \mathrm{~nm}\right)$ and a Nucleosil $\mathrm{C} 18$ column $(150 \times 3.2 \mathrm{~mm}$, particle size $5 \mu \mathrm{m}$, Supelco Inc. PA, USA). Samples were eluted with $65 \%(\mathrm{v} / \mathrm{v})$ phosphate buffer $(25 \mathrm{mM}, \mathrm{pH} 4.8)$ and $35 \%(\mathrm{~V} / \mathrm{v})$ methanol. A calibration curve was constructed using malonaldehyde bis(diethylacetal) as calibrator.

Nuclear factor $k B(N F-k B)$

NF-KB levels were measured in peripheral blood mononuclear cells (PBMC's) that were isolated with Lymphoprep (Axis-shield PoC As, Norway). Pellets of isolated PBMC's were stored at $-70{ }^{\circ} \mathrm{C}$ until preparation of the nuclear extracts. Measurement of the activated p50 subunit of the NF-kappaB dimer was performed with the Trans-AM NF-KB kit (Active Motif, Belgium) for the activated p50 subunit of the NF-KB dimer according to the kit's protocol. Total protein in nuclear extracts was measured using the Bio-rad protein assay (Bio-rad Laboratories, Veenendaal, The Netherlands). Results of the NF-kB assay were expressed as $\mu \mathrm{g}$ Hela eq/ $\mu \mathrm{g}$ protein.

\section{Statistics}

All results are expressed as mean \pm S.E.M., unless otherwise noted. Data were analysed using ANOVA for repeated measurements and paired t-test using SPSS 10.0 (SPSS, Chicago, IL, USA). Differences from baseline were analyzed by ANOVA with Dunnet post-hoc analysis with $P<0.05$ two-tailed, or by paired $t$ test analysis with $\mathrm{P}<0.05$ two-tailed. Correlations were assessed using the Pearson correlation coefficient, and were regarded as statistically significant with $\mathrm{P}<0.05$. 


\section{Results}

\section{CGMS}

Two subjects did not complete the study due to severe hypoglycaemia during CGMS monitoring and non-compliance to the calibration protocol. One subject had to be excluded from the analysis due to technical failure of the CGMSsensor. In table 2 the characteristics of the remaining participants are given.

Table 2. Characteristics of the participants.

\begin{tabular}{llll}
\hline Groups & DM+ & DM- & C \\
\hline Gender [M/F] & $4 / 5$ & $5 / 4$ & $3 / 2$ \\
Age [yrs] & $67 \pm 3$ & $63 \pm 3$ & $65 \pm 0.2$ \\
$\mathrm{HbA}_{1 \mathrm{c}}[\%]$ & $9.0 \pm 0.4 \#$ & $7.8 \pm 0.4 \#$ & $5.3 \pm 0.2$ \\
BMl [kg/m $\left./ \mathrm{m}^{2}\right]$ & $32.3 \pm 1.6$ & $30.9 \pm 1.0$ & $28.1 \pm 0.7$ \\
Diabetes duration [yrs] & $21 \pm 3 \$$ & $14 \pm 2$ & na \\
Daily insulin dose [U] & $32 \pm 6$ & $27 \pm 6$ & $\mathrm{na}$ \\
\hline
\end{tabular}

na: non-applicable; $D M+$ : type 2 diabetes with macro-vascular disease; DM-: type 2 diabetes free of clinical macro-vascular disease; $C$ : age-matched control subjects

\# $P<0.05$ vs controls; $\$ P<0.05$ vs group $B$

Figure 1 shows the mean of the blood glucose readings for the three subgroups during the three days of the CGMS study. The mean IAUC, IV and TAUC were calculated as the average from the three subsequent days. 


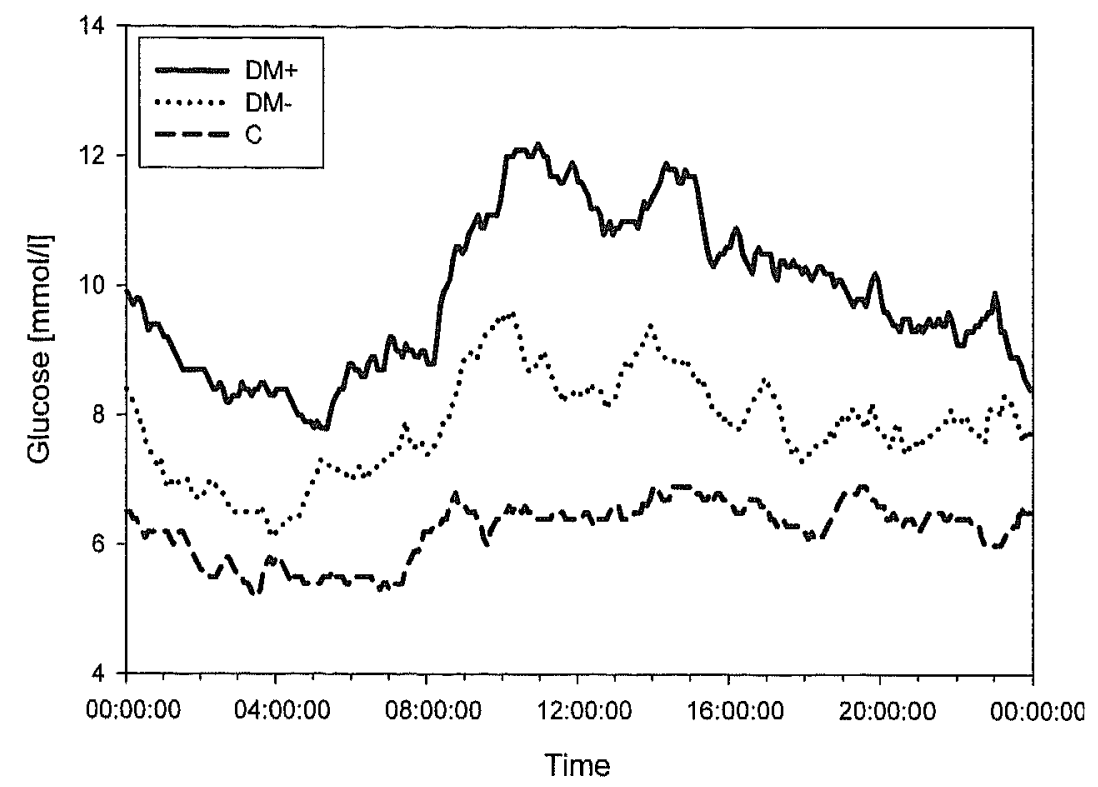

Figure 1. Mean of the blood glucose readings for the three subgroups during the three days of the CGMS measurement.

$\mathrm{DM}+$ : type 2 diabetes with macro-vascular disease; $\mathrm{DM}$-: type 2 diabetes free of clinical macrovascular disease; $C$ : age-matched control subjects

No difference was found between the type 2 diabetic patients with or without macrovascular disease (figure 2) this in spite of the longer diabetes duration ( $21 \pm 3$ yrs vs. $14 \pm 2 \mathrm{yrs}$ ) and worse metabolic regulation $\left(\mathrm{HbA}_{1 c}, 9.0 \pm 0.4 \%\right.$ vs. $7.8 \pm 0.4 \%$, non-significant) of diabetic participants with macrovascular disease. No significant difference was found in carbohydrate intake and activity levels. As expected, the diabetic subjects ( $D M+$ and $D M-$ ) showed significantly higher PPGE than the control subjects (diabetes vs. control; IAUC $238 \pm 35$ vs. $90 \pm 30$; IV $3.3 \pm 0.4$ vs. $1.3 \pm 0.4 \mathrm{mmol} / \mathrm{l}$; TAUC $1816 \pm 128$ vs. $1182 \pm 62$, all $P<0.05)$ 
Figure 2. Incremental area under the curve (IAUC), incremental value (IV) and total area under the curve (TAUC) of the blood glucose measurements in the all subject Data were obtained from continuous blood glucose recordings over a total period of 3 days, and averaged for each patient individually. Results are given as mean \pm S.E.M.

DM+: type 2 diabetes with macrovascular disease

DM-: type 2 diabetes free of clinical macro-vascular disease

$C$ : age-matched control subjects

* Diabetic vs, control subjects, $P<0.05$.
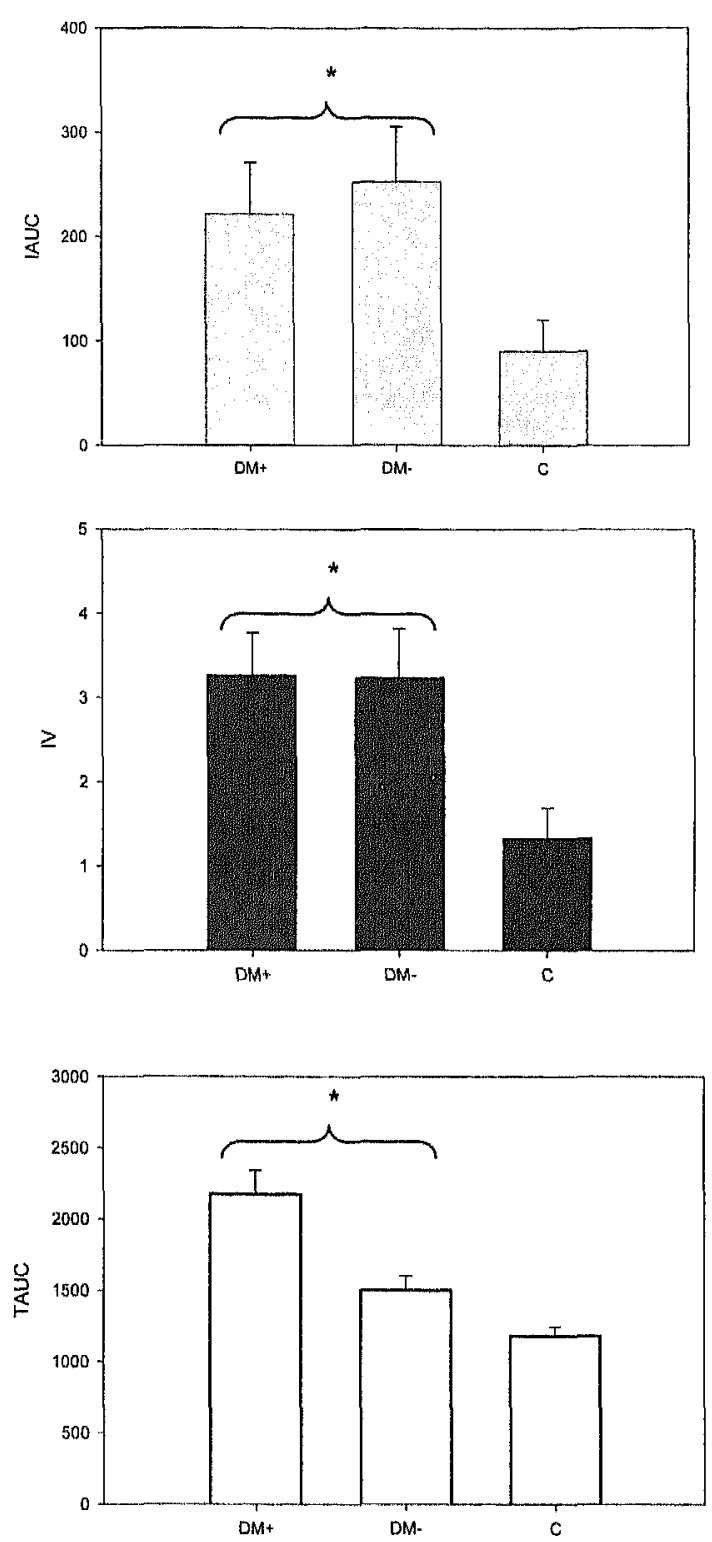


\section{Test meal}

Fasting plasma glucose levels in control subjects $(5.8 \pm 0.3 \mathrm{mmol} / \mathrm{l})$ were significantly different from diabetic subjects till 3 hours after the test meal, while the fasting plasma glucose levels between the two groups of diabetic patients $(D M+11.7 \pm 1.2 \mathrm{mmol} / \mathrm{l}$ and $D M-9.2 \pm 0.9 \mathrm{mmol} / \mathrm{l})$ were not different. Plasma glucose levels and relative glucose levels (corrected for fasting plasma glucose) increased to a similar extent in both groups of diabetic patients (figure 3 ) which were different from control subjects.

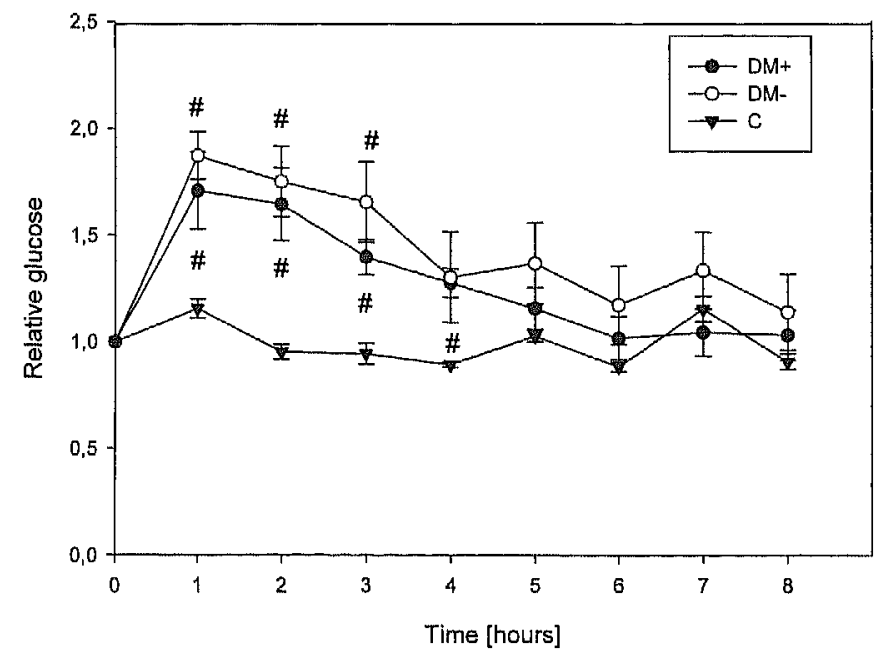

Figure 3, Relative glucose levels after the test meal. Of the diabetic subjects ( $D M+$ and $D M-) \#$ $\mathrm{P}<0.05$ vs. control subjects (C)

DM+: type 2 diabetes with macro-vascular disease; DM-: type 2 diabetes free of clinical macrovascular disease; $\mathrm{C}$; age-matched control subjects

IAUC, IV and TAUC calculated from the postprandial glucose levels in a similar fashion to the CGMS data showed no significant difference between the two groups of diabetic subjects. As expected PPGE of control subjects were significantly lower than of the diabetic subjects (respectively diabetes vs. control; IAUC $970 \pm 104$ vs. $56 \pm 16$; IV $7.9 \pm 0.7$ vs. $0.9 \pm 0.3 \mathrm{mmol} / /$ and TAUC $2853 \pm 145$ vs. $1074 \pm 57$, all $P<0.05$ ).

Although the blood glucose excursions during the day -as measured with the continuous monitoring- were markedly smaller than the blood glucose excursions after the AGE-rich meal, they appeared to correlate well. The 
measures IAUC, IV and TAUC after the test meal (pooled data of all subjects) showed a positive correlation with these measures during the CGMS monitoring $(r=0.56, P=0.01 ; r=0.55, P=0.01$ and $r=0.67, P=0.001$, respectively).

\section{a-dicarbonyls and CML}

In the diabetic subjects plasma levels of 3-deoxyglucosone (3-DG) and glyoxal but not methylglyoxal were elevated compared to control subjects at all time points (table 3 ).

Table 3. a-dicarbonyl and CML levels after the test meal.

\begin{tabular}{lllll}
\hline & Time [hours] & DM+ & DM- & $C$ \\
\hline 3-Deoxyglucosone & 0 & $155 \pm 10 \#, \$$ & $120 \pm 7$ & $99 \pm 8$ \\
[nmol/I] & 1 & $149 \pm 9 \$$ & $129 \pm 10$ & $99 \pm 5$ \\
& 2 & $157 \pm 9 \#$ & $124 \pm 7 \$$ & $98 \pm 3^{*}$ \\
& 3 & $172 \pm 14 \$$ & $142 \pm 8$ & $117 \pm 5$ \\
\hline Glyoxal & 0 & $238 \pm 22$ & $242 \pm 12 \$$ & $180 \pm 17$ \\
[nmol/l] & 1 & $251 \pm 19$ & $237 \pm 12$ & $172 \pm 26$ \\
& 2 & $240 \pm 19$ & $250 \pm 16$ & $160 \pm 35$ \\
& 3 & $244 \pm 17$ & $257 \pm 17$ & $166 \pm 16^{*}$ \\
\hline Methylglyoxal & 0 & $540 \pm 62$ & $542 \pm 26$ & $536 \pm 71$ \\
[nmol/l] & 1 & $531 \pm 60$ & $501 \pm 38$ & $618 \pm 110$ \\
& 2 & $518 \pm 54$ & $494 \pm 45$ & $531 \pm 63$ \\
\hline CML & 3 & $514 \pm 54$ & $489 \pm 41$ & $553 \pm 86$ \\
[ng/mg protein] & 4 & $96 \pm 35$ & $64 \pm 6$ & $58 \pm 14$ \\
& 8 & $60 \pm 13$ & $57 \pm 8$ & $76 \pm 6$ \\
\hline
\end{tabular}

Results expressed as mean \pm S.E.M.

\# $P<0.05$ vs. $D M-; \$ P<0.05$ vs. $C ;{ }^{*} P<0.05$ vs. $D M+/$.

$D M+$ : type 2 diabetes with macro-vascular disease; DM-: type 2 diabetes free of clinical macrovascular disease; $\mathrm{C}$ : age-matched control subjects

At baseline, the concentration of 3-DG was significantly higher $(P<0.05)$ in patients with macrovascular disease $(155 \pm 10 \mathrm{nmol} / \mathrm{l})$, than in diabetics without macrovascular disease $(120 \pm 7 \mathrm{nmol} / \mathrm{l})$ and control subjects $(99 \pm 8$ $\mathrm{nmol} / \mathrm{l})$. A comparable increase in 3-DG levels in time was observed in all three groups. This increase was a significant increase in diabetic subjects with 
macrovascular disease ( $3 \mathrm{~h}$ value vs. baseline; $172 \pm 14$ vs. $155 \pm 10, \mathrm{P}<0.05$ ) and control subjects $(117 \pm 5$ vs. $99 \pm 8, P<0.05)$.

TAUC of glyoxal showed a significant difference between controls and diabetic subjects for glyoxal $(P<0.05$, figure 4$)$ and TAUC of 3-deoxyglucosone showed a significant difference between the three groups $(P<0.05$, figure 4$)$.

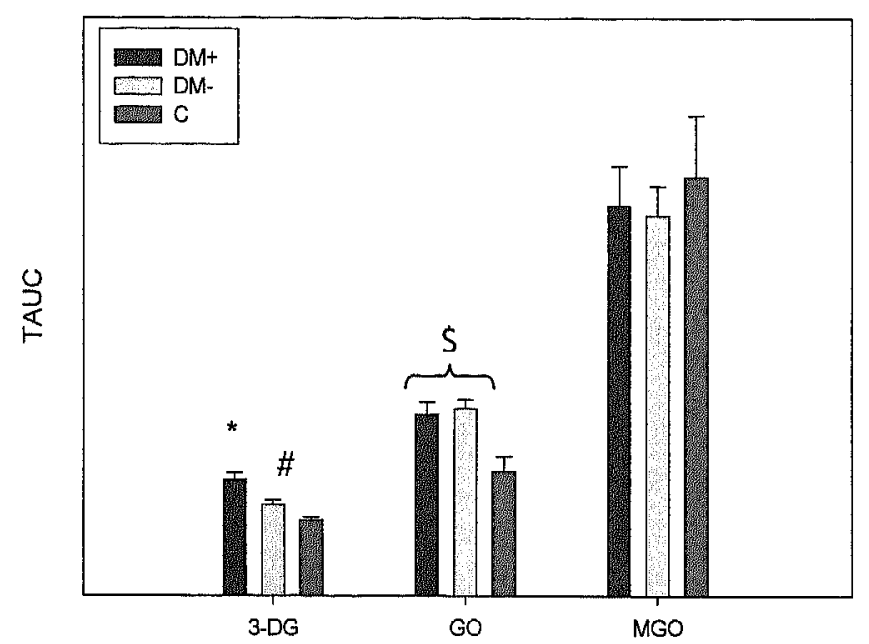

Figure 4. Total area under the curve (TAUC) of a-dicarbonyls calculated after the test meal in similar fashion to TAUC calculated from the test meal.

" DM+ vs. DM- and C, $P<0.05$; \# DM- vs. C, $P<0.05 ; \$$ diabetic vs. $C, P<0.05$

This figure is illustrative for the difference between groups, no quantitative data can be obtained from this graph.

DM+: type 2 diabetes with macro-vascular disease; DM-: type 2 diabetes free of clinical macrovascular disease; $C$ : age-matched control subjects

No significant differences were found for IAUC and IV levels for the three adicarbonyls.

PPGE (after test meal) were highly predictive for postprandial glyoxal and 3DG increase (IAUC glucose Vs IUAC glyoxal $: r=0.59, P=0.007)$, TAUC glucose vs TAUC $_{\text {glyoxal: }}: r=0.54, p=0.009 ;$ TAUC $_{\text {glucose }}$ Vs TAUC $C_{3-\mathrm{DG}}: r=0.68, P=0.000$ ) 
The CML concentration over the 8-hour period did not change significantly in the three groups.

No difference in CML concentration was found between the three groups (table 3).

\section{Markers of oxidative stress}

Indicators of oxidative stress (MDA and uric acid levels) and antioxidant capacity (TEAC) did not show differences between the three groups (table 4).

Table 4. Oxidative stress, anti-oxidant status parameters (at $t=0,2,4$ and 6 hours) after the test meal.

\begin{tabular}{lllll}
\hline & Time [hours] & DM+ & DM- & $C$ \\
\hline MDA & 0 & $3.8 \pm 0.1$ & $4.0 \pm 0.2$ & $4.1 \pm 0.1$ \\
{$[\mu M]$} & 2 & $4.0 \pm 0.3$ & $4.2 \pm 0.1$ & $4.4 \pm 0.1$ \\
& 4 & $4.0 \pm 0.3$ & $4.0 \pm 0.3$ & $4.2 \pm 0.1$ \\
& 6 & $3.9 \pm 0.3$ & $4.2 \pm 0.1$ & $4.2 \pm 0.1$ \\
\hline TEAC & 0 & $639.4 \pm 6.0$ & $632.0 \pm 11.7$ & $643.0 \pm 14.9$ \\
{$[\mu M$ Trolox] } & 2 & $637.9 \pm 3.9$ & $635.0 \pm 1.8$ & $647.0 \pm 6.3$ \\
& 4 & $637.8 \pm 6.5$ & $636.1 \pm 13.6$ & $634.3 \pm 18.3$ \\
& 6 & $627.2 \pm 5.9$ & $628.4 \pm 12.8$ & $618.0 \pm 7.5$ \\
\hline Uric acid & 0 & $273.5 \pm 17.2$ & $261.4 \pm 34.5$ & $332.5 \pm 26.5$ \\
{$[\mu M]$} & 2 & $279.4 \pm 15.4$ & $246.4 \pm 33.2$ & $281.1 \pm 33.4$ \\
& 4 & $278.0 \pm 13.5$ & $245.4 \pm 36.0$ & $275.0 \pm 36.2$ \\
& 6 & $269.3 \pm 18.0$ & $253.1 \pm 33.7$ & $264.9 \pm 35.0$ \\
\hline
\end{tabular}

Data expressed as mean of all subjects

MDA; Malondialdehyde, TEAC; total equivalent anti-oxidant capacity, CML; $\mathrm{N}^{\varepsilon}$ carboxymethyllysine

DM+: type 2 diabetes with macro-vascular disease; DM-: type 2 diabetes free of clinical macrovascular disease; $\mathrm{C}$ : age-matched control subjects

MDA levels were significantly increased at $t=2$ hours while TEAC and uric acid levels were significantly decreased at $t=6$ hours in all groups (pooled data, $P<0.05)$.

No difference in NF-kB activation in lymphoctes was found between the three different groups. Furthermore, no change in the activation of NF-kB was found over time (pooled data of all groups; $t=0,3.65 \pm 0.28 ; t=3,4.14 \pm 0.45$ and $t=6,3.80 \pm 0.34 \mu \mathrm{g}$ Hela eq/ $\mu \mathrm{g}$ protein). 
118 | Chapter 6

A positive correlation was found between $\mathrm{CML}$ and $\mathrm{NF}-\mathrm{KB}$ at $\mathrm{t}=0$ and $\mathrm{t}=6$ hours (respectively, $r=0.53$ and $r=0.45, P<0.05$ ) in all subjects. 


\section{Discussion}

Patients suffering from diabetes mellitus experience several episodes of hyperglycaemia during the day, even when they are under apparent good metabolic control by pharmacological or diet therapy. Episodes of hyperglycaemia usually occur after a meal and may have considerable metabolic and vascular effects. Several studies ${ }^{[7 ; 8 ; 15]}$ showed that these postprandial glucose excursions (PPGE) are important risks factors for the development of cardiovascular disease (CVD). There is still much debate whether these PPGE are independent risks factors or just markers for underlying abnormalities ${ }^{[6]}$. We hypothesised that occurrence and severity of these PPGE could contribute to the development of cardiovascular complications through formation of a-dicarbonyls and their resulting AGEs.

We found a significant difference in postprandial excursions and fasting blood glucose levels of 3-deoxyglucosone but not of glucose and other a-dicarbonyls, between type 2 diabetic patients with macrovascular disease and those without.

We used CGMS to profile blood glucose levels during three days and the PPGE showed -as expected- a considerable difference between diabetic and control subjects in handling a glucose load and overall glucose burden during the 3hour period after the meal, but not between diabetic subjects with and without macrovascular complications.

PPGE correlated significantly with the data from the test-meal indicating that data on the underlying molecular mechanisms obtained from the test meal can be extrapolated to the CGMS data.

Postprandial excursions after the test meal were considerably higher as compared with PPGE during CGMS monitoring due to the fact that insulin supplement during the test meal was not sufficient to cope with the higher caloric intake during this meal.

Beisswenger et al [9] showed that PPGEs correlated with postprandial excursion of methylglyoxal in type 1 diabetic patients. We found a positive correlation between the IAUC of glucose and glyoxal and between the TAUC of glucose, 3-deoxyglucosone and glyoxal in all participants but found no correlation between PPGEs and postprandial excursion of methylglyoxal. This could be explained by the different detoxification pathways for methylglyoxal (or a-dicarbonyls in general). These detoxification pathways catalysed by aldose reductase, glyoxalase, betaine aldhyde dehydrogenase or 2-oxaldehyde 
dehydrogenase show different affinities for the different $\alpha$-dicarbonyls and variations in these enzymes in part explain the variations in a-dicarbonyl profile between the various diabetic patients ${ }^{[16]}$.

As a-dicarbonyls are intermediates in AGE formation, postprandial excursions of a-dicarbonyls could increase AGE formation and accumulation. However we did not find a correlation between $C M L$ and the postprandial excursion of its precursor glyoxal.

One suggested underlying molecular mechanism responsible for the variety in diabetic complications is the interaction of CML with RAGE (receptor for AGEs). We did find a relationship between CML and NF-KB levels which could indicate the interaction of CML with RAGE resulting in an increase in intracellular oxidative stress and activation of $\mathrm{NF}-\mathrm{KB}$, promoting the upregulation of NF-KB controlled genes and consequently enhance production of nitric oxide and promoting inflammatory mediators ${ }^{[9]}$. However $\mathrm{CML}$ levels did not differ between subjects with or without macrovascular disease and could in this respect not explain the variety in complications in our subjects. Next to endogenous formation, AGEs can also be absorbed originating from food as shown by Koschinsky et al ${ }^{[17]}$ and could induce several pathological processes known to AGEs like an increase in inflammatory mediators ${ }^{[18]}$. However in our study we did not found an increase in plasma CML levels after ingestion of the test meal containing CML. Probably this is related to the fact that $90 \%$ of all CML will be excreted in the urine ${ }^{[17 ; 19]}$, with $10 \%$ remaining to interact with proteins. This $10 \%$ remaining in the circulation to interact with proteins is too low or the process of interaction is too slow to be detected in this study.

Postprandial glucose excursions play an important role in the development of cardiovascular complications in type 2 diabetic subjects whether as independent risk factor or as marker for underlying metabolic processes. We tried to identify the relation between PPGE and AGE formation processes but found little evidence to support this hypothesis. To clarify the relation of PPGE and these underlying metabolic abnormalities it is necessary to conduct further research together with analysis of a wider spectrum of AGEs and their precursors. 


\section{References}

1. Jerums $G$, Panagiotopoulos $S$, Forbes J, Osicka $T$, Cooper M. Evolving concepts in advanced glycation, diabetic nephropathy, and diabetic vascular disease. Arch.Biochem. Biophys. 2003;419:55-62.

2. Singh R, Barden A, Mori T, Beilin L. Advanced glycation end-products: a review. Diabetologia 2001;44:129-46.

3. Kato $\mathrm{H}$, van Chuyen $\mathrm{N}$, Shinoda $T$, Sekiya F, Hayase F. Metabolism of 3-deoxyglucosone, an intermediate compound in the Maillard reaction, administered orally or intravenously to rats. Biochim. Biophys. Acta 1990;1035:71-6.

4. Odani $H$, Shinzato $T$, Matsumoto $Y$, Usami J, Maeda K. Increase in three alpha,betadicarbonyl compound levels in human uremic plasma: specific in vivo determination of intermediates in advanced Maillard reaction. Biochem.Biophys. Res.Commun. 1999;256:8993.

5. Siperstein MD. Diabetic microangiopathy, genetics, environment, and treatment. Am.J.Med. 1988;85:119-30.

6. Heine RJ, Dekker JM. Beyond postprandial hyperglycaemia: metabolic factors associated with cardiovascular disease. Diabetologia 2002;45:461-75.

7. Heine RJ, Balkau B, Ceriello A, Del Prato S, Horton ES, Taskinen MR. What does postprandial hyperglycaemia mean? Diabet.Med. 2004;21:208-13.

8. Ceriello $A$, Hanefeld $M$, Leiter $L$ et al. Postprandial glucose regulation and diabetic complications. Arch. Intern.Med. 2004;164:2090-5.

9. Beisswenger PJ, Howell SK, O'Dell RM, Wood ME, Touchette AD, Szwergold BS. alphaDicarbonyls increase in the postprandial period and reflect the degree of hyperglycemia. Diabetes Care 2001;24:726-32.

10. Kessler LF, Passemard RF, Oberholzer JF et al. Reduction of blood glucose variability in type 1 diabetic patients treated by pancreatic islet transplantation: interest of continuous glucose monitoring. Diabetes Care 2003.

11. Schalkwijk CG, Posthuma $N$, ten Brink HJ, ter Wee PM, Teerlink $T$. Induction of 1,2dicarbonyl compounds, intermediates in the formation of advanced glycation endproducts, during heat-sterilization of glucose-based peritoneal dialysis fluids. Perit.Dial.Int. 1999;19:325-33.

12. Merbel, N. C., Mentink, C. J. A. L., Hendriks, G., and Wolffenbuttel, B. H. R. Liquid chromatographic method for the quantitative determination of Ne-carboxymethyllysine in human plasma proteins. Journal of Chromatography B: Biomedical Applications 808, 163168. 2004. 
$122 \mid$ Chapter 6

13. Van den Berg, R., Haenen, G. R. M. M., Van den Berg, H., and Bast, A. Applicability of an improved Trolox equivalent antioxidant capacity (TEAC) assay for evaluation of antioxidant capacity measurements of mixtures. Food Chemistry 66, 511-517. 1997.

14. Volpi NF, Tarugi P. Improvement in the high-performance liquid chromatography malondialdehyde level determination in normal human plasma. J.Chromatogr.B Biomed.Appl. 1998;713:433-7.

15. Boutati El, Raptis SA. Postprandial hyperglycaemia in type 2 diabetes: pathophysiological aspects, teleological notions and flags for clinical practice. Diabetes Metab Res.Rev. 2004;20 Suppl 2:513-\$23.

16. Vander Jagt DL, Hunsaker LA. Methylglyoxal metabolism and diabetic complications: roles of aldose reductase, glyoxalase-1, betaine aldehyde dehydrogenase and 2-oxoaldehyde dehydrogenase, Chem.Biol.Interact. 2003;143-144:341-51.:341-51.

17. Koschinsky $\mathrm{T}, \mathrm{He} \quad \mathrm{C}-\mathrm{J}$, Mitsuhashi $\mathrm{T}$ et al. Orally absorbed reactive glycation products (glycotoxins): An environmental risk factor in diabetic nephorpahty. Proc.Natl.Acad.Sci. 1997;94:6474-9.

18. Vlassara H, Cai W, Crandall J et al. Inflammatory mediators are induced by dietary glycotoxins, a major risk factor for diabetic angiopathy. Proc.Natl.Acad.Sci.U.S.A 2002;99:15596-601

19. Bergmann $R$, Helling $R$, Heichert $C$ et al. Radio fluorination and positron emission tomography (PET) as a new approach to study the in vivo distribution and elimination of the advanced glycation endproducts $N$ epsilon-carboxymethyllysine (CML) and $N$ epsiloncarboxyethyllysine (CEL). Nahrung 2001;45:182-8. 
General Discussion 


\section{General Discussion}

The aim of the research described in this thesis was to investigate specific (bio)chemical aspects of AGE formation in the development of late complications in patients with diabetes mellitus. One of the important aspects was how specific AGEs, like CML, change with short-term changes in glycaemia, such as in the postprandial state and after a meal containing AGEs, and with long-term changes in metabolic control. The latter was assessed in subjects with diabetes who went from poor to good metabolic control due to the institution of insulin therapy.

AGEs are a very heterogeneous group of compounds ${ }^{[1]}$, which poses a problem on how to choose or construct a reliable and reproducible assay to measure these compounds.

Several chemical structures and entities can be discriminated: some AGEs form cross-links, while others do not; some AGEs show fluorescence and can thereby be assessed through physical analytical methods. Some intermediate reactive products which are formed during AGE formation are also called AGEs by various authors and may interact in certain assays. All of these AGEs show different biochemical and (patho)physiological properties depending on their chemical structure, their interaction with proteins and other chemical structures and induction of the different molecular and signalling pathways.

As mentioned, some AGEs have the potential to crosslink long-living macromolecules like collagen, and drugs have been developed which are supposed to specifically 'break' these crosslinks ${ }^{[2]}$. This formed the basis for the first and novel approach to produce a reliable measurement

With this approach, we tried to use the formation of crosslinks as a marker for AGE-formation and accumulation in the whole body, in an attempt to measure the AGE-content of blood constituents and tissue in the untreated state and during treatment with such new drugs ${ }^{[3]}$. As collagen is one of the most prominent long-living macromolecules in most mammals, it can be used in this respect as a model molecule for long-term glucose-mediated changes. Accumulation of AGEs on long-living macromolecules like collagen will result in the formation of crosslinks, but also other proteins like elastin and other matrix molecules play an important role in the development of abnormalities of the large blood vessels in diabetes like reduced elasticity and increased vascular stiffness ${ }^{[4 ; 5]}$.

Collagen crosslinking was tested using differential scanning calorimetry (DSC), a method frequently used in polymer chemistry ${ }^{[6]}$. In vitro testing of tendon 
and skin collagen tissue obtained from rats and incubated in vitro in conditions of high glucose for a prolonged period of time showed an increased crosslinking with increasing glucose concentration, which indicates the formation of AGEs. However, tests with biological samples obtained from diabetic rats, which developed crosslinks in vivo, showed large variations in results between animals despite comparable reductions in arterial elasticity, which was observed with haemodynamic measurements performed in these animals ${ }^{[7]}$. Although the proposed measurement procedure was attractive from a pathophysiological point of view, we have concluded that due to this biological variation as well as variation of the assay, this method was not suitable for in vivo analysis on a larger scale and was rejected as standard assay for the measurement of AGE formation.

In the second approach, we used one of the better-characterised AGEs as a marker for AGE formation and accumulation, i.e. $N^{\varepsilon}$-carboxymethyllysine (CML). In addition to antibody assays, which use a great variety of either polyclonal or monoclonal antibodies ${ }^{[8-10]}$ more sophisticated methods to quantitate CML have slowly become available like GC-MS, LC-MS or HPLC [11${ }^{13]}$. Unfortunately, most of the latter methods are elaborate and require expensive equipment. We specifically chose not to use an assay, which is based on a polyclonal antibody. Although this method is extensively described in the literature ${ }^{[7 ; 14]}$, this polyclonal antibody proved to be imprecise in assays like an ELISA. Previous studies in our laboratory showed that such an assay both lacks linear dilutibility and optimal recovery after 'spiking' a sample with the AGE used as a standard in this assay.

Therefore, we decided to use a simple HPLC assay with pre-column derivatization in the present series of studies. It proved to be a reliable and well-reproducible method to measure $\mathrm{CML}$ levels. The results showed a significant and clinically relevant difference in CML plasma levels between diabetic subjects and healthy controls. CML concentrations $(90 \%$ confidence interval) ranged from 56 to $73 \mathrm{ng} / \mathrm{mg}$ protein in type 1 diabetic subjects and from 15 to $42 \mathrm{ng} / \mathrm{mg}$ protein in age-matched healthy controls.

This method uses no sophisticated equipment, is equally sensitive as comparable methods like mass spectrometry, has a favourable runtime and compared to several antibody assays a better accuracy and precision Therefore it can be easily incorporated in most clinical laboratories. The relevance of measuring CML has been demonstrated in several studies [15.17]. 


\section{Hyperglycaemia and AGE formation}

AGE formation results not only from the non-enzymatic glycation of proteins but also from reactive intermediates arising from lipid peroxidation and oxidative stress in general ${ }^{[18 ; 19]}$. Several authors have reported, with the use of assays with polyclonal antibodies against AGE proteins, a significant correlation between AGE antigens in serum and mean glycaemic control as assessed by $\mathrm{HbA}_{1 \mathrm{C}}$ levels at one point in time ${ }^{[7 ; 14 ; 20]}$, but as mentioned earlier these assays lack precision and reproducibility. It is not known how specific AGEs correlate with glycaemic control, and whether these specific AGEs follow a similar change over time with worsening or improvement of metabolic control. To assess this more in detail, we followed twenty-eight subjects ( 14 males, 14 females) with type 2 diabetes, who were insufficiently controlled on oral blood glucose-lowering medication (sulphonylurea with or without metformin) and therefore started insulin therapy, during one year. These subjects showed a marked improvement in glycaemic control as assessed by glycated haemoglobin $\left(\mathrm{HbA}_{1 \mathrm{c}}\right)$ levels, which fell from $10.0 \pm 0.3$ to $7.8 \pm 0.2 \%$. However, this improvement of glycaemic control did not coincide with a decrease in AGE levels. In this study we have assessed AGE levels by a conventional assay based on a polyclonal non-specific antibody (measuring 'total' serum AGEs), our highly specific HPLC-based CML assay and an antibody assay for the specific AGE compound, methylglyoxal-derived hydroimidazolone (MGHI; assayed in a collaborative effort by Dr. P. Torjesen at the Aker Sykehus in Oslo, Norway). The results clearly demonstrated that AGE levels follow a different time course compared to overall hyperglycaemia in these subjects with type 2 diabetes. Several possible explanations can be given for this. We suggest that both oxidative stress (related to diabetic state itself and stopping metformin therapy in some patients), formation of AGEproducts derived from lipid peroxidation and the presence of excessive postprandial glucose excursions (PPGE), as observed in several patients with diabetes mellitus, have their quantitative effects on AGE levels. It is therefore not feasible to use AGEs like CML and MGHI as a better marker or integrative value of long-term glycaemic control, opposed to our earlier finding with haemoglobin-AGE ${ }^{[21]}$. However, specific AGEs like CML retain their power in predicting the future development of diabetic complications, as demonstrated in the studies by Berg et al. ${ }^{[22]}$ and Miura et al. ${ }^{[23]}$. 


\section{Postprandial glucose excursions}

The glycaemic control of patients with diabetes mellitus is judged on the basis of $\mathrm{HbA}_{1 \mathrm{c}}$ measurements, and generally $\mathrm{HbA}_{1 \mathrm{c}}$ levels below $7.0 \%$ are considered as markers of excellent control. Nevertheless, these patients still can experience episodes of hyperglycaemia, which usually occur postprandially. These periods of high plasma glucose can lead to increased AGE accumulation through the rapid formation of highly reactive a-dicarbonyl compounds ${ }^{[7 ; 14]}$ to AGE accumulation and are thought to contribute to the development of longterm diabetic complications. Several studies already showed that these hyperglycaemic periods have an independent prognostic value for the progression and severity of diabetic complications ${ }^{\text {77;14;20;24-26]. }}$.

With this in mind, we hypothesized that in diabetic subjects with macrovascular disease higher levels of a-dicarbonyls would be found in the fasting condition and after a meal than in subjects free of cardiovascular disease. These high a-dicarbonyl levels could increase AGE accumulation, which may in part explain the variety in the progression and severity of diabetic complications. In our study, we evaluated the possible contribution of PPGE to the formation of AGEs derived from a-dicarbonyls precursors. These PPGE were measured after a test meal and continuously during 3 days using a Continuous Glucose Monitoring System (CGMS, MiniMed ${ }^{m}$ ) in type 2 diabetic patients with $(n=9)$ or without $(n=9)$ macrovascular comorbidity as well as in healthy matched controls $(n=5)$.

When the results obtained in diabetic subjects with macrovascular disease were compared with those without, no significant difference in fasting blood values and postprandial excursions of blood glucose (both from CGMS monitoring as well as after the test meal) was found. In addition, the levels of a-dicarbonyls were not different, except for 3-deoxyglucosone. Unfortunately no assay was available in our laboratory to directly asses the levels of AGEs resulting from 3-deoxyglucosone. Based on the fact that the postprandial $\alpha$ dicarbonyls were not different, we believe that more advanced AGEs will be similar In both groups.

We were able to confirm that PPGE correlated with a-dicarbonyl (3deoxyglucosone and glyoxal) levels in both diabetic and control subjects. However, no correlation was found between $C M L$ and postprandial excursions of its a-dicarbonyl precursor glyoxal within 8 hours after the test meal. 
As CML is but one of the AGEs resulting from these a-dicarbonyls, a broad analysis of all resulting AGEs next to CML should be conducted in order to more fully understand the relation between these a-dicarbonyls and AGEs.

\section{Exogenous AGE sources}

Next to endogenous sources, AGEs can also origin from heated food sources or smoking. The first part of the non-enzymatic glycation of proteins is also known as the Maillard reaction common in heated food. This results in several Maillard products, which are frequently being used in the food industry as colouring agents ${ }^{[27]}$. Thus, AGEs are present in a variety of food components and will be ingested with our normal diet. Although most of these AGEs will leave the human body through the digestive pathway (faeces and urine) a small portion of these AGEs will be resorbed and remain in the body ${ }^{[28]}$. During their stay in the gastro-intestinal tract, AGEs can undergo several rearrangements, which could result in reactive AGE compounds or precursors. After resorption, these reactive molecules could interact with serum proteins or form new AGEs and thus increase overall AGE accumulation in the human body.

In 20 type 2 diabetics, we assessed serum CML levels after a meal containing CML by measuring protein bound CML in plasma, but we did not find an association between the amount of CML ingested from the AGE-rich meal and subsequent plasma CML levels. After we had performed this study, a paper appeared by Bergmann et al. ${ }^{[29]}$ who showed in rats that both free circulating CML and CEL were cleared from circulation very rapidly with $10 \%$ remaining to interact with proteins. This $10 \%$ remaining in the circulation to interact with proteins is too low or the process of interaction with circulation proteins is to slow to be detected in this study. However, CML formation could still contribute to the development and progression of diabetic complications either by the rapid clearance of CML by interaction with the receptor for AGES and the resulting activation of molecular signalling pathways or by the accumulation on tissue proteins. CML is only one of the total pool of AGEs, so other AGEs can and will exist in food components and may show different behaviour when ingested.

To assess the role of ingestion of AGEs on the total AGE burden further prospective studies are needed with an evaluation of a broader spectrum of known and characterised AGEs. 
AGE-containing foods enriched with stable isotopes can be a tool for better assessing the fate of ingested AGEs in the body

\section{Oxidative stress}

Diabetes mellitus is a disease associated with increased oxidative stress, which plays an important role in its pathophysiology. One of the main causes of this increased oxidative stress is hyperglycaemia and the breakdown of glucose without oxygen (glucose autoxidation), AGE formation and increased conversion of glucose by the polyol pathway. This polyol pathway converts glucose to fructose, which is a process that requires NADPH (Nicotinamide Adenine Dinucleotide Phosphate). Increased flux of glucose through the polyol pathway depletes intracellular levels of $\mathrm{NADPH}$, which is required for regeneration of reduced glutathione (GSG). This depletion results in lower GSG levels and a corresponding decrease in antioxidant capacity, thus resulting in a reduced capacity for the body to fight toxic free radicals ${ }^{[30]}$.

We have assessed several parameters of antioxidant capacity in subjects with type 2 diabetes and compared these with healthy age-matched controls. However, there was no difference in the levels of three of these parameters, i.e. TEAC (Total Equivalent Anti-oxidant Capacity), MDA (MalonDiAldehyde) and uric acid between the groups and could in this respect not explain the variations in diabetic complications.

It is known that $\mathrm{N}^{\mathrm{E}}$-carboxymethyllysine (CML), one of the best-known and characterised AGEs, is formed through an oxidative pathway but can by itself generate free radicals by a receptor-mediated pathway. Interaction of AGES with RAGE increases intracellular oxidative stress resulting in the activation of the translation factor NF-KB that translocates into the nucleus and induces the expression of $\mathrm{NF}-\mathrm{kB}$ genes ${ }^{[31 ; 32]}$. In our studies, we found in type 2 diabetic patients a relation between $C M L$ and NF-KB, which could indicate the interaction of CML with the Receptor of AGE (RAGE). This may result in an increase in intracellular oxidative stress and activation of $\mathrm{NF}-\mathrm{KB}$, promoting the up-regulation of NF-KB controlled genes and consequently enhance production of nitric oxide and promoting inflammatory mediators ${ }^{[31]}$.

\section{Receptor for AGEs}

Next to AGE formation on proteins, which changes the structure and function of these proteins, AGEs can induce several intracellular processes after 
interacting with the Receptor for AGES (RAGE). RAGE is a multiligand receptor, which is -in contrast to many other receptors- upregulated in the presence of one of its ligands. Next to members of the $5100 /$ calgranulin family, B-sheet familiar structures and amphotherin ${ }^{[33]}$, AGEs are ligands. Activation of RAGE leads to a great variety in intracellular signalling, like activation of the Jak/Stat pathway, activation of p21 ${ }^{\text {ras }}$ and the mitogenactivated protein (MAP) kinase family ${ }^{[34]}$. Activation of these processes by interaction with RAGE could in part explain the effects of increased AGElevels on the progression and severity of diabetic complications.

It has been suggested that mutations in the gene encoding for this receptor and the subsequent increased or decreased activity of this receptor play an important role in the development and speed of progression of diabetic complications. In a study with type 1 diabetes subjects we have assessed the role of three polymorphisms of the RAGE gene (the Gly82Ser, T/A or T/del in the promoter region $374 \mathrm{bp}$ upstream of the start codon and T/C or T/del in the promoter region $429 \mathrm{bp}$ upstream of the start codon) on the development of retinopathy in subjects with type 1 diabetes.

We chose to assess this in an experimental setup which used two 'extreme phenotypes'; the first phenotype consisted of type 1 diabetic patients who had developed proliferative retinopathy early in the course of their disease, i.e. within 15 years of diabetes duration. The second phenotype consisted of patients with only a limited degree of background or non-proliferative diabetic retinopathy after more than 20 years of diabetes duration.

This extreme division of patients with diabetic retinopathy would allow a higher power than studies in which patients with different stages of the clinical course of retinopathy were studied ${ }^{[7 ; 14 ; 20 ; 35 ; 36]}$.

The most important reason to use this approach is that several known risk factors influence the course and progression of retinopathy, i.e. long-term glycaemic control, presence of hypertension, smoking etc. In the EDIC (Epidemiology of Diabetes Interventions and Complications) study previous participants of the DCCT (Diabetes Control and Complications Trial) were followed after cessation of the main study and it was clearly demonstrated how important glycaemic control is in this respect ${ }^{[7 ; 14 ; 20 ; 37 ; 38]}$. There were two groups of participants, those previous on intensive treatment (average $\mathrm{HbA}_{1 \mathrm{c}}$ during $\mathrm{DCCT} 7.0 \%$ ) and those on conventional treatment (average $\mathrm{HbA}_{1 \mathrm{c}}$ during DCCT $9.0 \%$ ) and they were followed for 4 years. During that period, both groups had an average $\mathrm{HbA}_{1 \mathrm{c}}$ of $8.0 \%$. Despite these similar levels of metabolic control, patients who previously were on intensive treatment had a $70 \%$ lower 
incidence of new or worsening of complications during these 4 years than those who were previously on conventional treatment. This implies that the deleterious effects of poor glycaemic control continue to influence the development of complications, even when better control has been achieved. Correcting for all of these confounding factors in the search for genes contributing to diabetic complications would imply that one must know all details of long-term glycaemic control, which is very difficult to achieve in such patients with long duration of disease.

With a considerable effort and collaboration with two neighbouring hospitals, i.e. in Sittard and Brunssum, we were able to identify 34 patients with early proliferative diabetic retinopathy and 51 patients with only background/nonproliferative diabetic retinopathy and disease duration $>20$ years. However, we were not able to find a difference in the distribution of the specific RAGE polymorphisms in patients with and without retinopathy. A new finding in this study was that patients with a specific 63bp deletion (from -407 to $-345 \mathrm{bp}$ ) in the promoter region of the RAGE gene had lower E-selectin and ICAM-1 and aberrant CML levels as those without. Lower levels of E-selectin and ICAM-1 could mirror a reduced leukocyte adhesion, one of the underlying mechanisms in the process of development of diabetic retinopathy ${ }^{[39: 40]}$ and therefore this could be a protective polymorphism. The prevalence of this polymorphism in our patients and in the general population is very low ${ }^{[41]}$.

A larger scale evaluation should give additional information on the prevalence of this deletion and its potential protective effect on the progression of diabetic retinopathy and AGE-RAGE interaction in general. Such studies are now ongoing.

\section{Concluding remarks}

The classical pathway for AGE formation involves the reaction of a reducing sugar, like glucose, with amino acid residues of a protein. In this respect AGE formation and accumulation is frequently associated with high blood and tissue glucose levels. However we showed that AGE formation follows a different time course as overall hyperglycaemia $\left(\mathrm{HbA}_{1 c}\right)$ supporting the concept that AGEs not only result from hyperglycaemia but also from other chemical processes in the body like oxidative stress and lipid peroxidation.

Type 2 diabetic patients with different severity of long-term complications showed similar levels of glycaemic stress after a meal (PPGE). This implicates that postprandial hyperglycaemia cannot account for the variation in severity 
of diabetic complications in our study. The underlying biochemical pathways like a-dicarbonyl formation and the resulting AGE formation may explain this variation.

3-DG one of the precursors of AGE formation differed between patients with and without cardiovascular complications. AGEs resulting from these $\alpha$ dicarbonyls could induce RAGE activation and the resulting cell signalling pathways (NF-KB induction) thus contributing to the development of late complications as was shown by the correlation between CML and NF-KB in our study. Next to AGE-RAGE interaction polymorphisms in the genes encoding for this receptor may play an important role in the development of diabetic complications as was shown by the gene-deletion present in the promoter region leading to decreased levels of sICAM-1 and SE-Selectin, two indicators of endothelial dysfunction.

In conclusion, formation of AGEs, their interaction with one of the receptors for AGEs and genetic variations in the genes encoding for this receptor could in part explain some of the variety in the progression and speed of progression of diabetic complications.

However, as AGEs are a very heterogeneous group of compounds we assessed only a small portion of the specific chemical AGE entities present in the human body and in future studies it is necessary to investigate a broader spectrum of AGE compounds. This shows the need for well-quantitated and reproducible assays to asses all AGEs resulting from the different pathways.

AGEs altering the native structure of proteins will probably be an indicator for long-term diabetic complications and ageing in general due to its relative slow and irreversible process of formation. However, interaction of circulating AGEs with one of their receptors and the resulting quick changes in the biochemical pathways will result in a more 'acute' occurrence of diabetic complications. Assessing all of these AGE molecules in concert with parameters of overall glycaemic control and the resulting cell signalling pathways could give a better insight into the processes occurring in diabetic subjects.

It must be recollected that diabetes mellitus is a multifactorial disease [42] with AGE formation and accumulation being just one of the molecular processes underlying the development of diabetic complications, and hypertension and dyslipidaemia being important other ones. Understanding all of these processes and their interaction in more detail could lead to a better 
General discussion | 133

diagnosis and treatment of diabetic subjects, and a better and complicationfree future for these patients. 


\section{References}

1. Ulrich $P$, Cerami A. Protein glycation, diabetes, and aging. Recent Prog. Horm.Res. 2001;56:1-21.

2. Monnier VM, Bautista $O$, Kenny $D$ et al. Skin collagen glycation, glycoxidation, and crosslinking are lower in subjects with long-term intensive versus conventional therapy of type 1 diabetes: relevance of glycated collagen products versus $\mathrm{HbA1C}$ as markers of diabetic complications. DCCT Skin Collagen Ancillary Study Group. Diabetes Control and Complications Trial. Diabetes 1999;48:870-80.

3. Sell DR, Monnier VM. Structure elucidation of a senescence cross-link from human extracellular matrix. Implication of pentoses in the aging process. J.Biol.Chem. 1989;264:21597-602.

4. Huijberts MSP, Wolffenbuttel BHR, Struijker Boudier HAJ et al. Aminoguanidine treatment increases elasticity and decreases fluid filtration of large arteries from diabetic rats. J.Clin. Invest. 1993;92:1407-11.

5. Bucala R, Tracey KJ, Cerami A. Advanced glycosylation products quench nitric oxide and mediate defective endothelium-dependent vasodilatation in experimental diabetes. J.Clin. Invest 1991;87:432-8.

6. Bailey AJ, Sims TJ, Avery NC, Miles CA. Chemistry of collagen cross-links: glucosemediated covalent cross- linking of type-IV collagen in lens capsules. Biochem.J. 1993;296 (Pt 2):489-96.

7. Crijns FR, Struijker Boudier HA, Wolffenbuttel BH. Arteriolar reactivity in conscious diabetic rats: influence of aminoguanidine treatment. Diabetes 1998;47:918-23.

8. Ikeda K, Nagai R, Sakamoto $T$ et al. Immunochemical approaches to AGE-structures: characterization of anti- AGE antibodies. J.Immunol.Methods 1998;215:95-104.

9. Farboud B, Aotaki-Keen A, Miyata T, Hjeimeland LM, Handa JT. Development of a polyclonal antibody with broad epitope specificity for advanced glycation endproducts and localization of these epitopes in Bruch's membrane of the aging Eye [In Process Citation]. Mol.Vis. 1999;5:11.

10. Ikeda $\mathrm{K}$, Higashi $\mathrm{T}$, Sano $\mathrm{H}$ et al. $\mathrm{N}$ (epsilon)-(carboxymethyl)lysine protein adduct is a major immunological epitope in proteins modified with advanced glycation end products of the Maillard reaction. Biochemistry 1996;35:8075-83.

11. Ahmed MU, Thorpe Suzanne R, Baynes John W. Identification of $\mathrm{N}^{*}$-Carboxymethyllysine as a Degradation product of fructoselysine in glycated protein. J.Biol.Chem. 1996;261:4889-94.

12. Drusch S, Faist V, Erbersdobler HF. Determination of Ne-carboxymethyllysine in milk products by a modified reversed phase HPLC method. Food Chemistry 1999;65:547-53. 
13. Friess $U$, Waldner $M$, Wahl $H G$ et al. Liquid chromatography-based determination of urinary free and total $\mathrm{N}$ (epsilon)-(carboxymethyl)lysine excretion in normal and diabetic subjects. J.Chromatogr.B Analyt. Technol.Biomed.Life Sci. 2003;794:273-80.

14. Makita $\mathrm{Z}$, Vlassara $\mathrm{H}$, Cerami A, Bucala R. Immunochemical Detection of Advanced Glycosylation Endproducts in vivo. J.Biol.Chem. 1992;267:5133-8.

15. Ando $K$, Beppu $M$, Kikugawa $K$, Nagai $R$, Horiuchi $S$. Membrane proteins of human erythrocytes are modified by advanced glycation end products during aging in the circulation. Biochem. Biophys. Res.Commun. 1999;258:123-7.

16. Hammes HP, Alt A, Niwa $T$ et al. Differential accumulation of advanced glycation end products in the course of diabetic retinopathy. Diabetologia 1999;42:728-36.

17. Dunn JA, MCCance DR, Thorpe SR, Lyons TJ, Baynes JW. Age-dependent accumulation of N epsilon-(carboxymethyl)lysine and $\mathrm{N}$ epsilon-(carboxymethyl)hydroxylysine in human skin collagen. Biochemistry 1991;30:1205-10.

18. Miyata $T$, Sugiyama $S$, Saito A, Kurokawa K. Reactive carbonyl compounds related uremic toxicity ("carbonyl stress"). Kidney Int. 2001;59 Suppl 78:S25-S31.

19. Bonnefont-Rousselot D, Bastard JP, Jaudon MC, Delattre J. Consequences of the diabetic status on the oxidant/antioxidant balance. Diabetes Metab 2000;26:163-76.

20. Chiarelli $F$, de Martino $M$, Mezzetti $A$ et al. Advanced glycation end products in children and adolescents with diabetes: relation to glycemic control and early microvascular complications. J.Pediatr. 1999;134:486-91.

21. Wolffenbuttel $B H$, Giordano D, Founds HW, Bucala R. Long-term assessment of glucose control by haemoglobin AGE measurement . Lancet 1996;347:513-5.

22. Berg TJ, Snorgaard $O$, Faber $J$ et al. Serum levels of advanced glycation end products are associated with left ventricular diastolic function in patients with type 1 diabetes. Diabetes Care 1999;22:1186-90.

23. Miura J, Yamagishi S, Uchigata $Y$ et al. Serum levels of non-carboxymethyllysine advanced glycation endproducts are correlated to severity of microvascular complications in patients with Type 1 diabetes. J.Diabetes Complications 2003;17:16-21.

24. Beisswenger PJ, Howell SK, O'Dell RM, Wood ME, Touchette AD, Szwergold BS. alphaDicarbonyls increase in the postprandial period and reflect the degree of hyperglycemia. Diabetes Care 2001;24:726-32.

25. Siperstein MD. Diabetic microangiopathy, genetics, environment, and treatment. Am.J.Med. 1988;85:119-30.

26. Ceriello $A$, Hanefeld $M$, Leiter $L$ et al. Postprandial glucose regulation and diabetic complications. Arch.Intern. Med. 2004;164:2090-5.

27. Maillard LC. Action des acides amines sur les sucres; formation des melanoidines par voie methodique. C.R.Hebd.Sceances.Acad.Sci. 1912;154:66-8. 
28. Koschinsky $\mathrm{T}, \mathrm{He} \mathrm{C}-\mathrm{J}$, Mitsuhashi $\mathrm{T}$ et al. Orally absorbed reactive glycation products (glycotoxins): An environmental risk factor in diabetic nephorpahty. Proc.Natl.Acad.Sci. 1997;94:6474-9.

29. Bergmann $R$, Helling $R$, Heichert $C$ et al. Radio fluorination and positron emission tomography (PET) as a new approach to study the in vivo distribution and elimination of the advanced glycation endproducts $N$ epsilon-carboxymethyllysine (CML) and $N$ epsiloncarboxyethyllysine (CEL). Nahrung 2001;45:182-8.

30. Bonnefont-Rousselot D. Glucose and reactive oxygen species. Curr.Opin.Clin.Nutr.Metab Care 2002;5:561-8.

31. Wendt $T$, Bucciarelli $L, Q u W$ et al. Receptor for advanced glycation endproducts (RAGE) and vascular inflammation: insights into the pathogenesis of macrovascular complications in diabetes. Curr.Atheroscler.Rep. 2002;4:228-37.

32. Valencia JV, Mone $M$, Zhang J, Weetall M, Buxton FP, Hughes TE. Divergent pathways of gene expression are activated by the RAGE ligands S100b and AGE-BSA. Diabetes 2004;53:743-51.

33. Stern D, Du YS, Fang YS, Marie SA. Receptor for advanced glycation endproducts: a multiligand receptor magnifying cell stress in diverse pathologic settings. Adv.Drug Deliv.Rev. 2002;54:1615-25.

34. Lander HM, Tauras JM, Ogiste JS, Hori O, Moss RA, Schmidt AM. Activation of the receptor for advanced glycation end products triggers a p21(ras)-dependent mitogen-activated protein kinase pathway regulated by oxidant stress. J.Biol.Chem. 1997;272:17810-4.

35. Hudson BI, Stickland MH, Futers TS, Grant PJ. Effects of novel polymorphisms in the RAGE gene on transcriptional regulation and their association with diabetic retinopathy. Diabetes 2001;50:1505-11.

36. Kumaramanickavel G, Ramprasad VL, Sripriya S, Upadyay NK, Paul PG, Sharma T, Association of Gly82Ser polymorphism in the RAGE gene with diabetic retinopathy in type II diabetic Asian Indian patients. J.Diabetes Complications 2002;16:391-4.

37. Effect of intensive diabetes management on macrovascular events and risk factors in the Diabetes Control and Complications Trial. Am.J.Cardiol. 1995;75:894-903.

38. Effect of intensive therapy on the microvascular complications of type 1 diabetes mellitus. JAMA 2002;287:2563-9.

39. Joussen AM, Poulaki V, Qin $W$ et al. Retinal vascular endothelial growth factor induces intercellular adhesion molecule- 1 and endothelial nitric oxide synthase expression and initiates early diabetic retinal leukocyte adhesion in vivo. Am.J.Pathol. 2002;160:501-9.

40. Kamiuchi $K$, Hasegawa $G$, Obayashi $H$ et al. Intercellular adhesion molecule-1 (ICAM-1) polymorphism is associated with diabetic retinopathy in Type 2 diabetes mellitus. Diabet.Med. 2002;19:371.6. 
41. Rudofsky G, Jr., Isermann B, 5chilling $T$ et al. A $63 \mathrm{bp}$ deletion in the promoter of rage correlates with a decreased risk for nephropathy in patients with type 2 diabetes. Exp.Clin.Endocrinol.Diabetes 2004;112:135-41.

42. Brownlee $M$. The pathobiology of diabetic complications: a unifying mechanism. Diabetes 2005;54:1615-25. 
Summary 


\section{Summary}

Diabetes is a multi-factorial disease leading to a great variety of complications. Several underlying molecular mechanisms are responsible for the development of these complications like increased flux through the polyol pathway, protein kinase $C$ activation, oxidative stress and the formation and accumulation of advanced glycation endproducts (AGEs). A variation in these molecular mechanisms could in part explain the variety in complications between diabetic patients.

The focus of this thesis was to study some important aspects of AGE formation and the role of AGEs in the development of retinopathy and macrovascular complications.

In several publications specific assays are used to measure AGE molecules as biomarkers for overall AGE formation and accumulation. However, these assays show great intra- and inter-assay variance and are of limited use. Furthermore, little is known about the interrelationship between overall and postprandial glycaemic control, AGEs and diabetic complications.

In this thesis, we described the development of a reliable and easy to use assay for the determination of specific AGEs. In addition the role of AGEs in the development and progression of complications in patients with diabetes mellitus as well as AGE formation in general was studied. More information on the general background of diabetes mellitus and AGEs is described in chapter 1 .

As AGEs are a very heterogeneous group of compounds and the current assays are of limited use, a specific and well-reproducible assay was needed.

In chapter 2, we described a method using one of the biochemical properties of AGEs, crosslinking of macromolecules. We used Differential Scanning Calorimetry (DSC) to asses the degree of glucose-mediated crosslinking in rat tendon and skin tissue collagen. Assessing the crosslinking degree of tendon collagen of diabetic male Wistar rats, DSC measurements showed a great variance between animals despite comparable arterial elasticity in vivo. To assess the usefulness of this method in more detail, rat tendon and skin tissue collagen isolated from healthy male Wistar rats was incubated with glucose and ribose to assess the change in crosslinking in vitro. These measurements showed to be both reproducible and sensitive enough to make a distinction between the different incubation protocols. Summarizing, DSC was suitable for assessing in vitro crosslinking but, due to the large biological variability in 
the crosslinking degree of tendon in diabetic rats this method was not suitable to assess in vivo crosslinking.

One of the well-known AGE structures was chosen as a marker for AGE accumulation and formation as a second approach. A HPLC method with precolumn derivatization has been developed for the detection of $\mathrm{N}^{\varepsilon}$ carboxymethyllysine (CML, chapter 3). This method was capable of determining protein-bound $\mathrm{CML}$ in the relevant concentration range with a limit of detection of $0.2 \mu \mathrm{g} / \mathrm{ml}$. This resulted in a well reproducible and easy to perform analytical method, which can easily be incorporated in most diagnostic laboratories.

During hyperglycaemia several AGEs are formed and it is known that overall serum AGE accumulation correlated with average glycaemic control in patients with type 2 diabetes and with the development of complications. However it is not known how specific serum AGEs will change when insulin therapy is optimised. We studied the change of serum $\mathrm{CML}$, methylglyoxalderived hydroimidazolone (MGHI) and total AGE after 6 months of insulin therapy in type 2 diabetic subjects who recently started insulin therapy (chapter 4). Levels of serum AGEs did not follow the same time course as average glycaemic control as assessed by HbA1c during insulin therapy. A slight, but not significant decrease in CML levels was observed, while MGHI even increased significantly.

Interaction of AGEs with one of their receptors can lead to several cellular processes, which play an important role in the development of diabetic complications.

Increased expression of adhesion molecules like E-selectin, intercellular adhesion molecule-1 (ICAM-1) and vascular cell adhesion molecule-1 (VCAM-1) are often used as markers for endothelial function, one of the hallmarks of macrovascular complications.

In this chapter, we showed that endothelial function improved after 6 months of insulin therapy as indicated by a small but significant decrease of soluble ICAM-1 and SE-selectin levels.

Improvement of overall glycaemic control leads to an improvement of endothelial function, but no correlation was found between overall glycaemic control and serum AGE levels. This indicates that the levels of these specific AGEs are influenced by other factors then hyperglycaemia, like oxidative stress. 
Analysis of a cohort of the Diabetes Control and Complication Trial (DCCT) showed evidence for possible genetic factors that influence the severity of diabetic retinopathy. Because of the pathophysiologic role of AGEs in the development of retinopathy, we studied the influence of three polymorphisms in the RAGE gene (the Gly82Ser, T/A or T/del in the promoter region $374 \mathrm{bp}$ upstream of the start codon and T/C or T/del in the promoter region $429 \mathrm{bp}$ upstream of the start codon).

In order to assess the relation of these polymorphisms with the resulting molecular changes, $\mathrm{CML}$, sICAM-1, sE-selectin and vascular endothelial growth factor (VEGF) levels were investigated in patients with and without diabetic retinopathy (chapter 5 ). These molecules represent the interaction of AGEs with RAGE and the resulting activation of several molecular pathways.

To enhance separation between the subject groups, we chose a study design of 'extreme phenotypes'. These were patients without retinopathy despite a $>20$ years diabetes duration, and patients who developed proliferative retinopathy well within 15 years diabetes duration. Even with this study design we did not find differences in the distribution of the specific polymorphisms in patients with and without retinopathy. However, an interesting correlation was found between a specific 63bp deletion (from -407 to $-345 \mathrm{bp}$ ) in the promoter region and low CML, sICAM-1 and sE-selectin levels in two patients without retinopathy. This could indicate a possible reduced leukocyte adhesion in subjects with this specific polymorphism, one of the underlying molecular mechanisms in the development of retinopathy. As this deletion was only found in two patients in the study population more research is needed to study this geno-phenotype interaction in more detail.

Postprandial hyperglycaemia plays an important role in the development of macrovascular complications in diabetes patients and AGE formation and accumulation could be one of the underlying metabolic processes. Next to the endogenous production of AGEs due to the non-enzymatic glycation of proteins or the reaction of a-dicarbonyls (arisen from lipid peroxidation or oxidative stress in general) with proteins, AGEs can also be ingested from diet.

In the study described in chapter 6 the role of post-prandial glucose excursions (PPGE) on the formation and accumulation of AGEs formed by adicarbonyls precursors was assessed both by a continuous glucose monitoring system (CGMS) and a test meal in diabetic subjects with and without 
macrovascular complications. PPGE were higher in patients with macrovascular complications and correlated well with post-prandial adicarbonyl levels. One of the a-dicarbonyls, 3-deoxyglucosone, was significantly higher in subjects with macrovascular complications. However, we did not find a correlation between CML and its precursor glyoxal.

Next to this we assessed levels of protein-bound CML after ingestion of the test meal, however no correlation was found between CML amount ingested and protein bound CML levels.

Although, PPGE correlated with a-dicarbonyl levels we could not find any evidence linking increased a-dicarbonyl levels to CML levels. This relation could be one of the molecular mechanisms explaining the variation in complications between diabetic patients. As CML is one of the AGEs resulting from the different a-dicarbonyls it is necessary to conduct a well-controlled study with evaluation of a broader spectrum of AGEs resulting from these adicarbonyls.

In chapter 7 the role of AGEs in the development of diabetic complications is discussed as well as the implications for further research in this area. Valuable information was obtained on AGE formation and accumulation and their role in the development and progression of diabetic complications.

AGEs altering the native structure of proteins will probably be an indicator for long-term diabetic complications, while interaction of circulating AGEs with one of their receptors and the resulting quick changes in the biochemical pathways will result in a more 'acute' occurrence of diabetic complications. However, the results of this thesis were not very conclusive in linking AGE levels to diabetic complications.

Obtaining more information on the formation of these AGEs and their resulting biochemical pathways as well as other factors influencing the development of diabetes (hypertension and dyslipidaemia) could contribute to a better treatment of diabetes. 
Samenvatting 


\section{Samenvatting}

Diabetes is een multfactoriële ziekte die kan leiden tot een grote verscheidenheid aan complicaties. Verschillende moleculaire mechanismen, zoals een toegenomen flux door de polyol pathway, proteine kinase $C$ activatie, oxidatieve stress en de vorming van advanced glycation endproducts (AGE's) zijn mede verantwoordelijk voor de ontwikkeling van deze complicaties. Een variatie in de intensiteit van deze mechanismen zou voor een deel de grote verscheidenheid aan complicaties in patiënten met diabetes kunnen verklaren.

De focus van dit proefschrift lag op het onderzoeken van enkele belangrijke aspecten van AGE vorming en de rol van AGE's in de ontwikkeling van retinopatie en macrovasculaire complicaties.

Verschillende publicaties laten het gebruik zien van specifieke AGE-moleculen als biomarkers voor AGE-vorming en ophoping. Echter de daarvoor gebruikte assays vertonen grote intra- en interassay varianties en hebben maar een beperkte waarde.

Verder is maar weinig bekend over de relatie tussen gemiddelde glucose waarde, de glucose waarden na een maaltijd, AGE's en diabetische complicaties.

In dit proefschrift wordt de ontwikkeling van een betrouwbare en eenvoudig te gebruiken meetmethode voor de bepaling van specifieke AGE's beschreven. Tevens wordt de rol beschreven van AGE's in de ontwikkeling en voortgang van diabetische complicaties en AGE-vorming en -ophoping in het algemeen. Meer informatie over de achtergrond van diabetes mellitus en AGE's wordt beschreven in hoofdstuk 1 .

Omat AGE's een heterogene groep van verbindingen zijn en de bestaande meetmethoden van beperkte waarde zijn, was er behoefte aan een specifiek en goed reproduceerbare meetmethode. In hoofdstuk 2 beschrijven we een methode die gebruik maakt van de biochemische eigenschappen van AGEs om macromoleculen te crosslinken. Er werd gebruik gemaakt van differential scanning calorimetry (DSC) om de mate van glucose gemedieerde crosslinking te bepalen van collageen in pezen en huid van ratten. DSC meting van de pezen van mannelijke Wistar ratten met diabetes liet een grote variatie tussen de dieren zien ondanks vergelijkbare arteriële elasticiteit gemeten in vivo. Om de validiteit van deze methode in meer detail te onderzoeken zijn 
DSC metingen gedaan van pezen en huid van gezonde Wistar ratten geïncubeerd met glucose en ribose. Deze metingen waren zowel reproduceerbaar als gevoelig genoeg om de verschillende incubaties van elkaar te onderscheiden. Samenvattend kan gezegd worden dat DSC een bruikbare methode is voor het bepalen van collageen crosslinking in vitro, maar door de grote biologische variatie van collageen crosslinking in de pezen van diabetische ratten is deze methode niet geschikt voor de bepaling van in vivo crosslinking.

Voor de tweede methode werd gebruik gemaakt van een bekende AGEstructuur als marker voor de ophoping en vorming van AGEs. Een HPLC methode met pre-kolom derivatisering werd ontwikkeld voor de detectie van $\mathrm{N}^{\mathrm{E}}$-carboxymethyllysine (CML), een van de bekende AGE-structuren (hoofdstuk 3). Deze methode is in staat om CML te bepalen in het relevante concentratie bereik met een detectielimiet van $0,2 \mu \mathrm{g} / \mathrm{ml}$. Dit resulteerde in een reproduceerbare en eenvoudig uit te voeren analytische methode die in de meeste diagnostische laboratoria geïmplementeerd kan worden.

Gedurende hyperglycemie worden verschillend AGE's gevormd en het is bekend dat serum AGE's correleren met de gemiddelde bloedglucosewaarde in patiënten met type 2 diabetes en de ontwikkeling van complicaties. Het is echter niet bekend hoe specifieke AGE niveaus veranderen gedurende insulinetherapie. We bestudeerden de verandering van $\mathrm{CML}$, methylglyoxaalderived hydrolmidazolone (MGHI) en totaal AGE na 6 maanden insulinetherapie in type 2 diabetespatiënten die recent gestart waren met insulinetherapie (hoofdstuk 4). Niveaus van serum AGE's volgden niet hetzelfde tijdspad als de gemiddelde bloedglucosewaarde ( $\mathrm{HbA1C}$ ) gedurende de insulinetherapie. CML niveaus daalden licht (niet significant) terwijl MGHI niveaus significant stegen.

Interactie van AGE's met één van de receptoren voor AGE's (RAGE) kan tot verschillende cellulaire processen leiden, die een belangrijke rol spelen in de ontwikkeling van diabetische complicaties. Expressie van adhesie moleculen zoals E-selectine, intracellular adhesion molecule-1 (ICAM-1) en vascular adhesion molecule-1 (VCAM-1) wordt vaak gebuikt als marker voor endotheelfunctie, die een belangrijke rol speelt in de ontwikkeling van macrovasculaire complicaties. 
In dit hoofdstuk lieten we zien dat endotheelfunctie verbeterd was na 6 maanden insulinetherapie wat bleek uit een kleine maar significante daling in oplosbaar ICAM-1 en E-selectine niveaus.

Verbetering van de gemiddelde bloedglucosewaarde ( $\mathrm{HbA1c}$ ) leidde tot een verbetering van de endotheelfunctie. Echter, er werd geen correlatie gevonden tussen deze gemiddelde bloedglucosewaarden en AGE's, hetgeen aantoont dat deze specifieke AGE's door ander factoren beïnvloed worden dan alleen hyperglycemie. Een mogelijke factor zou bijvoorbeeld de mate van oxidatieve stress kunnen zijn.

Analyse van een cohort van de Diabetes Control and Complication Trial (DCCT) toonde aan dat er mogelijke genetische factoren waren die de ernst van diabetische retinopathie kunnen beïnvloeden. Omdat AGE's betrokken zijn bij de ontwikkeling van retinopathie bestudeerden we 3 polymorfismen in het RAGE gen (het Gly82Ser, T/A of T/del in de promotor-regio 374 bp upstream van het start codon en $T / C$ of $T /$ del in de promotor-regio 429 bp upstream van het start-codon). Om de relatie te bestuderen tussen deze polymorfismen en de resulterende moleculaire mechanismen werden de serum niveaus van $C M L$, sICAM-1, sE-selectine en vascular endothelial growth factor (VEGF) bestudeerd in patiënten met en zonder retinopathie (hoofdstuk 5). Deze moleculen zijn een goede afspiegeling van de relatie tussen activatie van RAGE door AGE's en de resulterende moleculaire pathways. Om de een zo groot mogelijk onderscheidend vermogen tussen de groepen te creëren, werd er gekozen voor een 'extreme fenotypen' studieopzet. In deze opzet hebben we gekozen voor patiënten zonder retinopathie ondanks meer dan 20 jaar diabetes en patiënten die binnen 15 jaar diabetes proliferatieve retinopathie ontwikkelden.

We vonden echter geen verschillen in de verdeling van de polymorfismen in patiënten met en zonder retinopathie. Wel vonden we een correlatie tussen een specifieke 63 basenparen deletie (van -407 tot $-345 \mathrm{bp}$ ) in de promotorregio van het RAGE-gen en lage CML, sICAM-1 en SE-selelctine niveaus. Dit kan wijzen op een mogelijke gereduceerde leukocyt-adhesie in patiënten met dit specifieke polymorfisme, een van de moleculaire mechanismen in de ontwikkeling van retinopathie. Aangezien deze deletie slechts aangetoond werd in 2 personen binnen de studiepopulatie is meer onderzoek nodig om deze mogelijke relatie verder te onderzoeken. 
Post-prandiale hyperglycemie speelt een belangrijke rol in de ontwikkeling van macrovasculaire complicaties in diabetespatiënten. Vorming en ophoping van AGE's is een de onderliggende metabole processen in de deze ontwikkeling. Naast de endogene productie van AGE's door de nonenzymatische glycering van eiwitten of de reactie van a-dicarbonylen (afkomstig van lipidenperoxidatie en oxidatieve stress) met eiwitten, kunnen AGE's ook opgenomen worden uit de normale voeding.

In de studie beschreven in hoofdstuk 6 werd de rol van post-prandiale glucose excursies (PPGE) in de vorming en accumulatie van AGE's, gevormd door a-dicarbonylprecursors, bestudeerd. Dit werd gedaan bij personen met diabetes met en zonder macrovasculaire complicaties met behulp van een continue glucose monitoring systeem (CGMS) en een testmaaltijd. PPGE waren hoger in diabetespatiënten met macrovasculaire complicaties en correleerden met post-prandiale a-dicarbonylwaarden. Eén van deze a-dicarbonylen, 3deoxyglucosone, was significant hoger in diabetespatiënten met macrovasculaire complicaties ten opzichte van patiënten zonder deze complicaties. We hebben echter geen relatie kunnen vinden tussen CML en de a-dicarbonylprecursor glyoxaal.

Tevens hebben we de serum CML-niveaus bepaald na inname van de testmaaltijd, maar we vonden geen correlatie tussen de ingenomen hoeveelheid $C M L$ en serum CML-niveaus.

Ondanks dat PPGE correleerde met post-prandiale a-dicarbonylniveaus hebben we geen bewijs kunnen vinden voor de relatie tussen deze a-dicarbonylniveaus en CML. Deze relatie zou een van de moleculaire mechanismen kunnen zijn die de variatie in complicaties tussen verschillende diabetespatiënten zou kunnen verklaren.

Aangezien CML slechts een van vele AGE's is afkomstig van a-dicarbonyl precursors is het noodzakelijk om een goed gecontroleerde studie uit te voeren waarin een breder spectrum aan AGEs bekeken wordt.

In hoofdstuk 7 wordt de rol van AGEs in de ontwikkeling van diabetische complicaties bediscussieerd evenats de implicaties voor verder onderzoek op dit gebied. Belangrijke informatie is verkregen over de vorming en ophoping van AGEs en hun rol in de ontwikkeling en voortschrijding van diabetische complicaties.

AGE's die de natieve structuur van eiwitten veranderen zijn waarschijnlijk indicatoren voor lang termijn diabetische complicaties. Interactie van AGE's met één van de receptoren van AGE's en de daaruit volgende snelle 
1501

veranderingen in de biochemische mechanismen leidt tot een meer 'acuut' voorkomen van deze complicaties. Door meer informatie te verkrijgen over de vorming van deze AGE's, de door AGE's geactiveerde pathways en ander factoren die de ontwikkeling van diabetes beïnvloeden, kan een betere behandeling voor diabetespatiënten ontwikkeld worden. 
Dankwoord 


\section{Dankwoord}

Zoals een goede whisky tijd nodig heeft om te rijpen is hier dan ook na enige tijd mijn proefschrift. Natuurlijk hoort bij een proefschrift een dankwoord, dus bij dezen.

Ik zal het zo kort mogelijk houden, als er mensen zijn die ik vergeten zou zijn of vinden dat ze vermeld hadden moeten worden in dit dankwoord, dan bij dezen bedankt!!!

Om te beginnen wil ik mijn promotoren Bruce Wolffenbuttel en Wim Saris en co-promotoren Marleen van Baak en Paul Menheere bedanken.

Bruce jij hebt mij de mogelijkheid geboden voor dit onderzoek en was altijd een goed klankbord voor mijn ideeën. Nooit maakt je er een probleem van als ik een congres of symposium wilde bezoeken ondanks dat ik daar niet altijd iets kon vertellen, hiervoor bedankt.

Mijn eerste 2 jaar heb ik doorgebracht op het laboratorium endocrinologie en ben daar liefdevol opgevangen door Gabrielle, Paul en Geertje. Jullie hebben mij altijd geholpen tijdens en na mijn promotie, bedankt hiervoor, ik hoop dat we elkaar nog vaker zullen zien.

Verder wil ik iedereen van het lab MME bedanken voor hun hulp, koffiepauzes uitjes en kerstdiners die de afgelopen jaren een mooie afleiding zijn geweest. Freek jij bedankt voor de squash wedstrijden waar ik mijn frustratie/agressie goed kwijt kon.

$\mathrm{Na}$ deze 2 jaar ben ik verhuisd naar de 2e verdieping bij Humane Biologie en terecht gekomen bij Joost en Gijs. Een andere omgeving, maar niet minder leuk. Gijs en Joost, volgens mij hebben we het niet alleen gezellig gehad, maar hebben we ook vaker zitten te brainstormen over ons onderzoek en het leven in het algemeen. Onze kamer leek vaker wel een hulppost voor statistiek problemen, onderzoeksopzetten of gewoon het dorpscafé. Mede hierdoor zijn de laatste jaren voorbij gevlogen.

Joost ik denk dat wij deze traditie rustig voortzetten in Heerlen, waar onze kamer wederom mensen trekt zowel voor de gezelligheid als onze mentale en inhoudelijke ondersteuning.

Uiteraard wil ik alle andere medewerkers van Humane Biologie niet vergeten en van harte bedanken voor alle steun en plezier de afgelopen jaren. 
De laatste stuiptrekkingen van mijn proefschrift hebben plaatsgevonden in Heerlen. I $k$ wil al mijn collega's in Heerlen bedanken voor hun geduld als ik weer eens zei: "Mijn promotie, oh ergens dit jaar".

Het laatste stukje van mijn dankwoord wil ik bewaren voor Esther. Esther ik denk dat jij de laatste jaren nog wel het meeste geleden hebt onder mijn inspanningen om mijn proefschrift te voltooien. Hierdoor heb jij vaker in je eentje of samen met je vader aan ons huis moeten werken en mijn soms prikkelbare humeur moeten tolereren. Gelukkig zorgde jij er altijd voor dat ik niet hele nachten achter de PC zat. Bedankt, ik weet dat wij hierna alles samen aankunnen en ons vol overgave in nieuwe avonturen kunnen storten. 


\section{Publications}




\section{Publications}

\section{Full Papers}

1. Mentink CJAL, Hendriks M, Levels AAG, Wolffenbuttel BHR. Glucose mediated crosslinking of collagen in rat tendon and skin. Clinica Chimica Acta. 2002;321;69-76

2. van de Merbel NC, Mentink CJAL, Hendriks G, Wolffenbuttel BHR. A liquid chromatographic method for the quantitative determination of $\mathrm{N}^{\varepsilon}$-carboxymethyllysine in human plasma proteins. Journal of Chromatography B. 2004;808;163-168

3. Mentink CJAL, Kilhovd BK, Rondas-Colbers GJMW, Torjesen PA, Wolffenbuttel BHR. Time course of specific AGEs duringoptimized glycaemic control in type 2 diabetes. The Netherlands Journal of Medicine. 2006;64(1);12-18

4. Mentink CJAL, Swenne GNM, Venekamp WJRR, Looij BJ, Hendrikse F, Wolffenbutel BHR. AGE-induced cascade in diabetic retinopathy in patients with type 1 diabetes mellitus. Submitted for publication

5. Mentink CJAL, Wolffenbuttel BHR, van Baak MA, Schalkwijk CG, Hageman GJ, Bast A, Menheere PPCA, Saris WHM. Endogenous and Postprandial exogenous $A G E$ formation and accumulation in type 2 diabetic patients. In press

\section{Abstracts}

1. Wolffenbuttel BHR, Swennen GNM, Mentink CJAL, et al. Angiotensin converting enzyme (ACE) insertion/deletion (I/D) and Gly82Ser AGEreceptor polymorphism in subjects with Type 1 diabetes and early diabetic retinopathy. Diabetologia. 2003;46(Suppl. 2);1157

2. Mentink CJAL, Kilhovd BK, Torjesen PA, et al. Time course of specific AGEs during optimized glycaemic control in Type 2 diabetes. Diabetologia . 2004;47(Suppl. 1);1270

3. Wolffenbuttel BHR, Mentink CJAL, Schalkwijk CG. Postprandial Glucose Excursions and a-Dicarbonyls in Type 2 Diabetes. Diabetes. 2006(Suppl. 1). In press 
Curriculum Vitae 


\section{Curriculum Vitae}

Cyriel Mentink was born on September 19th 1975 in Elsloo, The Netherlands. In 1993 he completed his pre-university education at the "Scholengemeenschap Sint-Michiel" in Geleen. In the same year he started his study Chemical Engineering at Eindhoven University of Technology. In 1998 he completed his graduation project at the department of analytical chemistry entitled 'Research on the a-dicarbonyl group of AGEs' and received his master degree.

He continued this research during his PhD period which started in June 1999. In November 2003 he started as a teacher at Zuyd University, Heerlen, The Netherlands and as a member of the Centre of Expertise Life Sciences. 